\title{
A Review of the \\ Current Status of the Wind Energy Innovative Systems Projects
}

Irwin E. Vas

\section{MASTER}
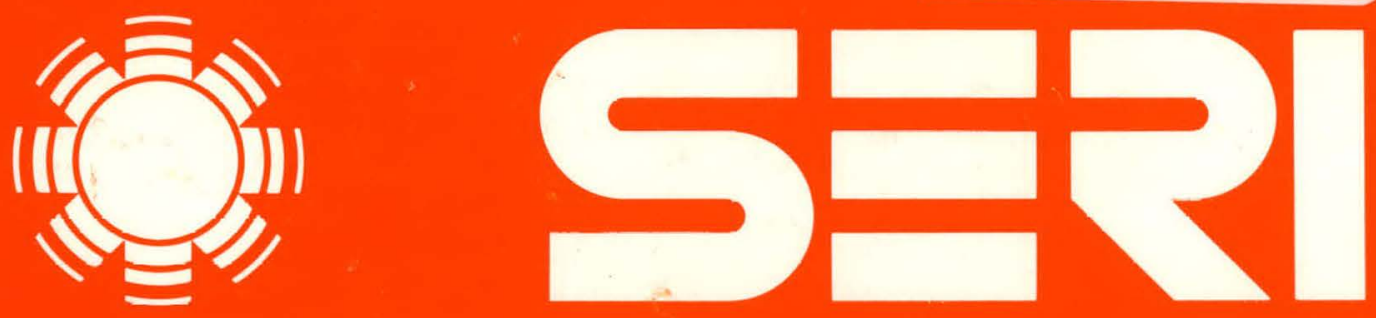

Solar Energy Research Institute

A Division of Midwest Research Institute

1617 Cole Boulevard

Golden, Colorado 80401

Operated for the

U.S. Department of Energy under Contract No. EG-77-C-01-4042 


\section{DISCLAIMER}

This report was prepared as an account of work sponsored by an agency of the United States Government. Neither the United States Government nor any agency Thereof, nor any of their employees, makes any warranty, express or implied, or assumes any legal liability or responsibility for the accuracy, completeness, or usefulness of any information, apparatus, product, or process disclosed, or represents that its use would not infringe privately owned rights. Reference herein to any specific commercial product, process, or service by trade name, trademark, manufacturer, or otherwise does not necessarily constitute or imply its endorsement, recommendation, or favoring by the United States Government or any agency thereof. The views and opinions of authors expressed herein do not necessarily state or reflect those of the United States Government or any agency thereof. 


\section{DISCLAIMER}

Portions of this document may be illegible in electronic image products. Images are produced from the best available original document. 
Printed in the United States of America Available from:

National Technical Information Service

U.S. Department of Commerce

5285 Port Royal Road

Springfield, VA 22161

Price:

Microfiche $\$ 3.00$

Printed Copy $\$ 5.25$ A 05

\section{NOTICE}

This report was prepared as an account of work sponsored by the United States Government. Neither the United States nor the United States Department of Energy, nor any of their employees, nor any of their contractors, subcontractors, or their employees, makes any warranty, express or implied, or assumes any legal liability or responsibility for the accuracy, completeness or usefulness of any information, apparatus, product or process disclosed, or represents that its use would not infringe privately owned rights. 
SERI /TP-635-469

UC CATEGORY: UC-60

\section{MASTER}

\section{A REVIEW OF THE CURRENT STATUS OF THE WIND ENERGY INNOVATIVE SYSTEM PROJECTS}

IRWIN E. VAS

MARCH 1980

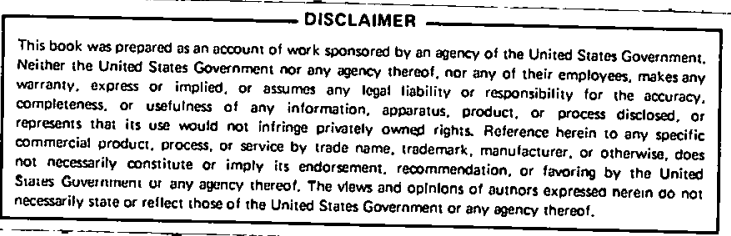

PREPAREED UNDER TASK NO. 3533.35

Solar Energy Research Institute

1536 Cole Boulevard

Golden, Colorado 80401

A Division of Midwest Research Institute

Prepared for the

U.S. Department of Energy

Contract No. EG. $77 \cdot C \cdot 01 \cdot 4042$ 


\section{THIS PAGE}

WAS INTENTIONALLY

LEFT BLANK 


\section{FOREWORD}

This technical paper was performed in compliance with Contract Number EG-77-C-01-4042 for the U.S. Department of Energy. The author acknowledges the support and encouragement offered by Louls Divone, Carl Aspliden, and George Tennyson of DOE. The efforts of Richard Mitchell of SERI in the production of the report are also appreciated.

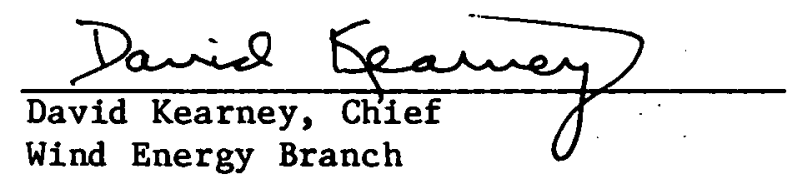

Approved for:

SOLAR ENERGY RESEARCH INSTITUTE

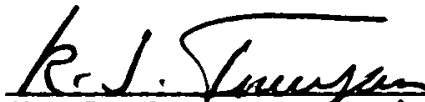

K. J. Touryan Acting Manager

Solar Therma Ocean, and Wind

Division 
'I'HIS' PAGE

WAS INTENTIONALLY

LEFT BLANK 


\section{SUMMARY}

The objective of the Wind Energy Innovative Systems prograin, a DOE program managed by SERI, is to determine the technical and economic feasibility of potentially cost-competitive innovative wind systems. Studies performed in this program are subcontracted to businesses and universities. In FY79, 17 studies were being funded, 11 of which wëre $R \& D$ studies that address various types of innovative extraction, augmentation, and electrofluid dynamic type systems. The remaining six were short-term studies assessing the value of innovative systems by generic order.

Technical monitoring of these studies is performed by SERI. All projects include theoretical thermodynamic and aerodynamic studies to confirm viability and performance characteristics and capabilities. These initial studies are followed by model designing and testing, economic evaluation, and, finally, the establishment of concept cost competitiveness. For those concepts that have the potential of being cost effective, additional proof-of-concept tests are to be conducted. From these tests, system costs, performance, and engineering data will be developed to determine with reasonable accuracy the cost of energy of a manufactured system.

The paper reviews this subcontracted research work with the exception of three studies which were initiated in the last quarter of FY79. 


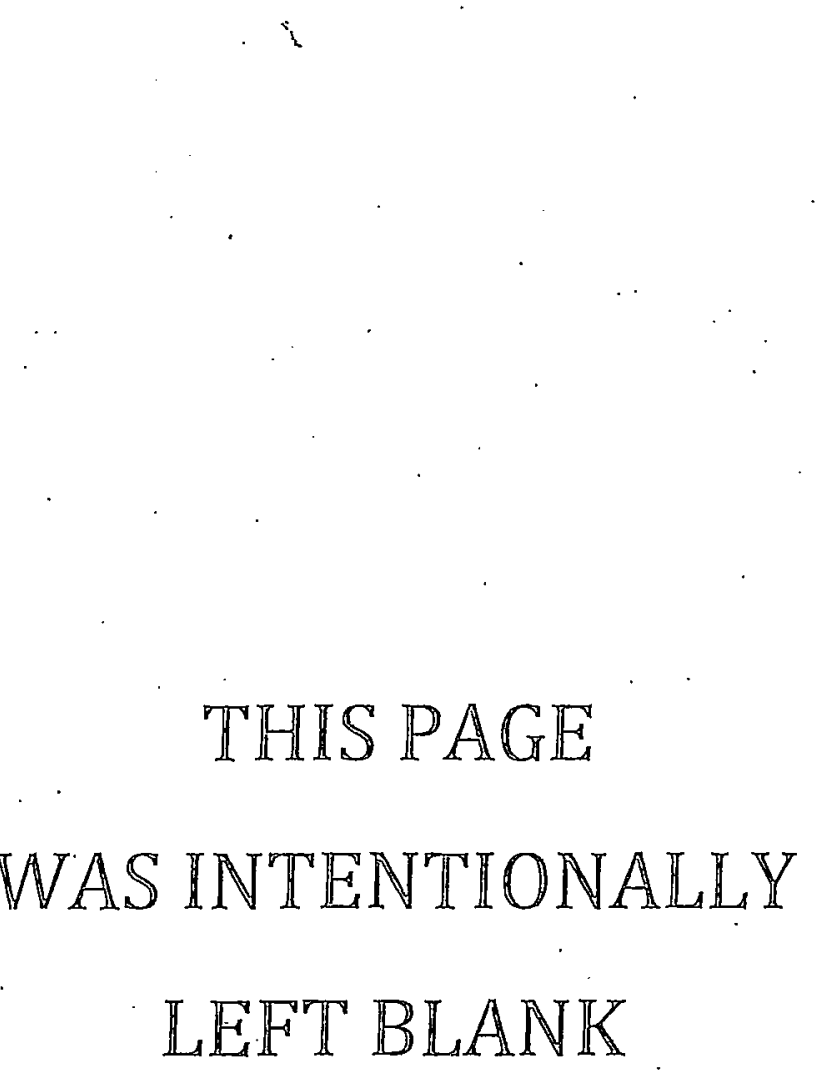


。

\section{TABLE OF CONTENTS}

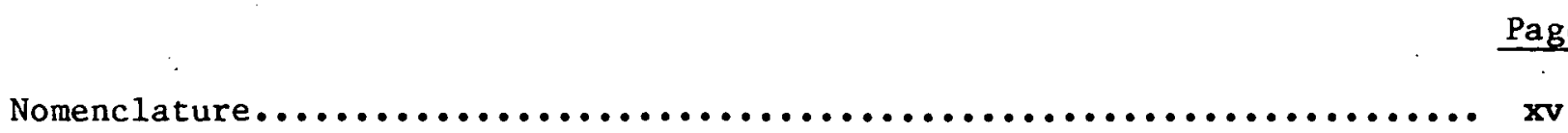

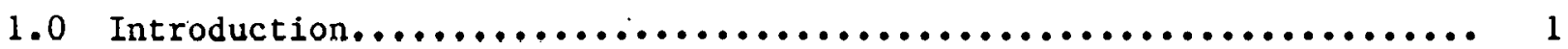

2.0 Innovative Straight-Bladed Vertical Axis Wind Turbine............ 5

2.1 Theoretical Studies................................. 5

2.2 Experimental Results................................. 8

2.3 Summary Remarks.................................... 11

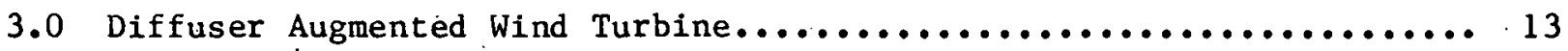

3.1 Theoretical studies.................................. 13

3.2 Experimental Studies.................................. 14

3.3 Summary Remarks.................................... 16

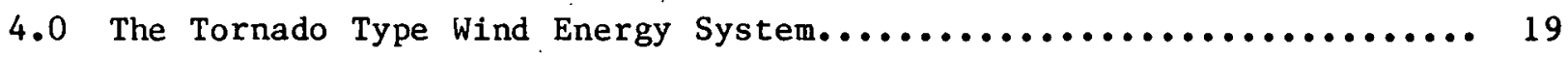

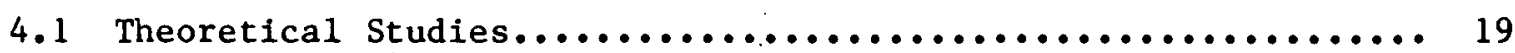

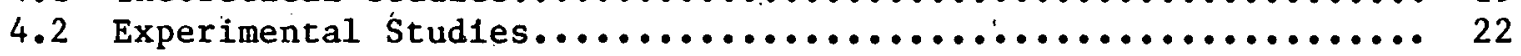

4.3 Summary Remarks..................................... 26

5.0 Wind-Powered Charged Aerosol Generator....................... 29

5.1 Experimental studies................................ 29

5.1.1 Single Electrode Generator Method................... 29

5.1 .2 Water Jet/Metal Contact Charging Method............. 30

5.1 .3 Electrojet Charging - Water/Air Method.............. 30

5.1 .4 Induction Charging/Water Jet Method................. 31

5.2 Summary Remarks................................... 32

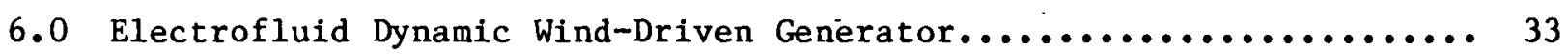

6.1 Theoretical studies............................... 33

6.2 Experimental Investigations........................... 36

6.2 .1 Direct Current Electrohydrodynamic Spray............ 36

6.2.2 Direct Current Electrohydrodynamic Spray with

Cross Field............................... 36

6.2.3 Bipolar Direct Current Electrohydrodynamic Spray...... 37

6.2.4 Bipolar Alternating Current Electrohydrodynamic Spray..................................... 37

6.2 .5 Generator Performance........................ 37

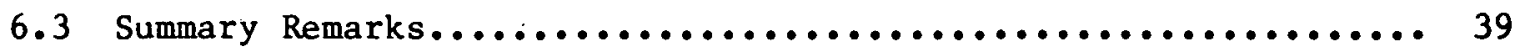


TABLE OF CONTENTS (Concluded)

$\underline{\text { Page }}$

7.0 Energy From Humid Air............................... 41

7.1 Natural Draft Tower............................... 41

7.2 Expansion-Compression Cycle Analyses................... 41

7.3 Summary Remarks.................................. 44

8.0 The Madaras Rotor Power Plant.......................... 45

8.1 Experimental Studies.............................. 46

8.2 Design Studies.................................. 47

8.3 Summary Remarks................................... 49

9.0 Vortex Augmentor Concept............................ 51

9.1 Experimental Studies............................ 51

y.2 Summary Kemarks................................. 53

10.0 Concluding Remarks................................. 55

References............................................ 57 


\section{LIST OF FIGURES}

$\underline{\text { Page }}$

2-1 Theoretical VAWT Performance Limits and Experimental Data........ 5

2-2 Geometric Airfoil in Curved Flow and Equivalent Virtual Airfoil in Rectilinear Flow................................. 6

2-3 Linear Variation of Virtual Camber and Incidence with C/R....... 6

2-4 The Merit Function $p(\theta)$ Calculated for the Geometric and Virtual Airfoils....................................... 7

2-5 Lift/Drag Comparison of Cambered and Symmetrical Airfoils........ 8

2-6 Outdoor Test Model of the VAWT.......................... 9

2-7 Experimental Drag Polars for Large Blades and NACA Section Data.... 9

2-8 Comparison of $C_{\text {Dmin }}$ from Wind Tunnel and Outdoor Tests........... 10

2-9 Indoor Blade. Test Facility .............................. 10

2-10 NACA 0015 Airfoil Blade on Indoor Test Machine................ 11

2-11 Circulation Controlled Blade for Indoor Test Machine............ 11

2-12 Typical Data from Indoor Tests.......................... 11

3-1 Basic Schematic of the DAWT with Reference Stations............. 13

3-2 Baseline Model Installation in the $2.1 \mathrm{~m} \times 3 \mathrm{~m}$ Wind Tunnel with 3-Bladed, Constant Chord Wind Turbine $0.46-\mathrm{m}$ Diffuser and Paraboloid lenterbody End Pleces........................... 14

3-3 Comparison of Turbine Performance in the Wind Tunnel for Different Augmentation Systems................................... 14

3-4 Comparison of DAWT Models Test Data with Theoretical Performance

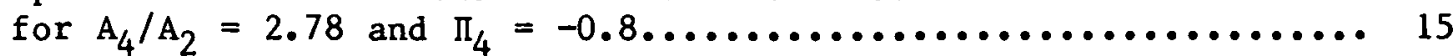

3-5 Comparison of Theoretically Optimum Performance with Model Test Data, $A_{4} / A_{2}=2.78 \ldots \ldots \ldots \ldots \ldots \ldots \ldots \ldots \ldots \ldots \ldots \ldots \ldots \ldots \ldots \ldots \ldots \ldots \ldots 15$

3-6 Comparison of Theoretically Optimum. Performance with Model Test Data, $A_{4} / A_{2}=4.0 \ldots \ldots \ldots \ldots \ldots \ldots \ldots \ldots \ldots \ldots \ldots \ldots \ldots \ldots \ldots \ldots \ldots$

3-7 Engineering Design of DAWT Field Test Article................. 16

4-1 Artist's Conçeption of Tornado-Type Wind Energy System........... 19. 


\section{LIST OF FIGURES (Continued)}

$\underline{\text { Page }}$

4-2 Control Volumes and Nomenclature for Flow Analysis............. 20

4-3 Inlet Flow Parameters as a Function of Viscous Core Radius, $\delta / R_{D} \ldots 20$

4-4 Accelerating Factor $\gamma$ Versus Inflow Parameter................ 20

4-5 Static Pressure Distribution at Tower Bottom................ 21

4-6 Plot of Power Coefficient Versus Disk Loading Coefficient and Comparison of Theory and Experiment..................... 21

4-7 Pressure Measurements on the Tower Bottom Wall with a Solid P1ug on a $3.81-\mathrm{cm}$ Diameter Screen.......................... 22

4-8 Measured Pressure Distributions Along the Tower Walls for $\mathrm{V}_{\mathrm{o}}=55.5 \mathrm{~m} / \mathrm{s}(124 \mathrm{mph})$ and $\mathrm{H}=76 \mathrm{~cm}$ (No Blower)........... 22

4-9 Experimental Setup with Screen Simulated Turbine.............. 23

4-10 Plot of Power Coefficient Versus Disk Loading Coefficient......... 23

4-11 Plot of Power Coefficient Versus Reynolds Number for $D / D_{2}=3.3 . \ldots 23$

4-12 Experimental Setup with Bladed Turbine and Electrical Generator.... 24

4-13 Plot of Power Coefficient Versus Tip Speed Ratio for Different H/D Ratos........................................ 24

4-14 Plot of Measured Disk Loading Coefficient Versils Tip Spoed Ratio... 25

4-15 Fixed-Vane Model 25-cm Diameter, 50-cm High.................. 25

4-16 Power Coefficient for 25-cm Diameter Fixed-Vane Mode1........... 26

4-1/ Photograph of the 5-m High Model under Construction............. 26

4-18 Photograph of the $0.75-m$ Diameter Turbine................... 27

5-1 Schematic of the Single Electrode System..................... 29

5-2 Schematic of the Electrojet Charging - Water/Air Method......... 30

3-3 Wind Velocity Versus Electric Efficiency.................. 30

5-4 Schematic of Water Microjet Charging Method Using Single Electrode....................................... 31

5-5 Water Pressure Versus Power........................... 32 


\section{LIST OF FIGURES (Continued)}

$\underline{\text { Page }}$

5-6 Water Pressure Versus Electric Power Out Over Total Power In...... 32

6-1 Schematic of an EFD Wind-Driven Generator................. 33

6-2 Specific-Charged Droplet Energy Cost Plotted in the Mobility-

Droplet Radius Plane................................. 34

6-3 Performance Map of an EFD Wind-Driven Generator............... 34

6-4 Power Versus Wind Velocity for the EFD Wind-Driven Generator...... 35

6-5 Annual Energy Production at an Average Wind Velocity of $10 \mathrm{~m} / \mathrm{s} \ldots \ldots 35$

6-6 Test R1g with Original Cylindrical Collector Electrodes.......... 37

6-7 Revised Test Rig with Side Walls Removed.................... 38

6-8 Test Generator Data Compared to Theory..................... 38

6-9 Theoretical Power Versus Number of Rods...................... 39

6-10 Theoretical Power for a Full-Sized Generator Using 30.4-cm

Diameter $\operatorname{Rod} . \ldots \ldots \ldots \ldots \ldots \ldots \ldots \ldots \ldots \ldots \ldots \ldots \ldots \ldots \ldots \ldots \ldots \ldots \ldots \ldots \ldots \ldots . . \ldots 39$

7-1 Schematic of a Natural Draft Tower...................... 41

7-2 Power Output Versus Cooling Temperature.................... 42

7-3 Power Output Versus Degree of Saturation.................... 42

7-4 Vortex Mechanization of an Expansion-Compression Cycle......... 43

7-5 Net Power Output Versus Time of Day...................... 43

7-6 Net Power Output Versus Month of Year...................... 44

8-1 The Madaras Rotor Power Plant........................... 45

8-2 Lift-Drag Polars of a Rotating Cylinder and Airfoil............46

Power Required to Rotate Cylinder for Various End Cap Diameter
Ratios and Two Aspect Ratios.......................... 46

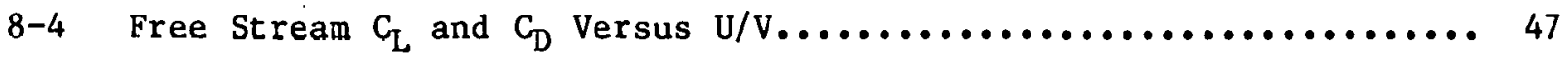

8-5 Net Power Output for One Rotor Versus Track Speed/Wind Speed...... 48 


\section{LIST OF FIGURES (Concluded)}

Page

8-6 Mutual Interference Loss Factor Versus Wind Speed for Various Number of Rotors..................................... 48

8-7 Unit Plant Cost Versus Rated Power for Racetrack Configuration..... 50

8-8 Energy Cost Versus Rated Power for Racetrack Configuration........ 50

9-1 Prototype Model of the VAC........................... 51

9-2 Schematic Diagram of the Sensor System.................... 52

9-3 Power Coefficient Vèrsus Tip Speed Ratio for the Prototype Rotor in Uniform Flow.................................. 52

9-4 Time Variation of Wind and Rotor Power.................... 53

9-5 Trace of Angular Flow Deviation from Delta Centerline Versus Time............................................. 53

9-6 Mean Power Coefficient Versus Angle of Attack................ 54 


\section{LIST OF TABLES}

$\underline{\text { Page }}$

$1-1 \quad$ R\&D Subcontractors................................... 2

1-2 Generic Studies Subcontractors........................... 3

3-1 Estimated Weight and Relative Cost for the First DAWT 18 Design Study............................................ 17

3-2 DAWT Cost Projections (Excludes Foundation and Electrical

Connect Costs)................................... 17 


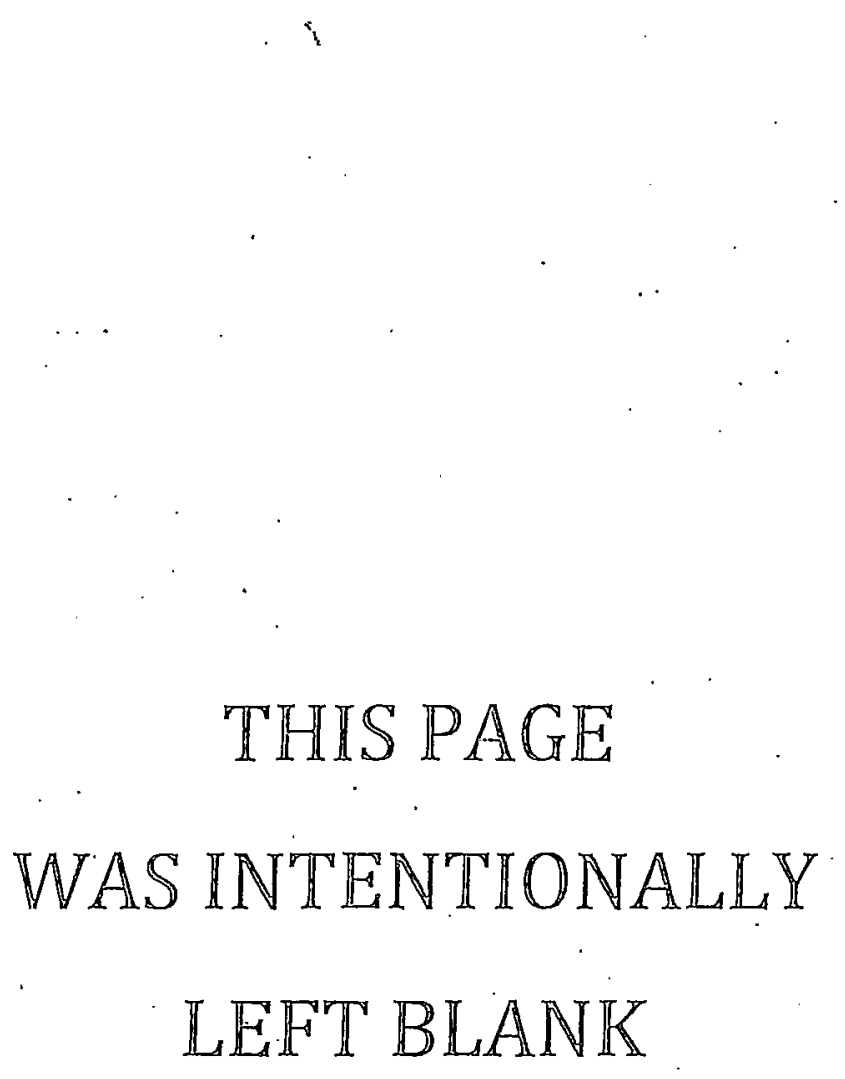




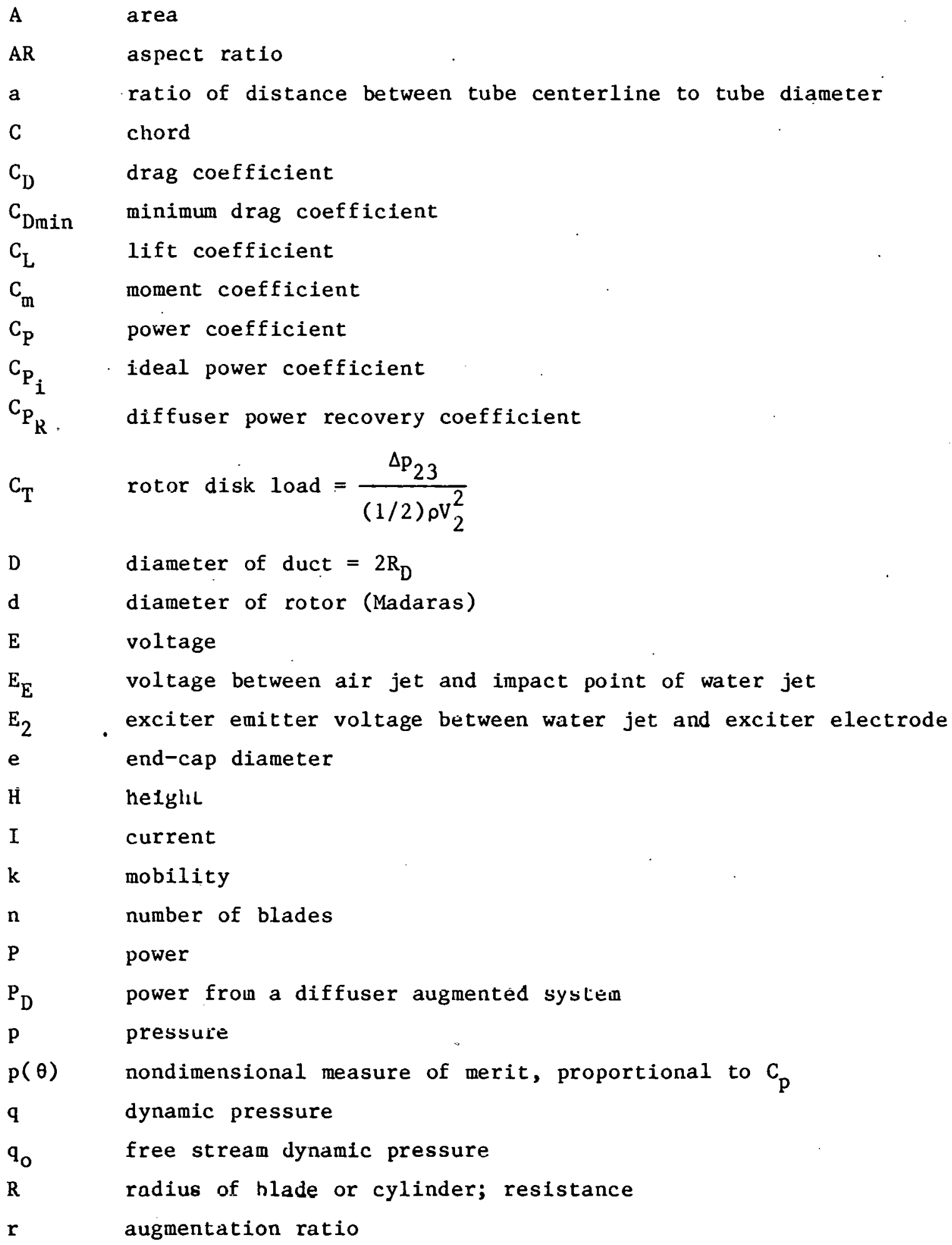




\section{NOMENCLATURE LIST (Concluded)}

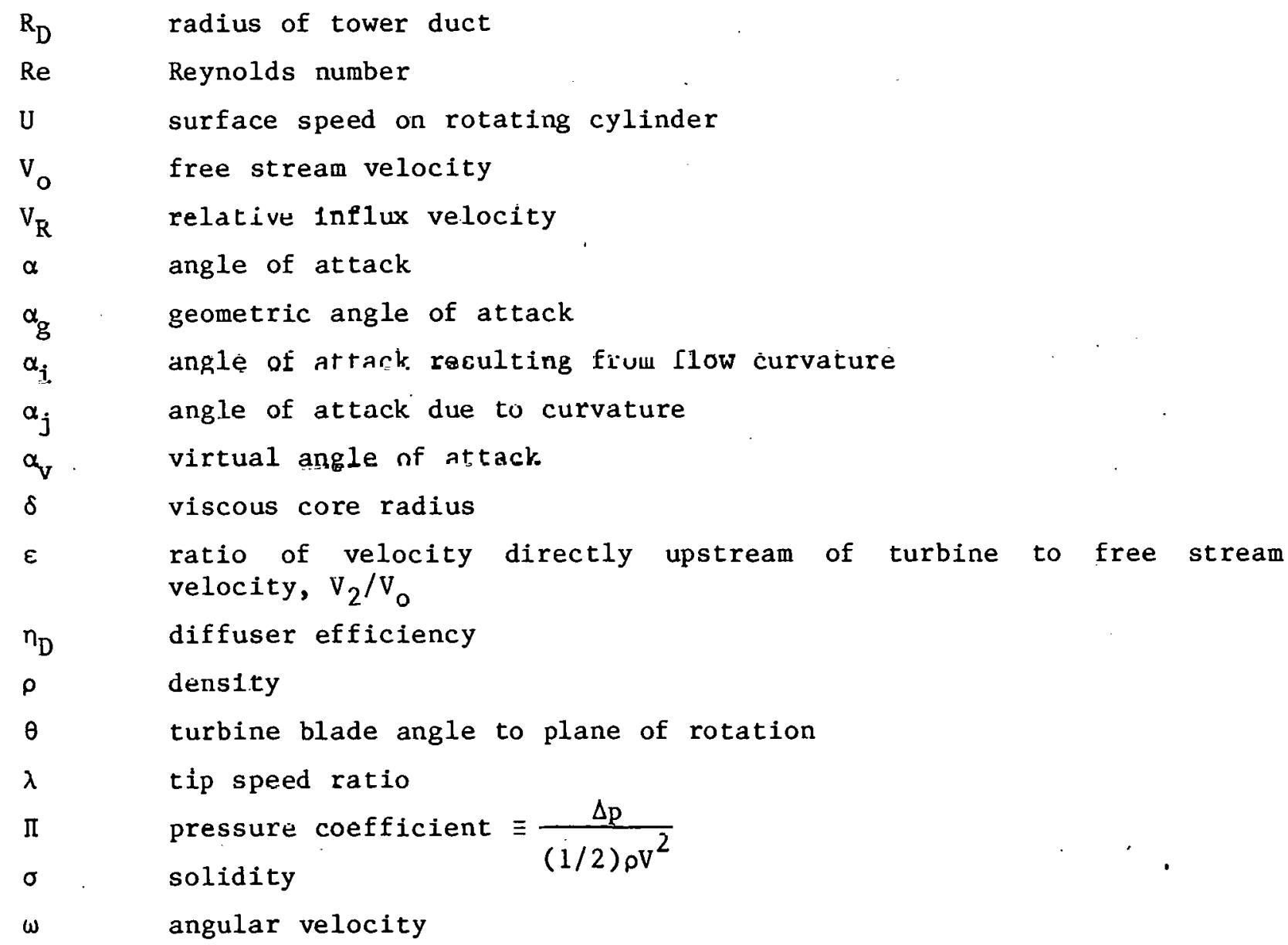




\section{SECTION 1.0}

\section{INTRODUCTION}

The role of the Solar Energy Research Institute (SERI) is to facilitate the acceleration to commercialization of solar technologies by conducting and managing research, development, and demonstration (RD\&D) projects and programs. One of the SERI FY79 programs was the Wind Energy Systems program that consisted of six tasks: Wind Energy Innovative Systems (WEIS), Cost Estimating and Engineering Analyis of Innovative WECS, Utility Analytical Modeling, Economics of SWECS Tied to Utilities, Product Liability Issues Associated with SWECS, and Environmental Impact Assessment of SWECS.

The responsibility to provide program management for the Wind Energy Innovative Systems program was authorized by the Wind Systems Branch, Department of Energy, during the latter part of FY78. The objective of the program is to determine the technical and economic feasibility of potentially cost-competitive innovative systems. Studies performed in this program are subcontracted to small and large private companies as well as to universities. In FY79, 17 studies were being funded, 11 of which were R\&D studies that address various types of innovative extraction, augmentation, and electrofluid dynamic type systems. The remaining six were short-term studies assessing the value of innovative systems by generic order. Three of these R\&D studies were initiated in the last quarter of FY79 and will not be discussed in this paper.

Technical monitoring of these studies is performed by SERI. A listing of the R\&D projects is provided in Table 1-1. All projects include theoretical thermodynamic and aerodynamic studies to confirm viability and performance characteristics and capabilities. These initial studies are followed by model designing and testing, economic evaluation, and finally, the establishment of concept cost competitiveness. For those concepts that have the potential of being cost effective, additional proof-of-concept tests are to be conducted. From these tests, system costs, performance, and engineering data will be developed to determine with reasonable accuracy the cost of energy of a.manufactured system.

In early 1979, generic studies were solicited and six short-term studies funded. Preliminary results from these studies were presented at the WEIS Conference held in May 1979. A listing of these assessment studies is given in Table 1-2.

The present paper reviews the research work conducted by the subcontractors. Details of the studies may be found in the references provided at the end of the text. 
Table 1-1. R\&D Subcontractors

\begin{tabular}{|c|c|c|}
\hline Project Title & Subcontractor & $\begin{array}{l}\text { Principal } \\
\text { Investigator }\end{array}$ \\
\hline $\begin{array}{l}\text { Innovative Wind Turbines } \\
\text { (VAWT) }\end{array}$ & West Virginia Univ. & Richard E. Walters \\
\hline $\begin{array}{l}\text { Diffuser Augmented Wind } \\
\text { Turbines (D } W T \text { ) }\end{array}$ & Grumman Aerospace & Ken Foreman \\
\hline $\begin{array}{l}\text { Tornado Type Wind Ellergy } \\
\text { Systems (Tornado) }\end{array}$ & Grumman Aerospace & James T. Yen \\
\hline $\begin{array}{l}\text { Tests and Devices for } \\
\text { Wind/Electric Power } \\
\text { Charged Aerosol Gen- } \\
\text { prator (EFD) }\end{array}$ & Marks Polarized & Alvin M. Marks \\
\hline $\begin{array}{l}\text { Electrofluid Dynamic } \\
\text { Wind Driven Generator } \\
\text { (EFD) }\end{array}$ & $\begin{array}{l}\text { Univ. of Dayton } \\
\text { Research Institute }\end{array}$ & John E. Minardi \\
\hline $\begin{array}{l}\text { Energy from Humid Air } \\
\text { (Humid Air) }\end{array}$ & $\begin{array}{l}\text { South Dakota School of } \\
\text { Mines and l'echnology }\end{array}$ & Thomas K. Niiver \\
\hline $\begin{array}{l}\text { The Madaras Rotor Power } \\
\text { Plant Phase I (Madaras) }\end{array}$ & $\begin{array}{l}\text { Univ, of Dayton } \\
\text { Research Institute }\end{array}$ & Dale H. Whitford \\
\hline $\begin{array}{l}\text { Vortex Augmentórs } \\
\text { Wind Energy Conversion } \\
\text { (Vortex) }\end{array}$ & $\begin{array}{l}\text { Polytechnic Institute } \\
\text { of Ncw York }\end{array}$ & Pasquale M. Sforzạ \\
\hline $\begin{array}{l}\text { The Yawing of Wind } \\
\text { Turbines with Bilade } \\
\text { Cyclic Pitch }\end{array}$ & $\begin{array}{l}\text { Washington Univ. } \\
\text { Technology Associates }\end{array}$ & K. H. Hohenemser \\
\hline Oscillating Vane Concept & United Technologies Corp. & R. L. Bielawa \\
\hline $\begin{array}{l}\text { Advanced and Innovative } \\
\text { Wind Energy Concept } \\
\text { Development-Dynamic } \\
\text { Inducer }\end{array}$ & AeroVironment, Inc. & Peter Lissaman \\
\hline
\end{tabular}


Table 1-2. Generic Studies Subcontractors

\begin{tabular}{|c|c|c|}
\hline Project Title & Subcontractor & $\begin{array}{c}\text { Principal } \\
\text { Investigator }\end{array}$ \\
\hline $\begin{array}{l}\text { A Definitive Generic Study } \\
\text { of Aug mented Horizontal } \\
\text { Axis Wind Energy Systems }\end{array}$ & AeroVironm ent, Inc. & Peter Lissa man \\
\hline $\begin{array}{l}\text { A Definitive Generic Study } \\
\text { of High Lift Device } \\
\text { Wind Energy Syste rs }\end{array}$ & AeroViron in ent, Inc. & Peter Lissa man \\
\hline $\begin{array}{l}\text { A Definitive Generic Study } \\
\text { of Aug mented Vertical } \\
\text { Axis Wind Energy Systems }\end{array}$ & New York Univ. & Martin $\mathrm{L}$ Hoffert \\
\hline $\begin{array}{l}\text { A Definitive Generic Study } \\
\text { of Augmented Horizontal } \\
\text { Wind Energy Syste ins }\end{array}$ & Tetra Tech, Inc. & Mark Harper \\
\hline $\begin{array}{l}\text { A Definitive Generic Study } \\
\text { of Sail Wing Wind Energy } \\
\text { Systems }\end{array}$ & $\begin{array}{l}\text { W ashington Univ. } \\
\text { Tech. Associates, Inc. }\end{array}$ & K. H. Hohene m ser \\
\hline $\begin{array}{l}\text { A Definitive Generic Study } \\
\text { of Vortex Extraction } \\
\text { Wind Energy Systems }\end{array}$ & $\begin{array}{l}\text { JBF Scientific Corp. } \\
\text { Research Institute }\end{array}$ & Theodore R. Kornreich \\
\hline
\end{tabular}




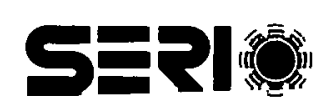




\section{SECTION 2.0}

\section{INNOVATIVE STRAIGHT-BLADED VERTICAL AXIS WIND TURBINE}

Theoretical and experimental studies have been carried out for the past five years at West Virginia University on straight-bladed vertical axis wind turbines. The major objective has been to evaluate circulation control airfoils that exhibit higher lift ratios than conventional airfoils and therefore should offer improved turbine performance with corresponding improved cost effectiveness. Previous work in the circulation control area has been conducted by other U.S. and Canadian research laboratories. A short review of the progress made in this project. is provided. Details may be obtained from the papers authored by the principal investigator and his staff cited in Reference 1.

\subsection{THEORETICAL STUDIES}

The capacity of vertical axis wind turbines to utilize wind energy from all directions has made these turbines the focus of studies for several years. At West Virginia University thonretical studies have been carried out to determine specific problems associated with blade interaction. One of the aspects initially investigated was the complex phenomenon of aerodynamics associated with the interaction of the blade and its wake. A vortex model was developed to provide information about the interaction between the blade and the wake. This model made it possible to estimate the power coefficient, $C_{p}$, under the idealized assumption of zero blade and support structure drag. The results of these calculations, shown in Fig. 2-1, indicate that the power coefficient for a vertical axis machine may exceed the theoretical Betz limit for propeller type machines. Performance prediction methods for vertical axis machines are seni-empirical and require a knowledge of the blade drag. A theoretical study was carried out that showed that the orbital motion of the blades resulted in large boundary layer radial pressure gradients that could affect both the lift and the drag. These results should be confirmed by experimental studies.

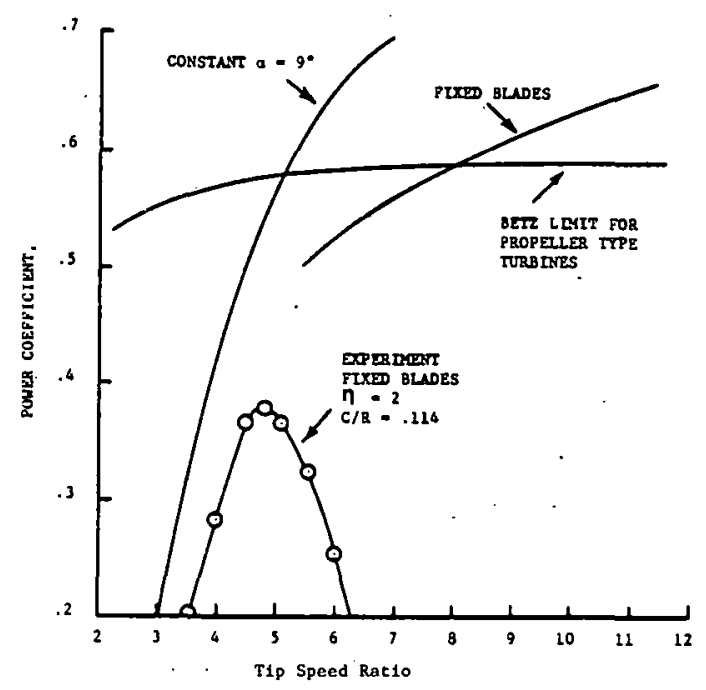

Figure 2-1. Theoretical VAWT Performance Limits and Experimental Data

One of the usual assumptions in analytical. studies has been that an average instantaneous blade relacive inflow velocity and angle of attack could be accurately defined. This assumption, however, may produce significant errors in the analysis. It is important to consider local conditions at the blade, and one has to look at the local angle of attack, $\alpha$, and relative inflow velocity, $v_{r}$. Whereas $V_{r}$ changes along the chord by 


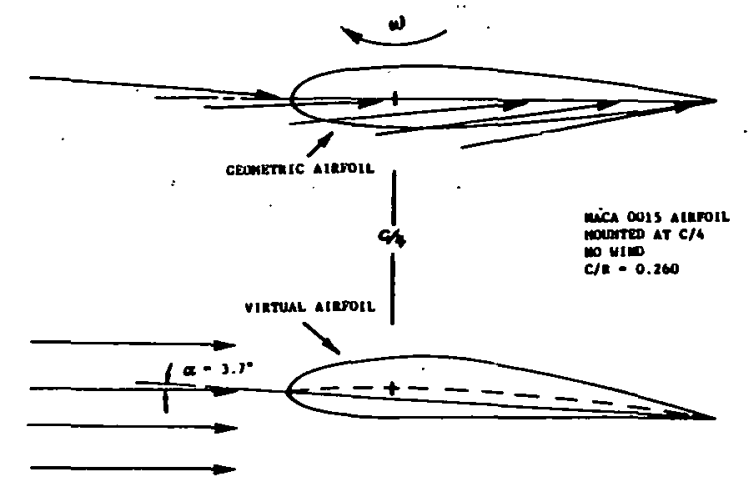

Figure 2-2. Geometric Airfoil in Curved Flow and Equivalent Virtual Airfoil in Rectilinear Flow

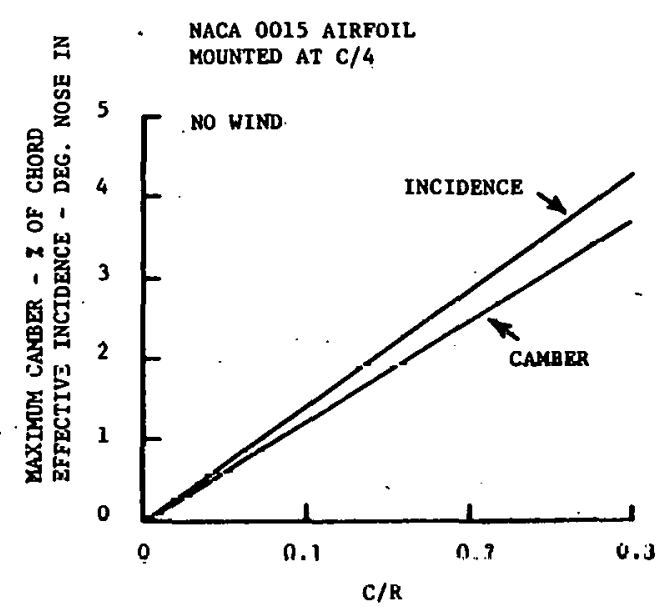

\section{Figure 2-3. Linear Variation of Virtual Camber and Incidence with $\mathbf{C} / \mathbf{R}$}

a small amount, the changes in $\alpha$ can be quite large, depending upon the blade location relative to the free stream, the tip speed ratio, and chord to radius ratio, $C / R$. This effect is more significant as $C / R$ increases.

The blade motion produces curvilinear streamlines that modify the local relative velocity and angle of attack of the blades. Therefore, the resulting aerodynamic properties for a blade would be different to a similar blade in rectilinear flow. This observation led to speculation that perhaps symmetrical airfoils in curvilinear flow would exhibit aerodynamic qualities of cambered airfoils in rectllinear flow. This phenomenon has been noted previously but considered unimportant for blades of small $\mathrm{C} / \mathrm{R}$. The investigators at West Virginia University, however, decided to study this problem in more detail.

The curvilinear airflow produced by vertical axis turbines can be examined utilizing conformal mapping techniques. The actual geometric airfoil in the curved flow may be transformed to an equivalent airfoil in rectilinear flow, which actually produces a change in the camber. This change is tormed "virtual cam ber" and with it comes a "virtual incidence" for a symmetric airfoil in curvilinear flow. Virtual angle of attack, $\alpha_{v}$, is a sum of the angle of attack due to the curvature, $\alpha_{j}$, and the geometrical angle of attack, $\alpha \cdot$. This is illustrated in Fig. 2-2 for a symmetric NACA 0015 airfoil mounted at its quarter-chord point, and the virtual alrfoil in a rectilinear flow sleuation. The analysis indicates that flow curvature incroduces an effective angle of incidence in addition to the usual blade angle of attack, as well as modifications to the airfoil camber. The magnitude of both of these changes is dependent upon $\mathrm{C} / \mathrm{R}$ as shown in Fig. 2-3. It was also found that for blades used on an outdoor VAWT test model at WVU, small chord blades $(C / R=0.114)$ trausfurmed to airtuils having $1.4 \%$ camber and $1.6^{\circ}$ incidence and large chord blades $(C / R=0.260)$ transformed to afrfoils having $3.2 \%$ camber and $3.7^{\circ}$ incidence.

Virtual camber causes an upward shift in the lift curve and introduces a moment coefficient that produces counter torque over the entire blade orbit. Virtual incidence acts to 
shift the lift curve. The effect of these influences on power extraction nay be observed with the aid of a nondimensional measure of merit, $p(\theta)$, which is directly related to the power cuefficient, $C_{P}$. For the large chord blades mounted at their quarter-chord in fixed pitch opertion at a tip speed ratio of 5.5 , $p(\theta)$ is plotted in Fig. 2-4 for both the virtual and geometric airfoils. There is a sharp drop in $p(\theta)$ at approxinately $50^{\circ}$ and $330^{\circ}$ as a result of blade stall. For the geometric airfoil the maximum angle reached for $\lambda=5.5$ is $\alpha_{i}=10.5^{\circ}$. The virtual incidence causes an increase in drag and a reduction in torque. On the downstream side of the turbine, $p(\theta)$ is reduced everywhere, since the virtual airfoil produces very little lift at negative angles of attack.

On integrating the $p(\theta)$ curve, the net measure of merit for the virtual airfoil is $22 \%$ of that expected for the geonetric airfoil; however, this result would change at different tip speed ratios and $C / R$ values. A similar analysis was carried out for small blades and showed sinilar results. It was noted that for small blades the efficiency actually increased on the upstream side of the turbine but losses on the downstrean side more than offset the front side gain. It was cuncluded Llial will a suitable conbination of virtual camber and incidence one could possibly produce a net gain of $\mathrm{C}_{\mathrm{p}}$. Analys is based on the properties of virtual airfoils is valid in evaluating airfoils and their pitch characteristics. The $p(\theta)$ nethod is important in determining performance relationships of blades with each other, however, it cannot be used to accurately predict $\mathrm{C}_{\mathrm{P}}$.

Flow blockage is extremely important in considering turbine perfornance. It depends on rotor solidity, therefore, a choice of $C / R$ cannot be made

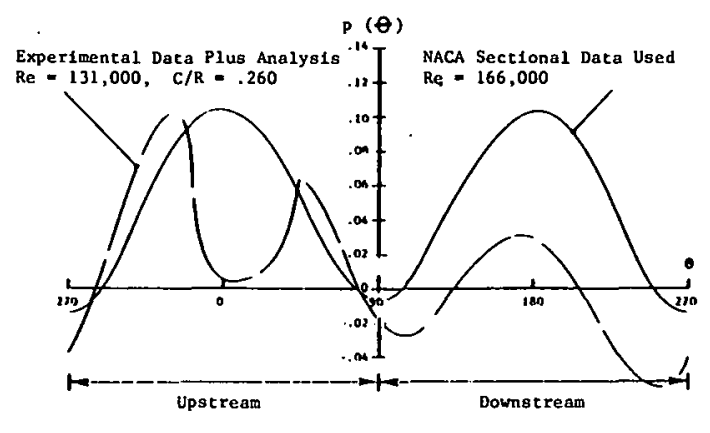

\section{Figure 2-4. The Merit Function $p(\theta)$ Calculated for the Geometric and Virtual Airfoils.}

on the basis of flow curvature alone. There are certain definite advantages in using blades that have a large value of $C / R$. Larger rotor solidity can be achieved with fewer blades resulting in lower costs. In addition, large blade chords provide higher Reynolds numbers with improved lift and drag characteristics. The airfoil section should only be decided after careful evaluation of all of these characteristics.

Symmetric airfoils have been chosen for Darrieus turbines because their lift-drag characteristics are identical at positive and negative $\alpha_{g}$ corresponding to upstream and downstream orbital positions and because $C_{m}$ is zero and concributes no counter torque. However, virtual canber and incidence change the premise on which these airfoils have been chosen. For a given $\alpha_{g}$ more lift is produced upstream than downstream and the additional values of $\alpha_{i}$ may cause blade stall. Using the inverse conformal transformations developed in the project, it is possible to design a geometric airfoil for assumed values of tip speed ratio $C / R$ and blade mounting point. The airfoil that may result from this development is one whose virtual equivalent is really cambered. Such an airfoil would experience an increased power extrac- 
tion on the upstream side of the turbine due to an increased value of $C_{L}$ and diminished efficiency on the downstream side which might be more than offset by the upstream improvements. However, at present it is not certain whether the net power extraction will be increased in designins for front or back side optinization. This study can only be pursued experimentally or with the aid of an accurate model of flow blockage.

Power extraction on the upstream portion of the turbine may be greatly inproved as a result of virtual camber. If the blade shown in Fig. 2-4 had not stalled at $\theta$ of $30^{\circ}$ and $330^{\circ}$, $p(\theta)$ would have been higher over the entire upstrean side. For variable pitch machines the stall problem can be avoided by adjusting the blade pitch schedule. If the favorable effects on the front side could be extended to the back side, overall efficiency would be greatly improved, which suggests that variable camber would be beneficial.

Variable camber has been used extensively on fixed-wing aircraft in the form of leading and/or trailing edge devices and boundary layer control devices. Cyclic manipulation of blade pitch has been carried out quite effectively; therefore, it is

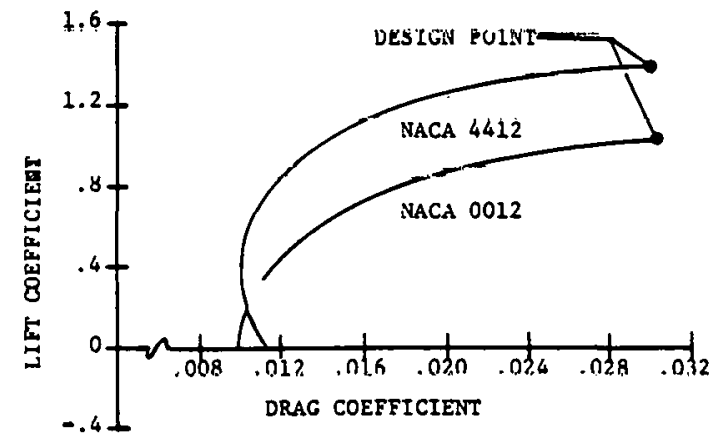

Figure 2-5. Lift/Drag Comparison of Cambered and Symmetrical Airfoils possible to consider such control by plain or split flaps. It would be necessary to determine whether the increased aerodynamic drag and moments using flapped airfoils would provide a net improvement. The drag polars of a symmetric NACA 0012 and a cambered NACA 4412 airfoil are shown in Fig. 2-5. In this example a liftto-drag ratio improvement of $34 \%$ at the operating point produces an estimated 38\% increase in $p(\theta)$ for blades of $\mathrm{C} / \mathrm{R}=0.10$.

Improvements associated with variable camber can also be achieved by boundary layer or circulation control. 'l'he latter concept is being investigated by blowing over and around a curved trailing edge. By this method large lift coefficients may be developed over a wide range of angle of attack. Improvements in $\mathrm{C}_{\mathrm{P}}$ can result even when power requirements die to the blowing are considered. As applied to the vertical axis wind turbine, blowing is alternatively applled to the upper and lower surfaces $180^{\circ}$ out of phase. This method of affecting variable camber results in a maximum $C_{p}$ that occurs at a lower tip spced ratio. In reducing the tip speed ratio the centrifugal forces that are proportional to the square ot angular velocity are also reduced, thereby reducing the structural design criteria.

\subsection{EXPERIMENTAL RESULTS}

To determine the performance of vertical axis turbines a knowledge of the blade drag lo required. As a result of the theoretical studies, an experimental configuration was designed in order to perforn outdoor tests to develop turbine blade drag and power coefficients (Fig. 2-6). The purpose of these tests was to determine the behavior of tip speed ratio, solidity, and Reynolds number by varying blade chord, radius, and spin speed. Measurements were made 


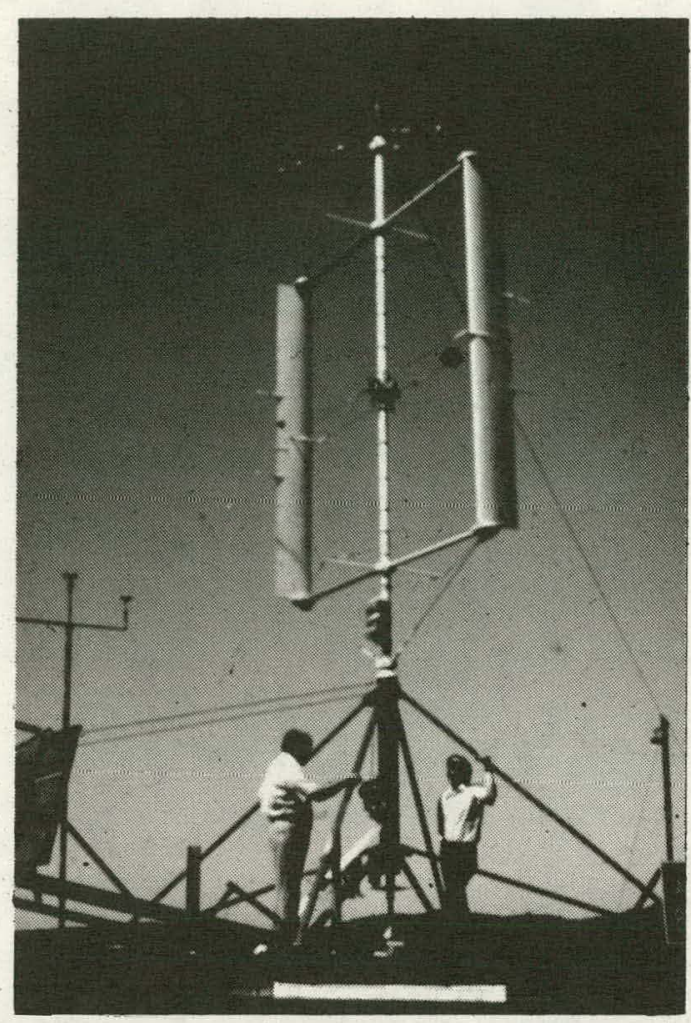

Figure 2-6. Outdoor Test Model of the VAWT

with a $17.4-\mathrm{cm}$ blade chord with $\mathrm{C} / \mathrm{R}=$ 0.114 and a $39.7-\mathrm{cm}$ blade chord with a $C / R$ of 0.26 . The blade cross section was NACA 0015 with a span length of $3.25 \mathrm{~m}$. Typical power coefficient results obtained from the tests are shown in Fig. 2-1. From the measurements an effective drag coefficient was determined to be a function of the aerodynamic drag and moment. Preliminary results from the measurements indicated that the minimum drag coefficient increased with increasing Reynolds number, a result that is contrary to the nurmally observed trend associated with laminar boundary layers at low Reynolds numbers. In addition, $\mathrm{C}_{\mathrm{Dmin}}$ apparently occurred at negative values of $\alpha$, a characteristic indicative of ${ }^{g}$ nonzero airfoil incidence and/or camber. The studies also indicated that the usual assumptions of constant $V_{R}$ and $\alpha_{g}$ over the entire blade chord could introduce a substantial error in blade aerodynamic analysis. These findings differed from previous studies by other investigators who had concluded that the orbital motion and the resulting flow curvature were negligible for symmetrical airfoils at small C/R.

Drag data developed from the experimental configuration (Fig. 2-7) have been compared with airfoil section data for the NACA 0015 corrected for finite span effects. For the large blades the drag does not agree with the corrected sectional data with a minimum drag coefficient approximately $75 \%$ greater than expected and occurring at a large negative angle of attack $\alpha_{g}$ approximately $-5^{\circ}$. Analytical studies indicated the existence of an effective angle of incidence of $3.7^{\circ}$ that would, in large part, account for the $\alpha_{g}$ shift. For the smaller blade the drag compared well except for large $\alpha_{g}$ corresponding to high-lift coefficlents.

Because the difference in the drag characteristics of the large and

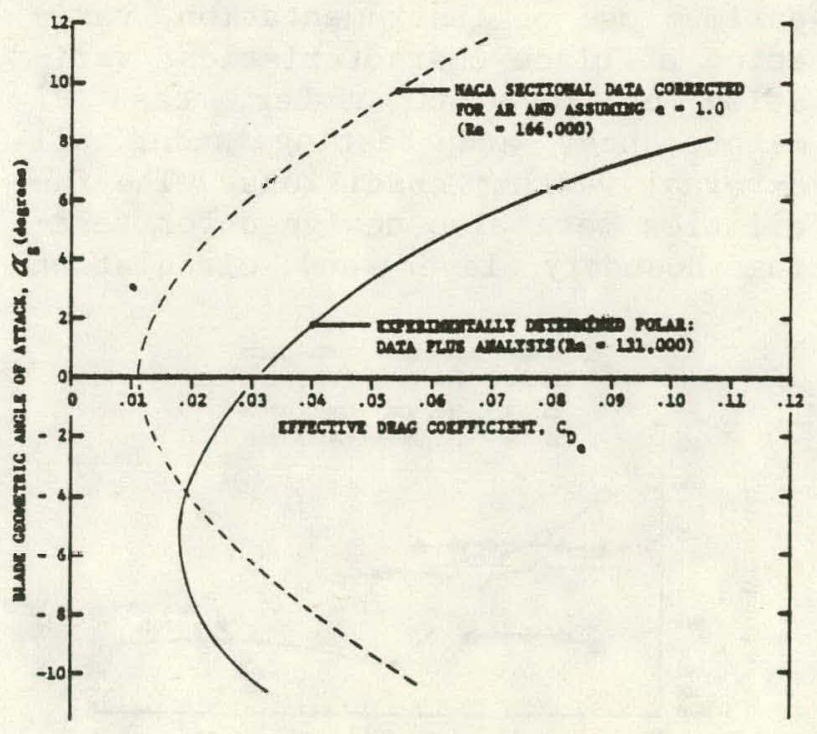

Figure 2-7. Experimental Drag Polars for Large Blades and NACA Section Data 
small blades could result from airfoil shape or roughness differences, each blade was tested in the WVU lowspeed wind tunnel. The test results, shown in Fig. 2-8, demonstrated only minor differences in drag characteristics for two-dimensional sections of the small and large chord blades. However, the wind tunnel test results and the outdoor turbine results exhibit a significant difference. One also notes that the minimum drag coefficient does not decrease as the Reynolds number increases as predicted by the NACA results. It was concluded by West Virginia University that these drag characteristics were due to flow curvature with its accompanying virtual camber and possible boundary layer efferts.

The outdoor test turbine results showed that important blade aerodynamic information could be deduced from tests at zero wind velocity. It was decided to construct an indoor facility that could be used to systematically investigate aerodynamic parameters (Fig. 2-9). Such testing allows for efficient model changes, optimum use of instrumentatinn, variation of blade characteristics, variation of Reyuulds number, ease of maintenance, and testing under all external weather conditions. The facilities were also designed for testing boundary layer and circulation

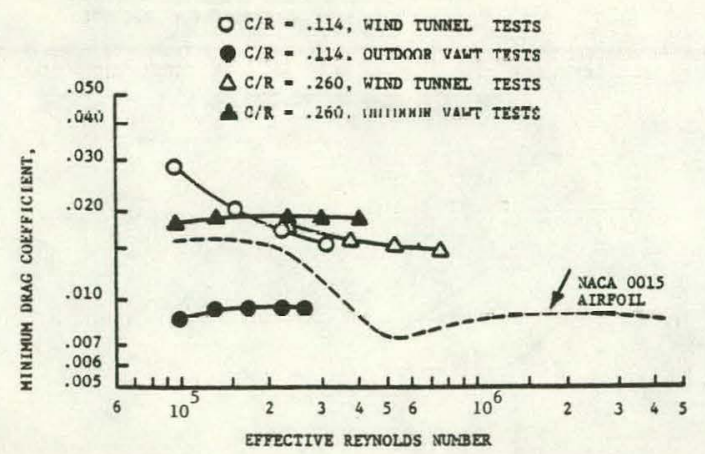

Figure 2-8. Comparison of $C_{D \min }$ from Wind Tunnel and Outdoor Tests

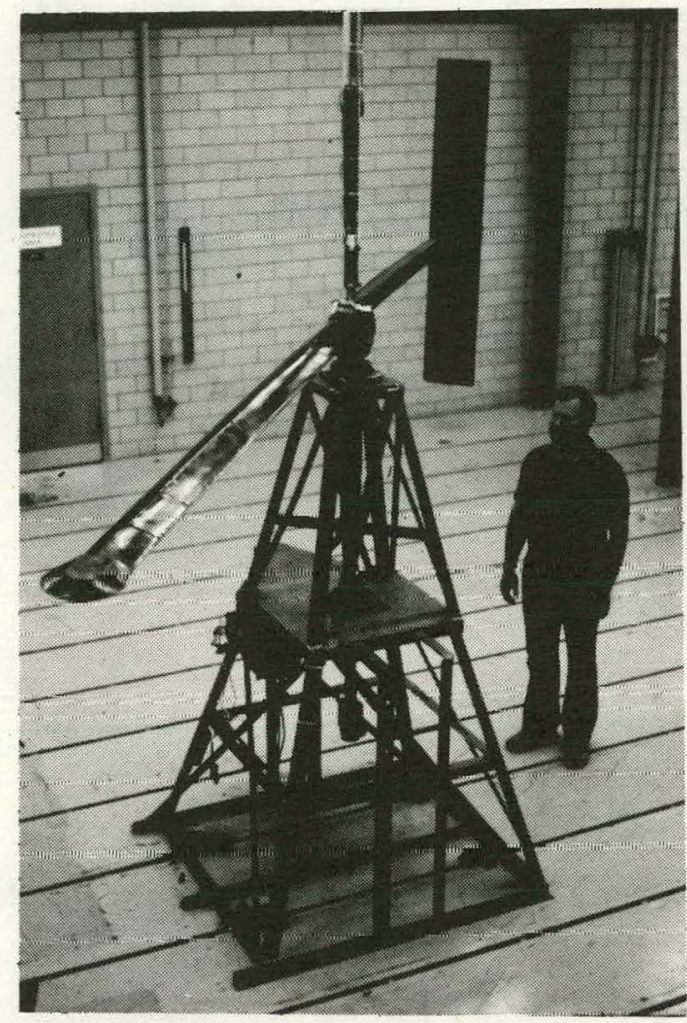

Figure 2-9. Indoor Blade Test Facility

control blades by suction and blowing. Blade aerodynamic lift, drag, and pitching moment are measured by a three-component internal strain gauge balance. A torque cell on the shaft provides data to cross-check the acr odynamic drag and pitching moment. Pracision slip rings mounted alop the shaft have sufficient capacity to monitor blade stresses, internal pressures, and balance fouling. Tlie data is sampled and fed through an analog to a digital convertor to an on-line mini-computer that processes the data in real time or stores information for future use. The centrifugal force resulting from blade rotation is balanced by a counter weight located on the support arm an equal distance from the central shaft thereby permitting the evaluation of the single-bladed machine.

Tests of conventional blades and circulation control blades are currently 


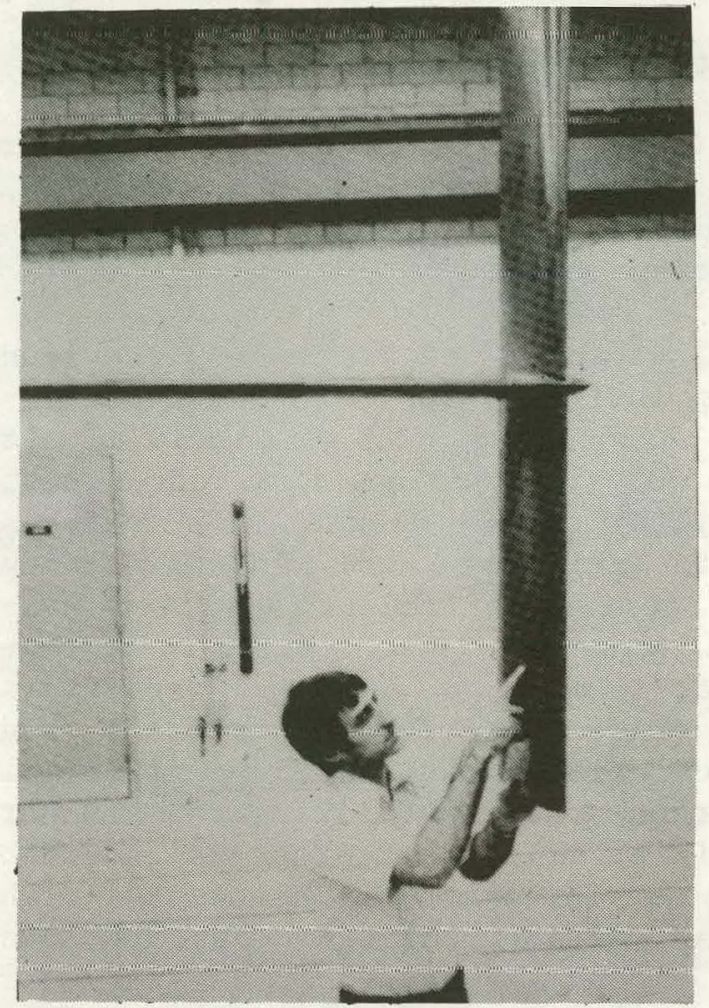

Figure 2-10. NACA 0015 Airfoil Blade on Indoor Test Machine

in progress. Photographs of such blades are shown in Figs. 2-10 and 2-11. Comparisons are to be made between these measurements and published data. Preliminary tests have been run in the indoor facility to define structural integrity, to check instrumentation, to develop sottware, and to determine tare characteristics. Some typical results are shawn in Fig. 2-12 for the drag and moment coefficient over the angle of attack range. These efforts are in progress at this time.

\subsection{SUMMARY REMARKS}

Results of the theoretical and experimental research conducted at West Virginia University have indicated that blade characteristics in curvilinear flow are significantly different from blade characteristics in

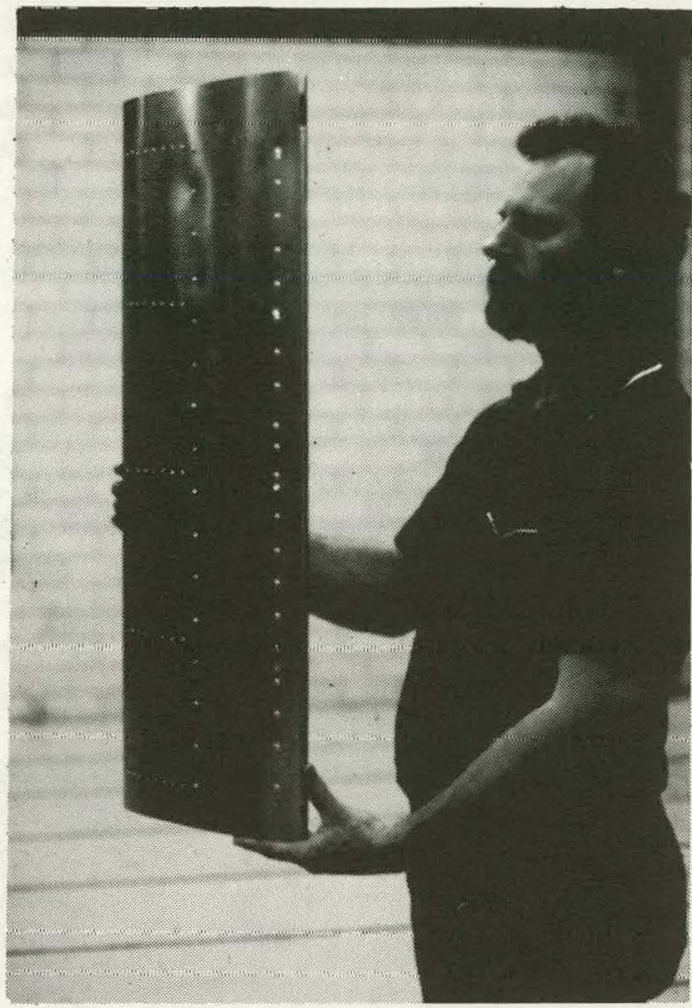

Figure 2-11. Circulation Controlled Blade for Indoor Test Machine

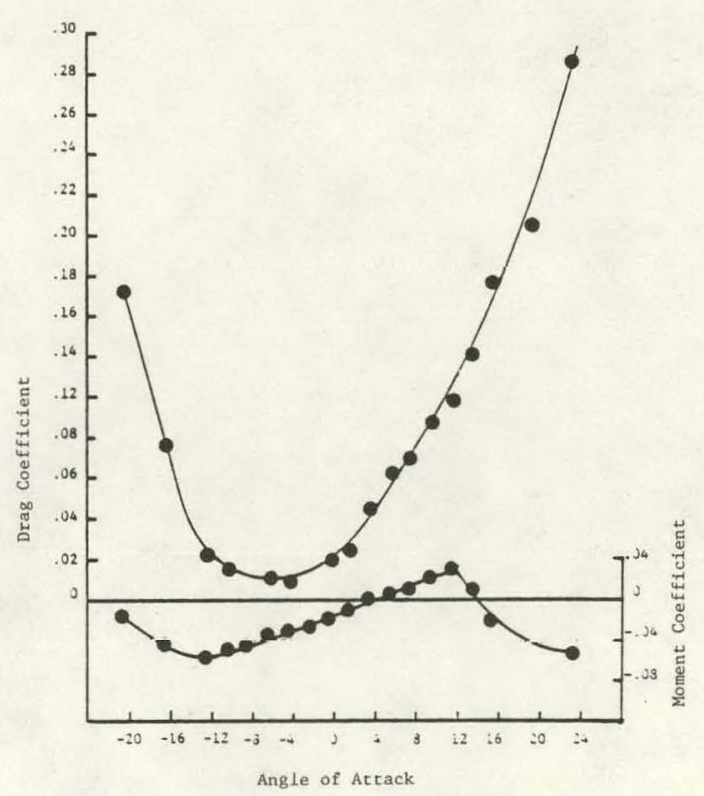

Figure 2-12 Typical Data from Indoor Results 
rectilinear flow. Virtual camber, virtual incidence, and large boundary layer pressure gradients result from flow curvature and act to alter the airfoil characteristics.

Analytical methods have been developed that may be used to predict virtual camber and incidence as a function of airfoil geometry and turbine operating parameters. These methods may be used to optimize blade geometry and pitch schedule, thereby improving turbine power extraction. This method has not been experimentally verified as yet but is to be investigated in subsequent research.

Variable camber that can be achieved with leading and trailing edge devices or by circulation control may result in increases in power coefficient. Verification of this phenom- ena is consistent with current goals of the project.

In order to provide confirmation for the predictions of the analytical studies, an external facility was constructed.

Preliminary measurements provided some insight into the complex phenomena associated with the curvilinear flow of the turbine. An indoor test facility to evaluate the various characteristics used in developing the power coefficient has been constructed. The facility has the capability of varying parameters relating to both conventional and circulation control airfoils. Current studies utilizing this indoor facility will provide an insight into the complex phenomena associated with a VAWT with circulation control. 


\section{SECTION 3.0}

\section{DIFFUSER AUGMENTED WIND TURBINE}

For the past three years, Grumman Aerospace Corporation has been performing a study to evaluate the diffuser augmented wind turbine (DAWT) concept. The work has been both analytical and experimental with the major emphasis directed toward experimental verification of the concept. The objective of the study is to develop a cost-effective system by devising a means of increasing the power generating capability of a conventional wind turbine by increasing the mass flow through the rotor. Preliminary efforts of this concept have been carried out in England and Israel. Details of the Grumman Study are provided in Reference 2.

\subsection{THEORETICAL STUDIES}

For a conventional wind turbine, only $59.3 \%$ of the energy in the air intercepted by the rotor disk can be extracted. In the case of a diffuser augmented wind turbine with a turbine of the same area and wind speed, because of the pressure recovery of the diffuser it is possible to sustain a reduced pressure downstream of the rotor (Fig. 3-1). As a result, the

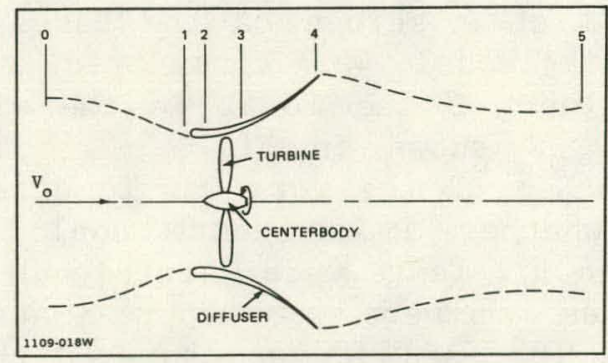

Figure 3-1. Basic Schematic of the DAWT with Reference Stations air speed ahead of the DAWT is greater than the free speed by the ratio $\varepsilon$. Thus, the power extracted from the DAWT is given by:

$P_{D}=\varepsilon A_{2} V_{o}^{2}\left[\varepsilon^{2}(1 / 2) \rho V_{o}^{2}+P_{2}\right]$

Utilizing one-dimensional theory, it is possible to define an augmentation ratio as

$$
r=\frac{C_{P_{i}}}{0.593}=\frac{C_{T}}{0.593}\left(\frac{q_{2}}{q_{0}}\right)^{3 / 2}
$$

The maximum value of $r$ can also be calculated and is given as

$$
r_{\max }=\frac{9}{8}\left(1-\Pi_{4}\right)\left[\frac{1-\Pi_{4}}{3\left(1-C_{P_{R}}\right)}\right]^{1 / 2} \text {, }
$$

where

$$
C_{P_{R}}=n_{D} 1-\left[\frac{A_{2}}{A_{4}}\right]^{2} .
$$

The value of $\pi_{4}$ and $\eta_{D}$ or $\varepsilon$ are to be determined from experiment.

One-dimensional theory implies that the diffuser area ratio between the base of the diffuser and the throat should be as high as possible. It is well known that separated flows in adverse pressure gradients are prevalent for angles in excess of $20^{\circ}$. Preliminary investigations by Grumman involved developing methods to demonstrate that area ratios between 2 and 4 were feasible using included angles greater than $20^{\circ}$ and possibly even as high as $90^{\circ}$. The purpose of using 


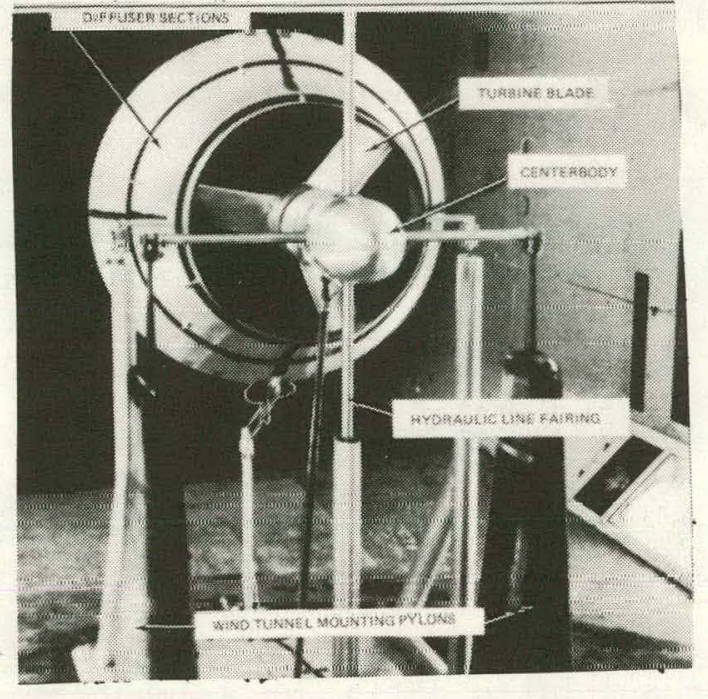

Figure 3-2. Baseline Model Installation in the $2.1 \times 3 \mathrm{~m}$ Wind Tunnel with Three-Bladed, Constant Chord Wind Turbine 0.46-m Diffuser and Paraboloid Centerbody End Pieces

large angles was to make the diffuser section as short as possible with the possibility of reducing system costs.

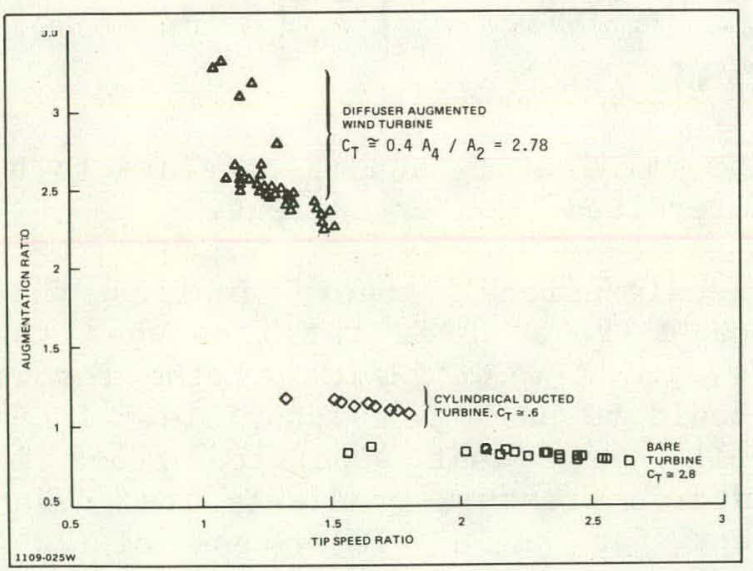

Figure 3-3. Comparison of Turbine Performance in the Wind Tunnel for Different Augmentation Systems

\subsection{EXPERIMENTAL STUDIES}

A multiphased study was carried out using various wind tunnel facilities and models. The first series of models were tested in an open jet. The model size was approximately $4.5 \mathrm{~cm}$ in diameter, which gave a Reynolds number of approximately $7 \times 10^{4}$ based on the model exit diameter. The models utilized screens of various solidities to simulate turbine disk loadings. Many designs were tested; for example, straight walls with slots to suppress flow separacion, flapped ring wings, etc. From these studies a baseline diffuser design was chosen for additional testing. This baseline had the following characteristics: area ratio of 2.78 , included angle of $60^{\circ}$, length-todiameter ratio of 0.5 with a twostaged walled slot-flow. Measurements with this model indicated that the exit pressure coefficient $\Pi_{4}$ was below atmospheric pressure with a value of -0.56 .

The next phase used larger models with Reynolds numbers approaching $10^{h}$. Tesls were conducted only with the baseline geometry utilizing screens to simulate a turbine disk loading. The purpose of these tests was to confirm the low value of base pressure coefficient, which was found to be approximately -0.83 .

During the next phase the effect of flow in the diffuser using a turbine instead of a screen on the baseline diffuser mudel was considered. A photograph of the model in the wind tunnel is shown in Fig. 3-2. The last phase of the work was to determine whether improvements could be made in $\pi_{4}$. Tests were carried out at Reynolds numbers of approximately $0.13 \times 10^{6}$, and it was observed that improvements in the diffuser performance were possible using a shorter diffuser, termed the "dump diffuser." 
Preliminary measurements to determine the augmentation ratio are shown in Fig. 3-3. A short cylindrical duct improved the performance of the base turbine by a factor of about 2.0; the performance with a designed diffuser is approximately 4.5 times the value of the base turbine.

Using a one-dimensional analysis it is possible to calculate the augmentation ratio as a function of disk loading coefficient for various values of diffuser efficiency. Results of these calculations are shown in Fig. 3-4. The locus of peak augmentation ratio is also shown on the figure for a pressure coefficient of -0.8 as well as rneasured data using screens and a turbine. The effect of disk loading is not strong for greater values of $\mathrm{C}_{\mathrm{T}}$ occurring after $r_{\text {nax }}$. The peak turbine data is also considerably higher than the screenequipped data. The use of a turbine appears to have a major impact upon the efficiency of the diffuser. This could be because the turbine wake supplies energy towards the diffuser wall for the flow downstrearn of the turbine and aids the slot flow.

Further comparison of the model tests with optimum performance data is shown in Fig. 3-5 where the calculations are again for the onedimensional configuration. Shown in the figure is the baseline diffuser with screen where the maximun level of augmentation ratio is approximately 2.5. The data taken froin the baseline diffuser with a turbine varies betweel 3 and 3.5 , and were taken at a tip speed ratio of approximalely 1.0 . The effect of tip speed ratio is shown on the figure and it is observed that an increase in the tip speed ratio could significantly affect the ilynentation ratio.

A comparison of the current measurements made with an area ratio of 2.78

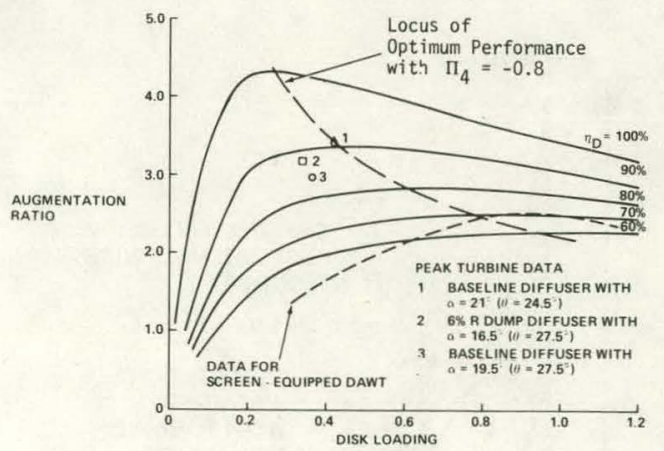

Figure 3-4. Comparison of DAWT Models Test Data with Theoretical Performance for $A_{4} / A_{2}=2.78$ and $\Pi_{4}=-0.8$.

and "potential" performance of systems are shown in Fig. 3-6. For a larger system with an increase in tip speed ratio an augmentation factor of approximately twice current value appears feasible.

An engineering design for a prototype baseline DAWT was performed using an augmentation ratio of 2 (which was demonstrated at the time the study was initiated). The system used a 5.4-1n turbine (a modified Grumman Windstream 25), has a 5.6-m diffuser entrance diameter, $9.1-\mathrm{m}$ exit diameter, and an overall length of $4 \mathrm{n}$

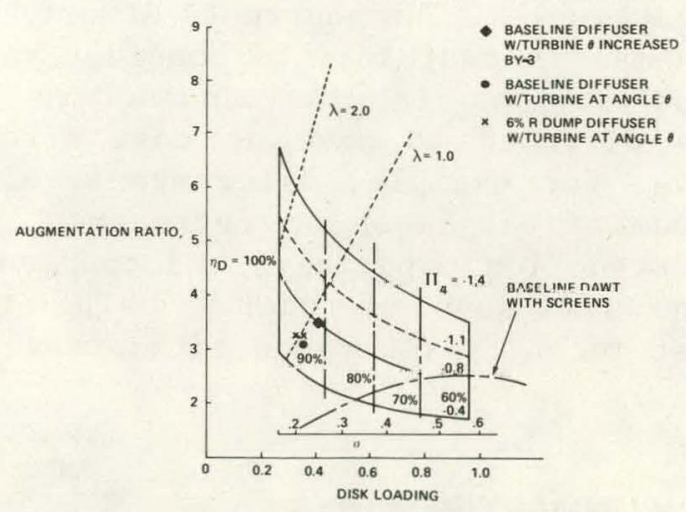

Figure 3-5. Comparison of Theoretically Optimum Performance with Model Test Data, $A_{4} / A_{2}=2.78$. 


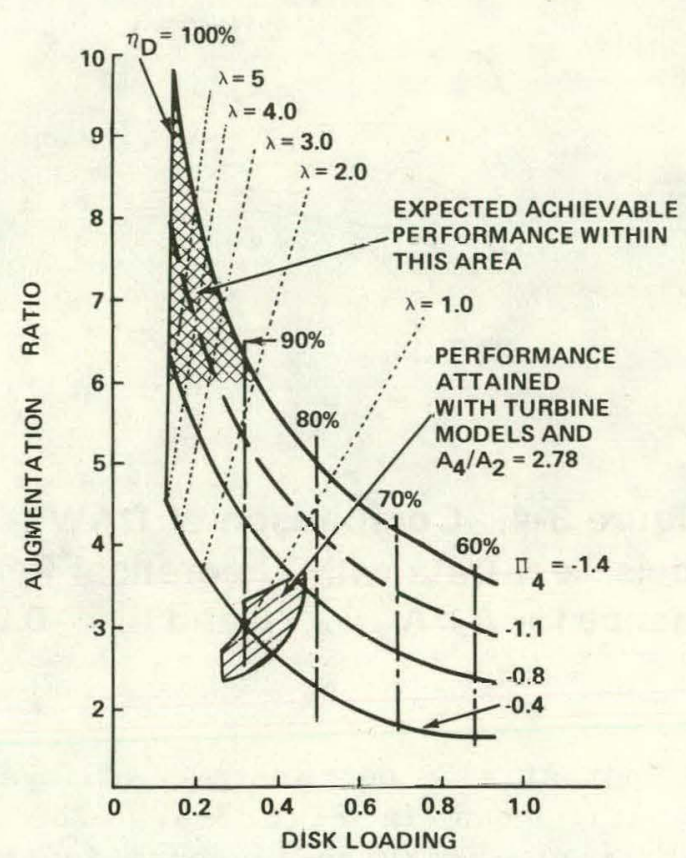

Figure 3-6. Comparison of Theoreti cally Optimum Performance with Model Test Data, $A_{4} / A_{2}=4.0$

(Fig. 3-7). Several modifications to Lhis preliminary design were made. Weights and costs for the DAWT in this preliminary study are given in Tables 3-1 and 3-2. The major cost item is the diffuser and its construction. The current effort by Grumman is twofold: to consider various options in the manufacture of the diffuser to make it cost effective, for example, using steel, aluminum, fiberglass, or ferrocement as construclion materials; and to determine the cost of energy using the most recent performance estimates.

\subsection{SUMMARY REMARKS}

The diffuser augmented wind turbine has the potential to generate significant amounts of energy from avail-

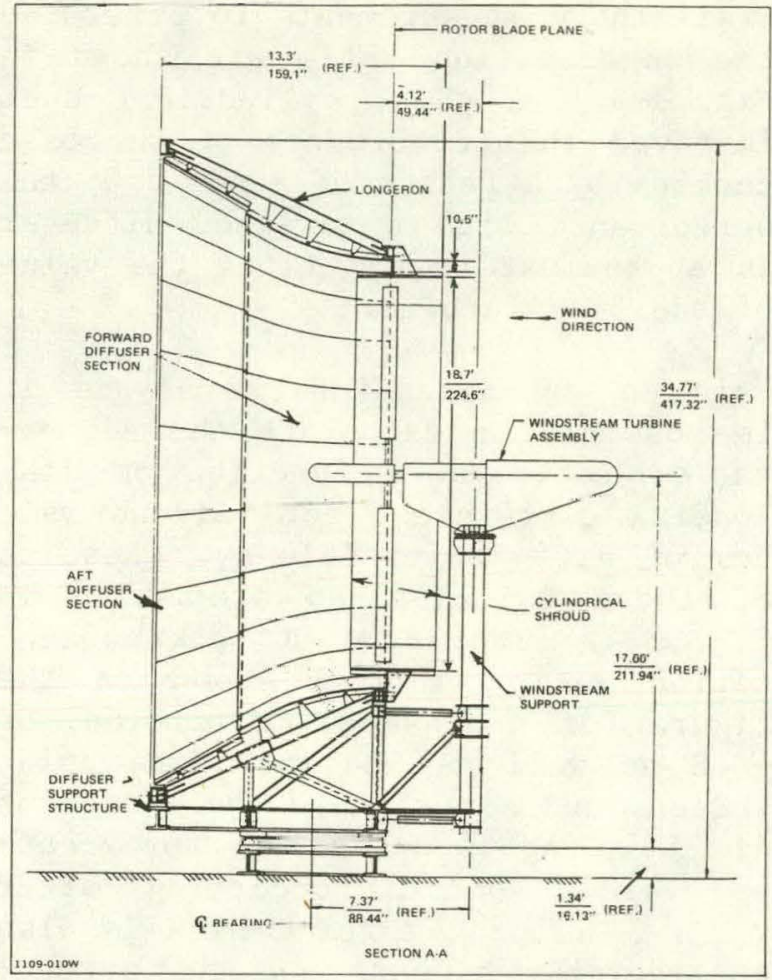

Figure 3-7. Engineering Design of DAWT Field Test Article

ahle wind. Current wind Lunnel studies have shown that models using a turbine produced a higher augmentatiull Lhan those using a screen to simulate the turbine. Augmentation ratios of 3.5 have been measured at a tip speed ratio of unity. The preliminary analysis indicates that this value could possibly be doubled if the tip speed ratio is increased. The first estimate tor the system showed that the majus component cusl was attributed to the diffuser.

The current study is to examine manufacturing techniques assuciated with different materials for the diffuser. It is anticipated that results from this study could provide direction and guidance of an engineering design for a potentially cost effective diffuser augmented wind turbine. 
Table 3-1. Estimated Weight and Relative Cost for the First DAWT 18 Design Study

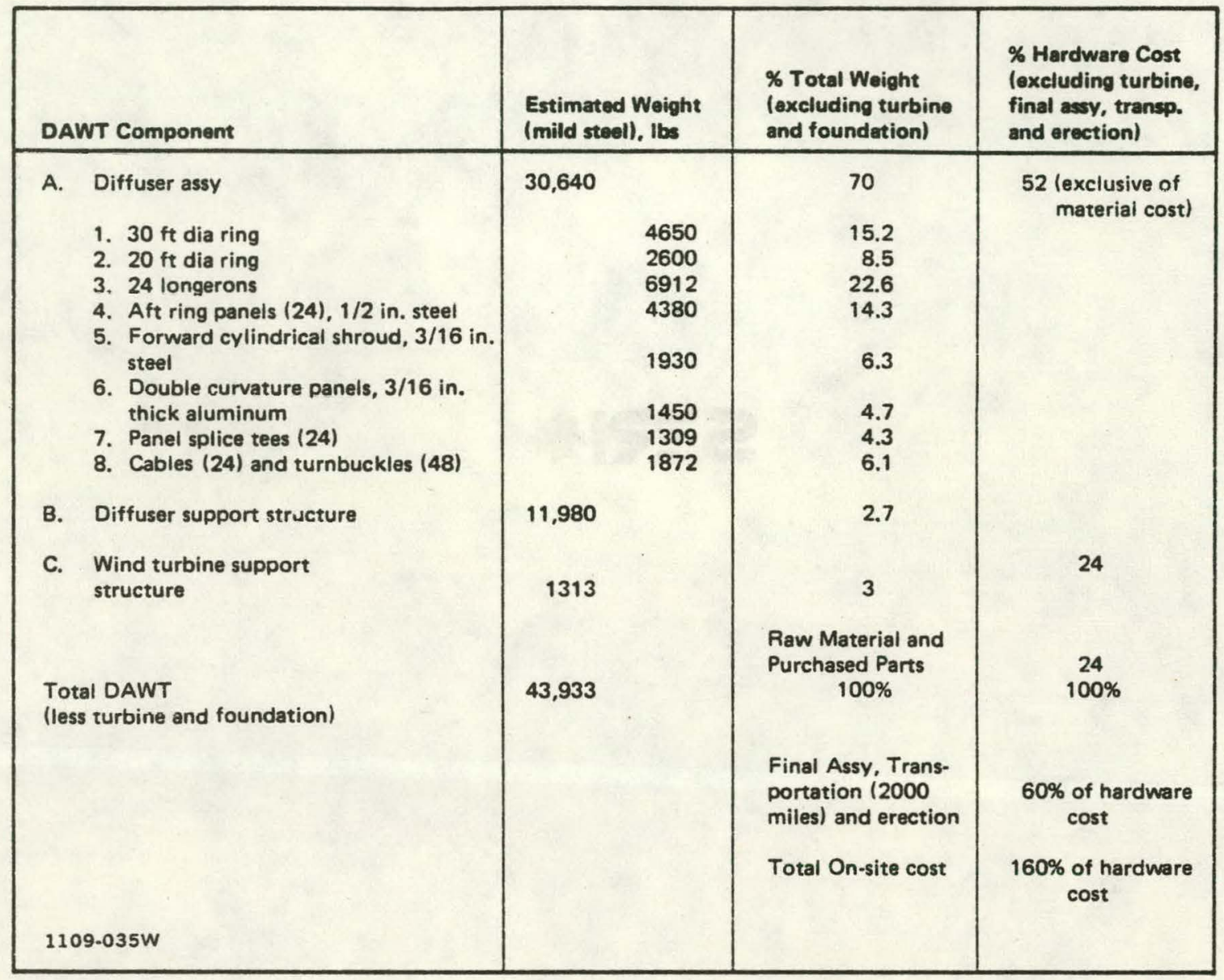

Table 3-2. DAWT Cost Projections (Excludes Foundation and Electrical Connect Costs)

DIFFUSER \& SUPPORT STRUCTURE ( 45,000 LBS)

- Prototype Estimates

U.S. Steel (American Bridge) \$250k \$5.50/lb

Bath Iron Works \$275k \$6.10/lb

Grumman \$590k \$13.40/lh

- Grumman Windstream Wind Turbine ( 2000 lbs)

Production Cost $\sim \$ 25,000 \quad \$ 12.50 / \mathrm{lb}$

- Production Cost Estimate (Department of Commerce Statistics)

$(2-3) \times(\mathrm{Mt} \mid$ Cost $/ \mathrm{Ib}) \approx 0.40-0.60 / \mathrm{lb}$

$\therefore$ Total Cost-Production Diffuser $\$ 18-\$ 27 k$

1109-033W 


\section{S=P*}




\section{SECTION 4.0}

\section{THE TORNADO TYPE WIND ENERGY SYSTEM}

The Tornado Type Wind Energy System was first proposed by Grumman Aerospace Corporation in 1975. Since that tine analytical and experimental studies have been carried out by Grumman with the major objective determining technical and economic feasibility of the system. Two types of tornado systerns have been considered: one with a spiral cross section, the other with permanently fixed vanes. An artist's conception of a tornado system is shown in Fig. 4-1. A vortex is produced within the hollow tower with free air that enters the tower through a tangential inlet system. The vortex is exhausted out of the top of the tower. The turbine is located at the bottom of the tower so that it can receive external air. The pressure differential between the external air and that resulting froin the vortex flow within the tower produces a high mass flow across the turbine, thereby producing turbine augmentation. The major efforts in the study are to determine optimum configurations and performance of full-scale systems. Several simplified analytical methods have been developed, wind tunnel tests have bcen carried out on models of various sizes, and predictions have been made for full-scale systems. Reference 3 provides additional information sources on this system.

\subsection{THEORETICAL STUDIES}

The modeling of the fluid mechanics of the tornado system is a very difficult task. Several attempts have been made to model the flow about the systen; however, the interaction be- tween one part of the system and another is complex. In all the theoretical studies, simplifying assumptions have been used in order to simulate some portion of the system.

Recent analytical work has been carried out by Grumman using conservation of mass, momentum, and angular momentum for a control volume encompassing the tower. In combination with the radial monentum equation it is possible to describe the inlet flow, internal fluid mechanics, and the flow conditions at the top of the tower. It is also possible to estimate the power coefficient as a function of disk loading under the conditions of a known flow-field pattern.

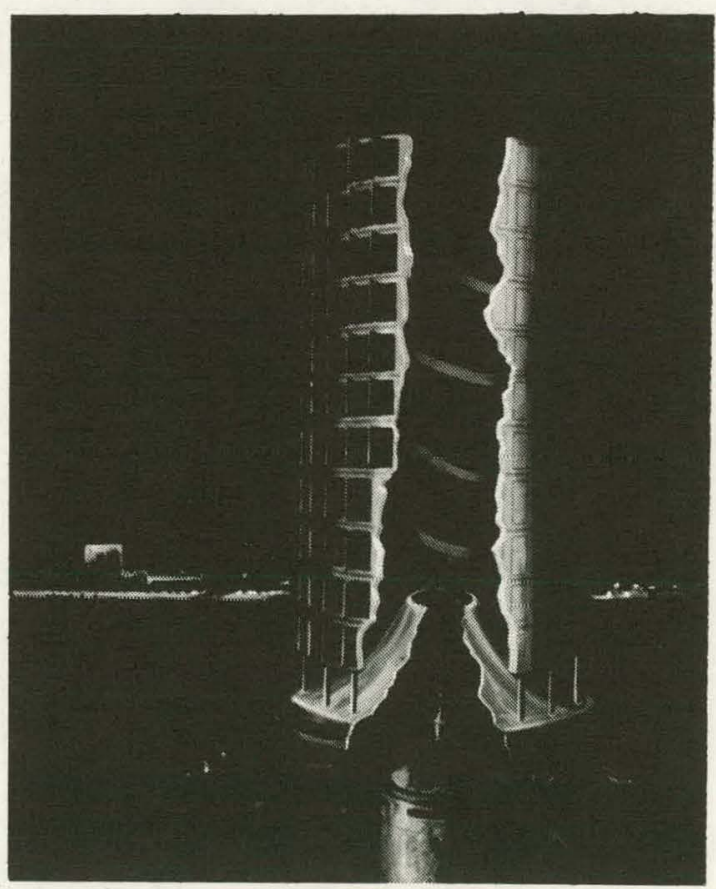

Figure 4-1. Artist's Conception of Tornado-Type Wind Energy System 
The numerical analysis was performed using a spiral-type geometry with a cylindrical control volume (Fig. 4-2). The velocity at the inlet of the tower is related to the free stream velocity by $\gamma$ which is greater than unity if the flow is acceler-
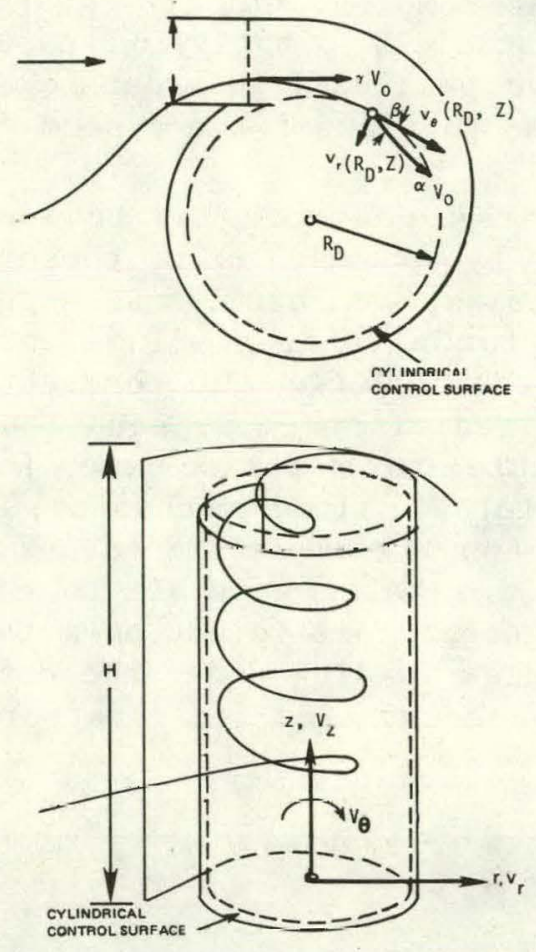

Figure 4-2. Control Volumes and Nomenclature for Flow Analysis

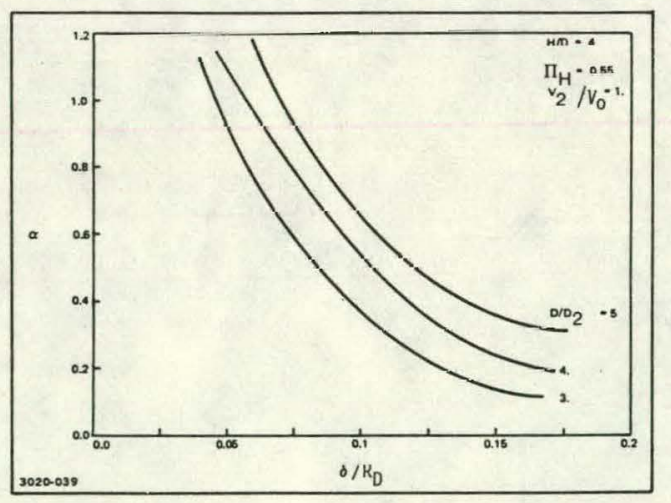

Figure 4-3. Inlet Flow Parameters as a Function of Viscous Core Radius $\delta / R D$. ated. The angle of allack, $\alpha$, is a dimensionless quality that relates total velocity inside the flow volume to the free stream velocity. The angle, $\beta$, is between the total velocity component and the tangent direction. In general, $\alpha, \beta$, and $\gamma$ are all functions of the space coordinate, $z$; however, it is assumed for this study that they represent mean values and are treated as unknowns that are to be determined. The control volume is taken around the cylinder of radius $R_{D}$ and height $\mathrm{H}$. End conditions at the top of the tower are specified. Steady, incompresoible flow is assumed, and viscous core radius, $\delta$, is a parameter of the problem.

For specific values of $\delta / R_{D}$ the iesulting equations $c$ an be solved for $\alpha$ and $\beta$. The typical set of curves for $\alpha$ as a function of $\delta / R_{D}$ is shown in Fig. 4-3. It is observed that $\alpha$ can be greater than unity for small values of $\delta / R_{D}$ only. Analysis also indicates that under specific conditions the value of $\gamma$ can be greater than unity as is shown in Fig. 4-4. The parameter, $\gamma$, was found by assuming that all mass entering the inlel goes inco the cylindrical

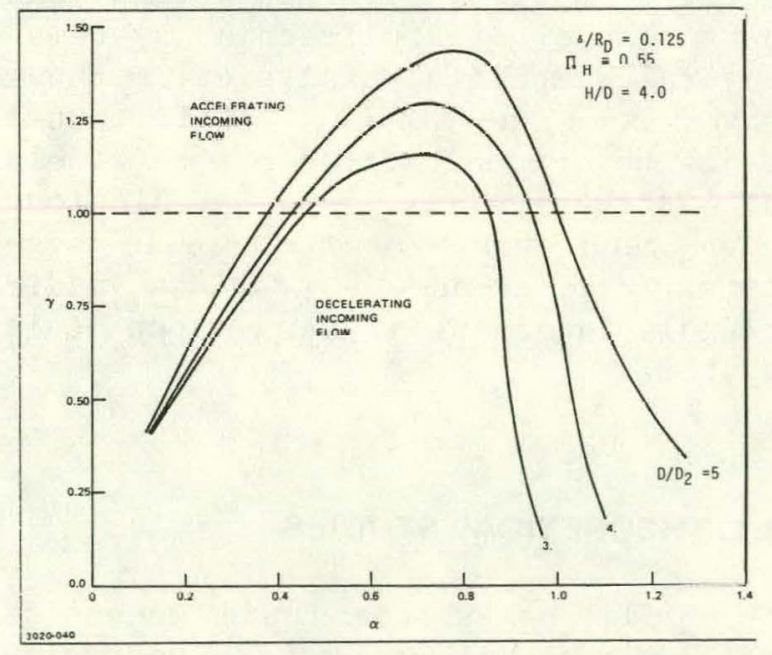

Figure 4-4. Accelerating Factor $\gamma$ Versus Inflow Parameter 
volume. An accelerating flow is indicated for $\gamma>1$ signifying a converging incoming stream tube or a capture area larger than the frontal area. It is important to note that the simple analytical model predicts the possibility of an accelerating flow.

The pressure distribution at the bottom of the tower can be obtained by assuming radial equilibrium of the centrifugal force with the inward pressure gradient force. This can be calculated if one assumes that the viscous core radius is constant. A considerable variation of pressure is predicted across the bottom of the tower (Fig. 4-5). Utilizing the pressure distribution obtained at the bottom, the disk loading, and the static pressure inmediately upstream of the turbine, one can calculate the power coefficient defined as:

$$
\mathrm{C}_{\mathrm{P}}=\frac{\Delta \mathrm{p}_{23} \mathrm{v}_{2} \mathrm{~A}_{2}}{(1 / 2) \rho \mathrm{v}_{0}^{3} \mathrm{HD}}
$$

The plot of the power coefficient versus disk loading coefficient is shown in Fig. 4-6. In general, the experimental results fall between the predictions using $\delta / R_{\mathrm{D}}$ of 0.1 and 0.18. The theoretical calculations indirate that the power coefficient increases as the viscous core radius decreases. The upper boundary of $\delta / R_{D}=0.1$ was chosen to represent the best possible performance of the system. Maximum value of power coefficient, therefore, is limited to about $17 \%$ with this simplified analysis. A decrease in the viscous core may be brought about by increasing the size of the system.

The numerical studies carried out have provided some preliminary insight into the phenomena of tornadotype flows. The simplified analytical study indicates the importance of viscous core radius, substantiation

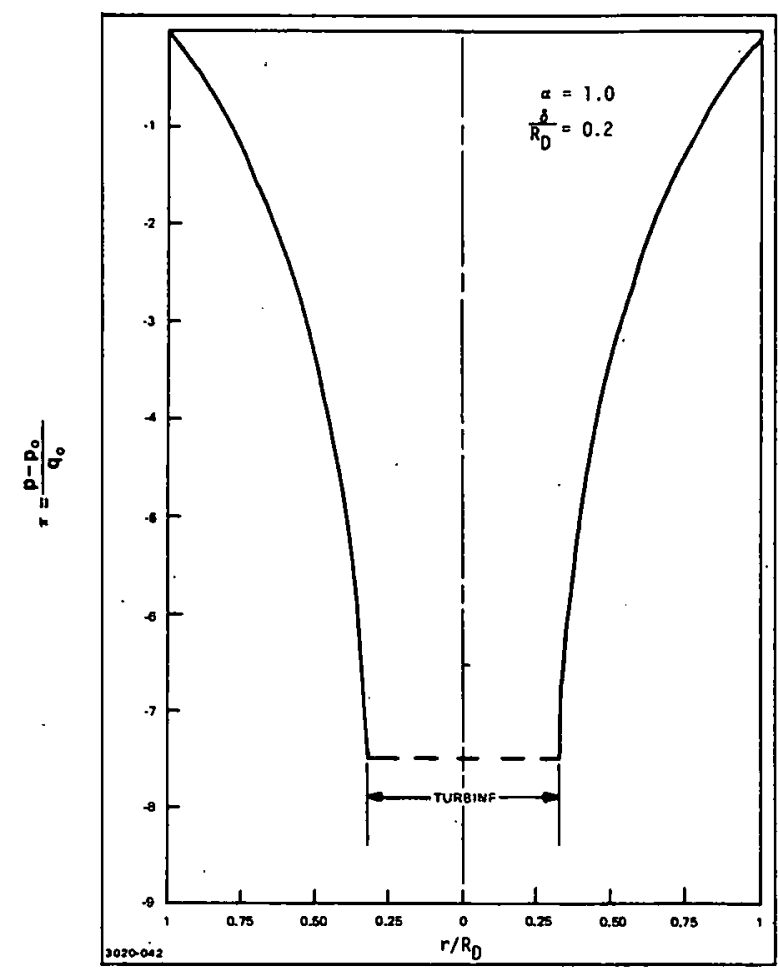

Figure 4-5. Static Pressure Distribution at Tower Bottom

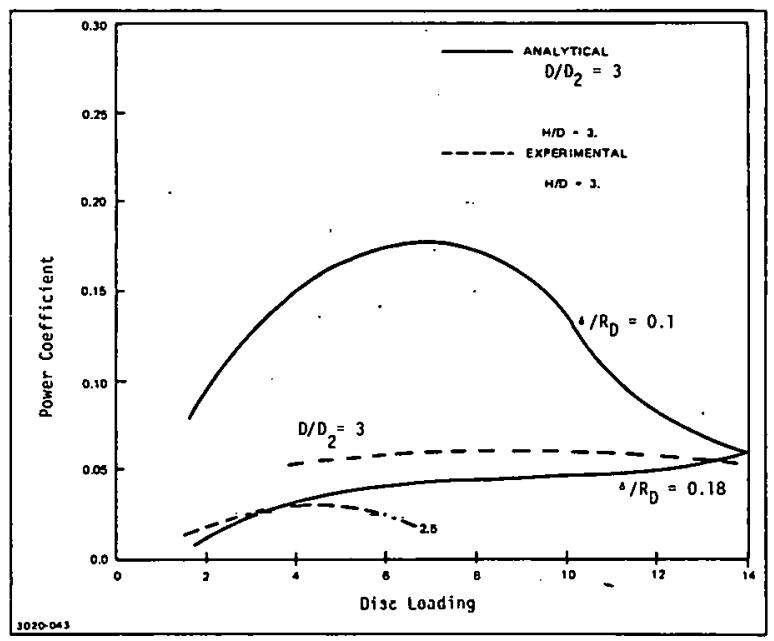

Figure 4-6. Plot of Power Coefficient Versus Disk Loading Coefficient and Comparison of Theory and Experiment 


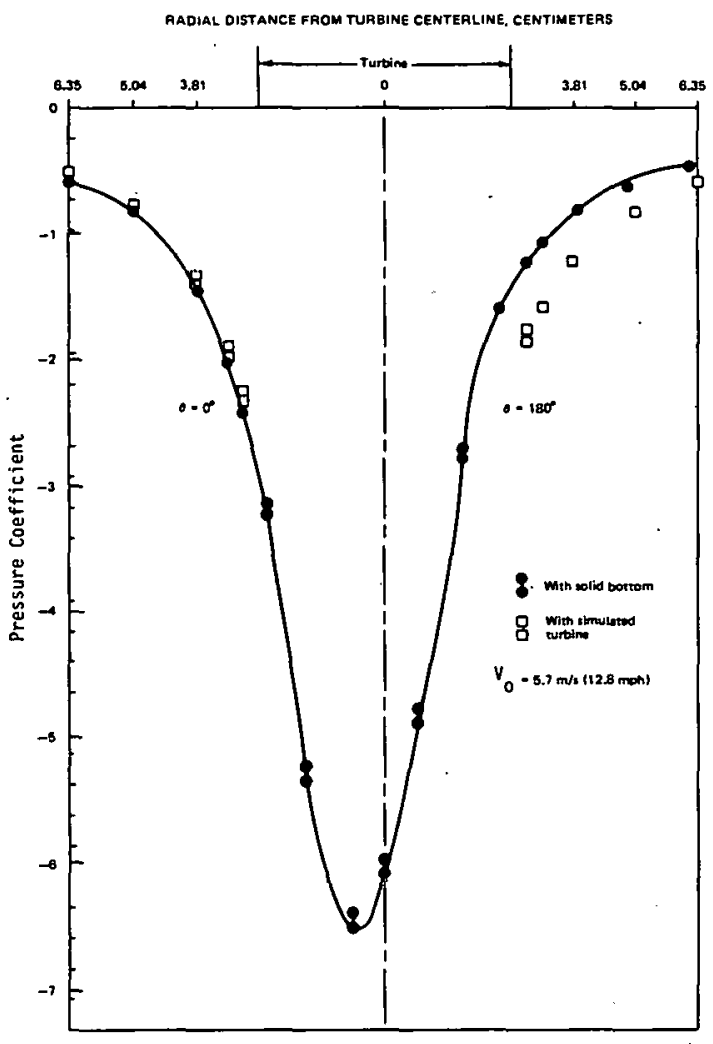

Figure 4-7. Pressure Measurements on the Tower Bottom Wall with a Solid Plug or a $3.81-\mathrm{cm}$ Diameter Screen

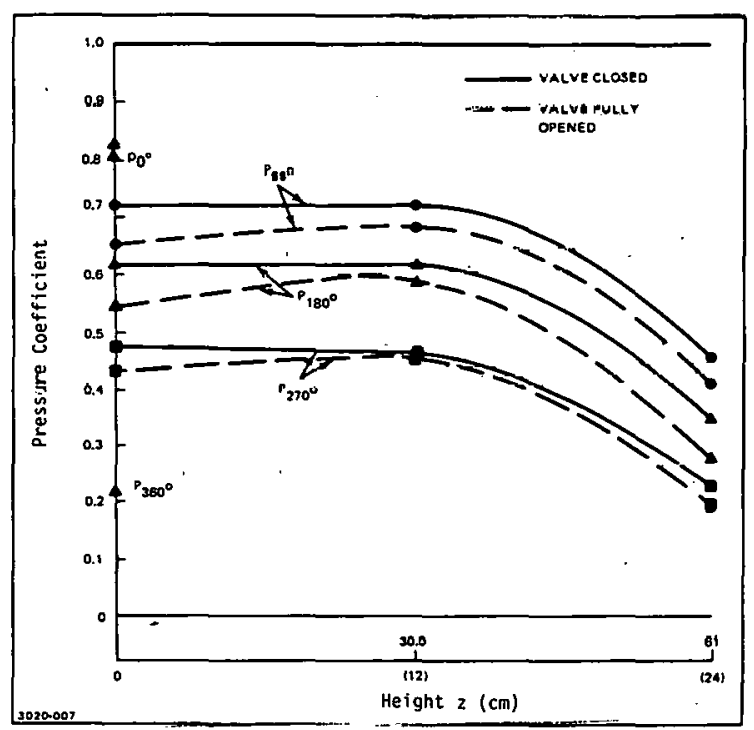

Figure 4-8. Measured Pressure Distributions Along the Tower Walls for $V_{O}=55.5 \mathrm{~m} / \mathrm{s}$ (124 mph), and $\mathrm{H}=76 \mathrm{~cm}$ (No. Blower) of favorable effects of pressure gradients, and power coefficient levels that might be obtained. In general, some of these analytical studies have confirmed the initial measurements that have been carried out. It should be emphasized that these are very preliminary analytical studies and only provide guidelines for the performance characteristics of the system. Further work has to be done to take into account the bottom wall turbine flow interaction and the interaction of the free stream wind with the exiting vortex. Both of these will have major implications on the performance of the wind turbine.

\subsection{EXPFRIMENTAL STUDIEG}

The major thrust of the project has been to confirm some of the basic concepts associated with the system. Experimental studies were carried out with spiral-shaped and fixed-vaned towers. The major number of studies have been carried out in a wind tunnel with a cross section of $0.6 \times 0.9 \mathrm{~m}$ at a speed of $5.8 \mathrm{~m} / \mathrm{s}$. A mode1 $0.36 \mathrm{~m}$ in height and $0.13 \mathrm{~m}$ in diameter was used. The purpose of these initial studies was to make static pressure measurements at the bottom of the tower to determine if the vortex pressure distribution was significantly weakened due to the presence of a turbine that exhausted into the core of the vortex. In one case the tower had a solid bottom, in the second case the turbine was simulated by a set of screens. I'ypical measurements made on the model are shown in Fig. 4-7 from which it was concluded that the vortex would be strengthened by the use of the turbine. In these tests a turbine, which would normally produce a swirl, is simulated by a screen.

The surface pressure was measured along the tower height to determine 
if there was a favorable or unfavorable interaction between the vortex and the tower itself. A favorable pressure gradient exists as is shown in Fig. 4-8, which would tend to keep the vortex from breaking up. Confirmation of this type of interaction was determined by kerosene vapor visualization techniques. The najor experimental study was conducted in the $1.2 \mathrm{~m} \mathrm{x} 1.8 \mathrm{~m}$ facility at approximately $8 \mathrm{~m} / \mathrm{s}$. The method of installation of the model in the tunnel is shown in Fig. 4-9. In this particular case, the duct was placed on the tunnel wall and the inlet was below the tunnel floor. Screens were used to simulate the pressure drop across a turbine at different disk loading coefficients.

Tests were made for $C_{T}$ ranging from 0 to 20 at specific values of $\mathrm{D} / \mathrm{D}_{2}$ and H/D. The data was taken with two spiral configurations, one with $12.7-\mathrm{cm}$ diameter and $25.4-\mathrm{cm}$ height, the other with $25.4-\mathrm{cm}$ dianeter and $53.3-\mathrm{cm}$ height. The value of $\mathrm{C}_{\mathrm{T}}$. was varied by changing the mesh size and number of screens to simulate a turbine. A typical set of data is shown in Fig. 4-10, where the power coefficient is based upon frontal area. In general, it is observed that a rapid increase in power coefficient occurs at low values of $\mathrm{C}_{\mathrm{T}}$.

After summarizing all the data, one can look at the power. coefficient as a function of Reynolids numbers for the models tested. It is observed that the power coefficient increases as the Reynolde number increases and for lower values of $H / D$. It appears that reducing the height-to-diameter ratio at a fixed Reynolds number would be desirable. A maximum value of $6 \%$ was measured for the power coefficient at the hiuhest Reynolds number of $13.5 \times 10^{4}$ (Fig. 4-11). The rate of change of the power coefficlent with Reynolds number and

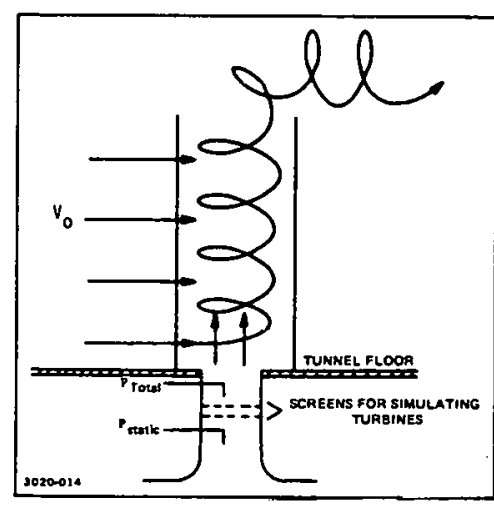

\section{Figure 4-9. Experimental Setup with Screen-Simulated Turbine}

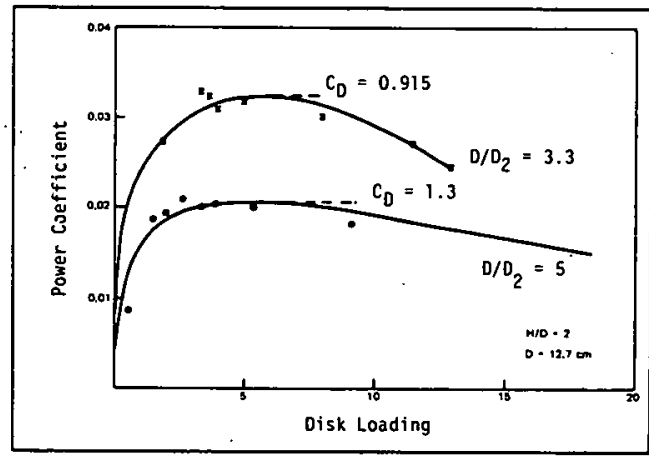

Figure 4-10. Plot of Power Coefficient Versus Disk Loading Coefficient

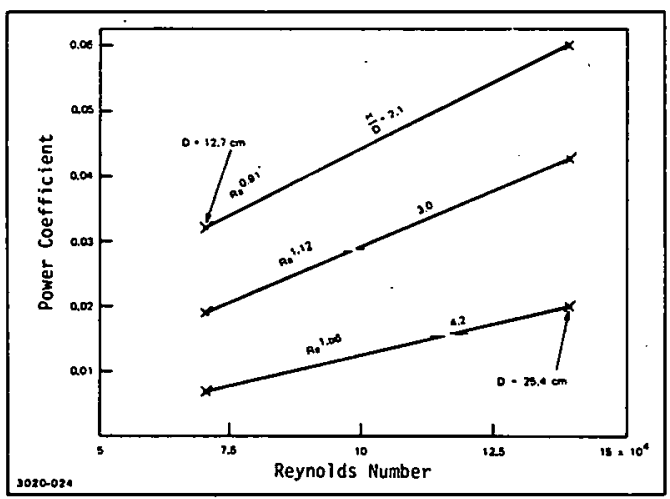

Figure 4-11. Plot of Power Coefficient Versus Reynolds Number for $D / D_{2}=3.3$ 


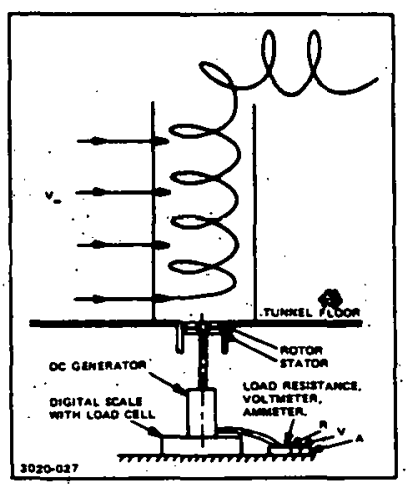

Figure 4-12. Experimental Setup with Bladed Turbine and Electrical Generator

height-to-diameter ratio is also observed. The data avallable indicates a strong variation in the exponent, $\mathrm{m}$, which relates $\mathrm{C}_{\mathrm{p}}$ to $\mathrm{Re}$. There is no avallable information to indicate the value of $m$ at high Reynolds numbers. It is important to determine the range of $\mathrm{m}$ as the current models are very small with low Reynolds numbers.

The next set of measurements were carried out with crude turbines to replace the screen. The schematic of this system is shown in Fig. 4-12. A DC electrical generator with resistive loads was connected to the turbine. The generator was precalibrated to give a measure of generator efficlency as a function of rpm and load resistance. The turbines used in the current study were limited to $10 \mathrm{~cm}$ in diameter and restricted to operate at lecs than $5000 \mathrm{rpm}$ For Reynolds numbers less than $10^{4}$ the lift coefficient is usually low, the drag coefficlent high, and stall angle low compared to large blades at high Reynolds numbers, therefore, data taken from these measurements are probably low.

Typical data taken from the $10-\mathrm{cm}$ turbine with $\mathrm{C}_{\mathrm{T}}=3, \lambda=1$ is shown

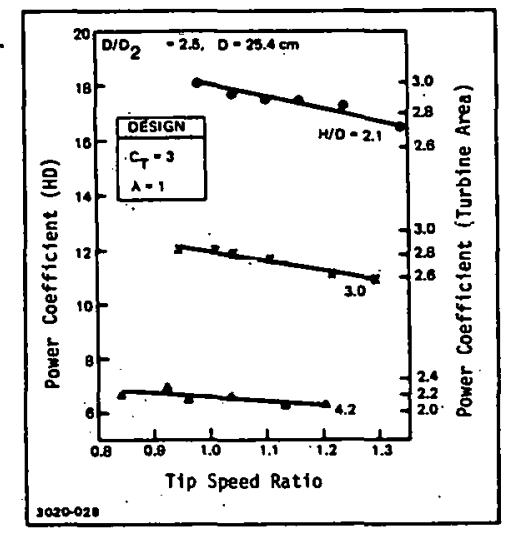

\section{Figure 4-13. Plot of Power Coefficient Versus Tip Speed Ratlo for Different H/D.Ratios}

in Fig. 4-13. As shown on the plot; the power coefficient increases as $\dot{H} / \mathrm{D}$ decreases. The effect of tip speed ratio is not critical, the blade being designed for a tip speed ratio of 1 . The power coefficlent, based on turbine area, is also shown and has a value close to 3 . The best power coefficient of $18 \%$ comes from the shortest tower. This value is better than those given by the screen-simulated turbine and is probably due to the favorable interaction betwecn the vortex and the turbine. The turbine, which rotates in the op-: posite direction to the vortex, illparts an angular momentum into its exhaust flow, in the same direction as the vortex. In contrast, the exhaust from the screen-simulated test turbine has no angular. momentum and, therefore; tends to slow down the vortex when it merges with and attalne tha. same rotating speed as the vortex. The measured disk loading is strongly dependent upon tip speed ratlo as shown in Fig. 4-14. It should be emphasized that all of these measurements have been carried out for a spiral-type model.

A study is currently under way with the second configuration utilizing 
fixed vanes. The study is to assess the number and shape of the vanes, and the size of the system for optimum performance. Fixed vanes have a definite economic/cost advantage over movable vanes. The difference between the fixed-vane configuration and a spiral configuration is that losses may result due to leakage on the leeward side of the tower.

Several fixed-vane models have been constructed. One of these, shown in Fig. 4-15, is $25 \mathrm{~cm}$ in diameter and $50 \mathrm{~cm}$ in height. The model is equipped with a $10-\mathrm{cm}$ diameter turbine and has been tested in the $1.2 \mathrm{~m} \times 1.8 \mathrm{~m}$ wind tunnel at $8 \mathrm{~m} / \mathrm{s}$. Several variations of this model have been made including flaps that are attached to the vane, vane angle setting, vane positioning, and bottom inlet configuration. Some typical data is shown in Fig. 4-16, which indicates that the power coefficient based on frontal area varied between $6 \%$ and $14 \%$, depending upon the configuration. This is less than the best value of $18 \%$ that was obtained by the spiral cross-sectional model. The reduction in performance is assumed to be primarily due to

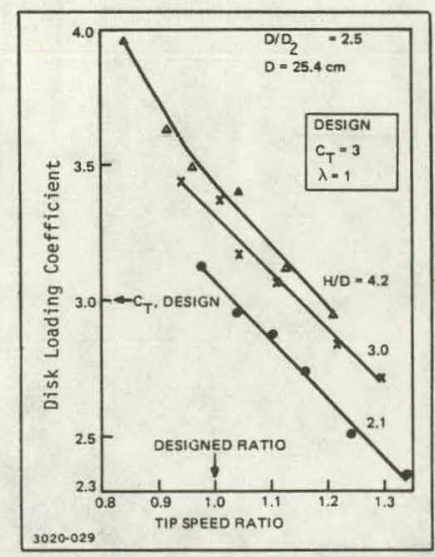

Figure 4-14. Plot of Measured Disk-

Loading Coefficient Versus Tip Speed Ratio leakage across the vanes. With such a large variation of power coefficient, it is necessary to confirm its validity over a larger range of Reynolds numbers and to optinize the performance of the system based upon geometric characteristics. This is extrenely important in that the previous measurements utilizing the spiral tower indicated a strong variation of power coefficient with Reynolds number. It is necessary to confirm the scaling law for this type of configuration, which is not easy to predict based upon the present information.

The largest model tested at the present time has been approximately $1 \mathrm{~m}$ in height, using the vane configuration. At the present time, Grumman is constructing models of approximately $5 \mathrm{~m}$ in height, with a $2-\mathrm{m}$ diameter tower and a $0.75-\mathrm{m}$ diameter turbine, Fig. 4-17. Such a configuration is to be tested in one of the larger wind tunnels when test time becomes available. A turbine rotor made from aluninum filled epoxy resins and reinforced with steel rods has been constructed for this model, Fig. 4-18. Each blade of the turbine

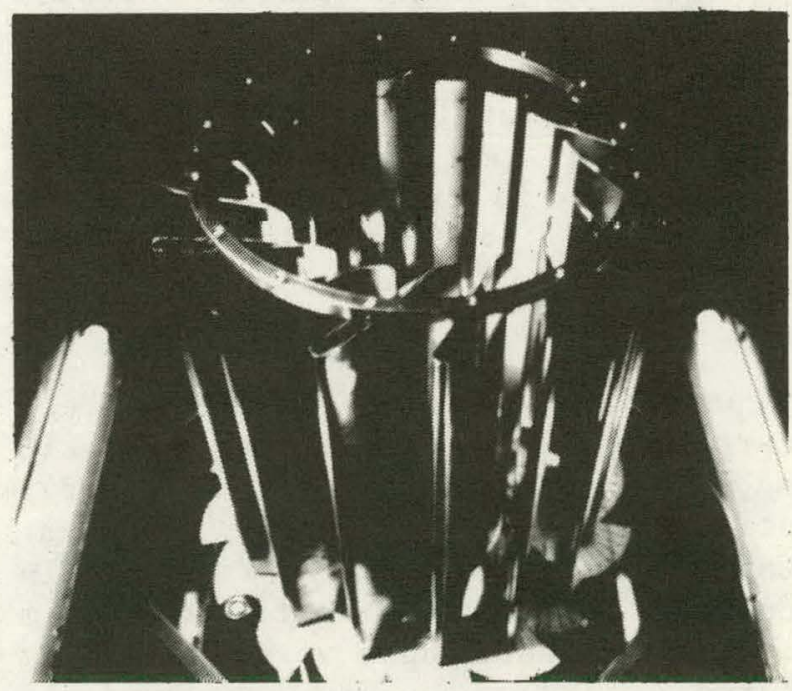

Figure 4-15. Fixed-Vane Model 25-cm Diameter, 50-cm High 


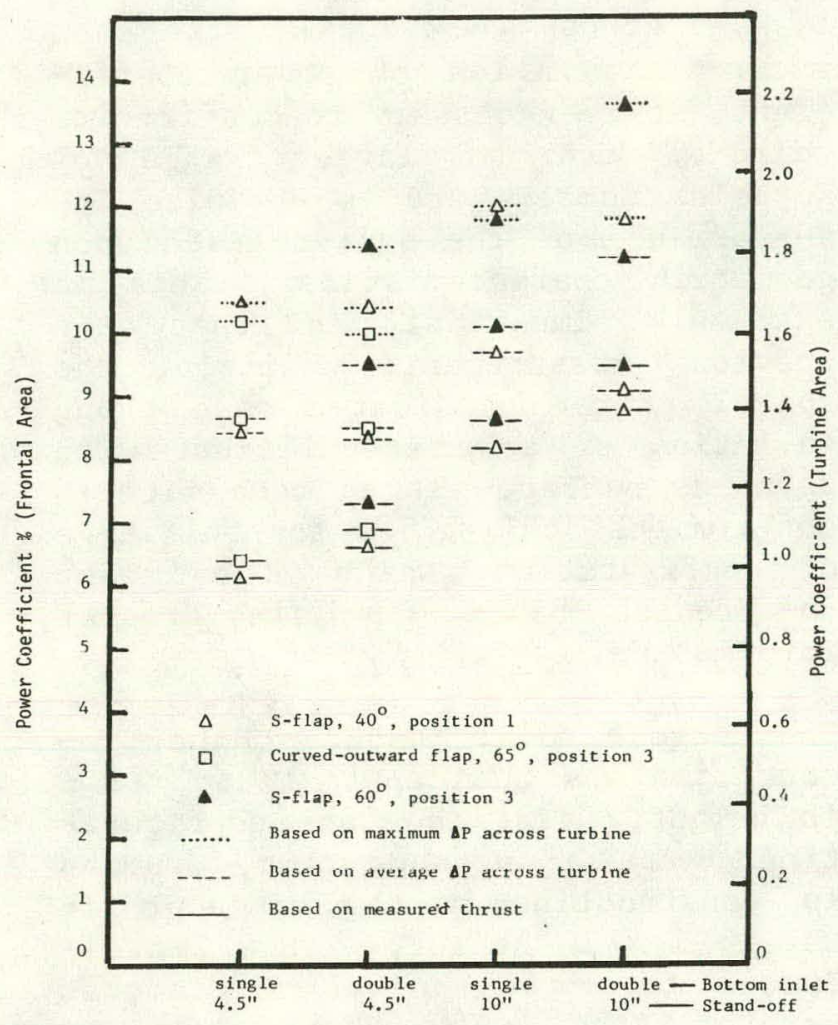

Figure 4-16. Power Coefficient for 25-cm Diameter Fixed-Vane Model

has a designed twist and adjustable pitch. The turbine has been tested at wind speeds up to $20 \mathrm{~m} / \mathrm{s}$, at rotating speeds up to $1500 \mathrm{rpm}$ delivering approximately $1 \mathrm{HP}$ based upon torque and rpm measurements. This turbine is to be installed in the tower that is currently being assembled.

A preliminary cost analysis has been carried out to determine an approximate value for the cost of energy utilizing the tornado system. Capital cost of the system was calculated for tower heights from $30 \mathrm{~m}$ to $300 \mathrm{~m}$ based upon a $90 \%$ learning curve. Other assumptions used in this analysis included $C_{P}$ values of 0.1 and 0.3 based on tower frontal area, power factor of 0.42 , rated wind speed of $11 \mathrm{~m} / \mathrm{s}$ and utilization of concrete for the tower.

The variation in the first unit cost depended strongly upon the size of the machine and $i$ ts assumed performance characteristics. It is essential to have a better understanding of the performance capabilities of the system in order to develop costs for the system. The study by Grumman anticipates that the mature system cost might pussibly meet the cost goals set by the Department of Energy•

\subsection{SUMMARY REMARKS}

The analytical studies carried out indicate the importance of the vis-

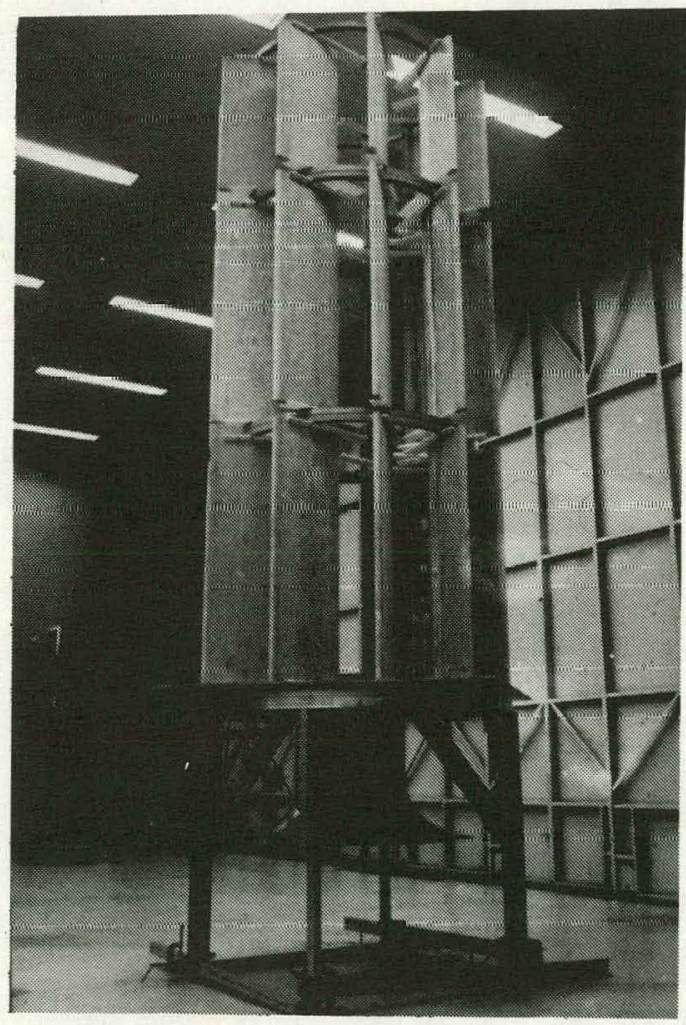

Figure 4-17. Photograph of the 5-m High Model under Construction 


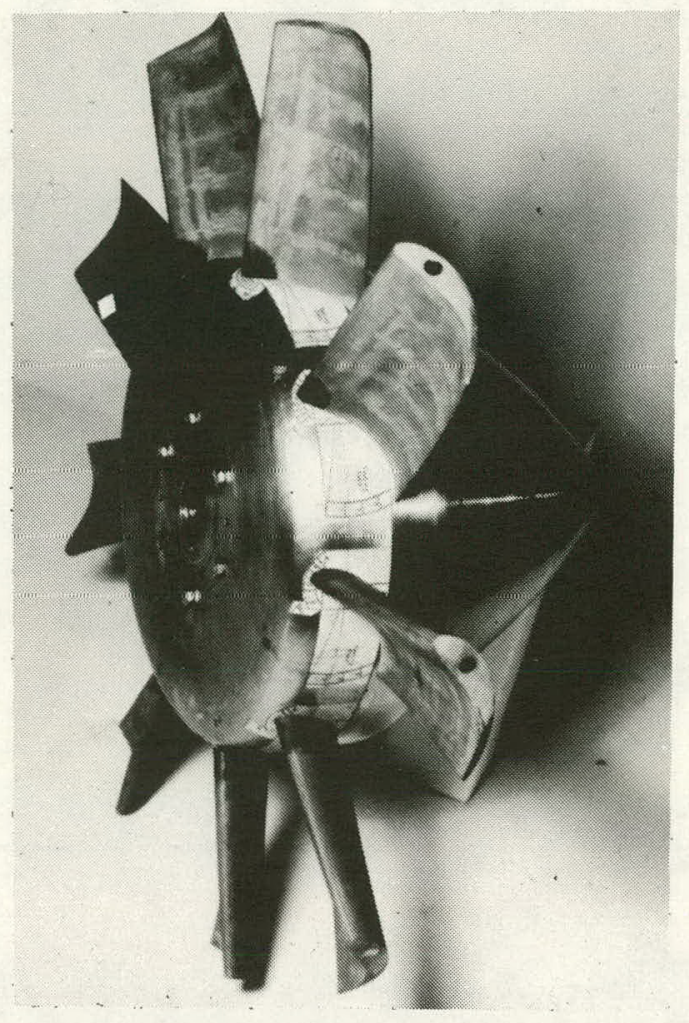

Figure 4-18. Photograph of the $0.75-\mathrm{m}$ Diameter Turbine cous core and level of the power coefficient that is attainable within the framework of the analysis. The experimental studies have shown that there is strong dependence on heightto-diameter ratio and Reynolds number.

The performance of the fixed-vane system is not as good as the spiral system.

The major emphasis of the current work is to provide some insight of the flow phenomena at higher Reynolds numbers in order to determine the scaling law for the system. In addition, it is important to determine the loads on the system due to wind forces so that a cost effective design can be carried out for the structure. The results of the current ongoing studies will provide us with some insight as to how the system scales in order to develop a realistic method of determining system cost. 
SEㄱㄴ 


\section{SECTION 5.0}

\section{WIND-POWERED CHARGED AEROSOL GENERATOR}

The wind power generator is a charged aerosol electrofluid dynamic (EFD) generator operating at atmospheric pressure powered directly by the wind. Work on the charging mechanism for this generator has been carried out by the Marks Polarized Corporation for the past four years under government sponsorship. The concept involved is to develop a system that provides charged particles utilizing minimum external energy and to have these particles driven by the wind. The unique characteristic of the generator is that it has no moving parts. Various methods of developing charged particles have been indicated in the past. There is no problem in developing charged particles; the major problem is to provide these charged particles with the correct size in sufficient quantity and with minimum expenditure of energy. The study undertaken by Marks Polarized Corporation has been to investigate various charging methods, provide some analytical background as to the effectiveness of these methods, and develop a method of providing charged particles of the correct size and mobility in an eçonomic manner.

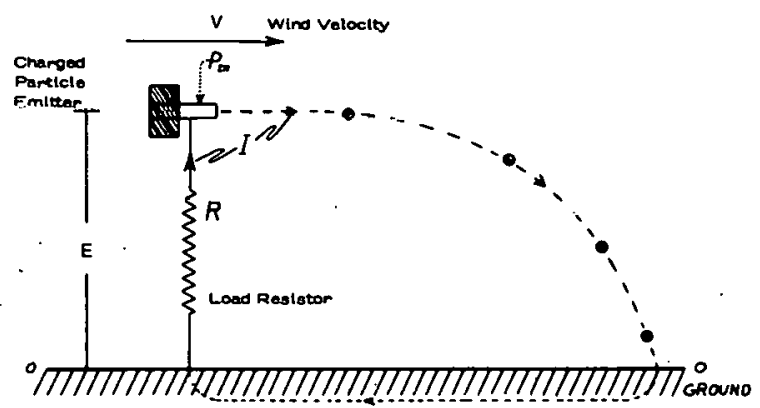

Figure 5-1. Schematic of the Single Electrode System
Eight methods of charging were initially identified, and four were investigated analytically and experimentally. At the present time, the method that shows the best potential is being further studied. Details of these studies may be found in Reference 4 .

\subsection{EXPERIMENTAL STUDIES}

\subsubsection{Single Electrode Generator Method}

A simple system for evaluating the EFD concept is the single electrode generator that is shown schematically in Fig. 5-1. The emitter is powered by a source of input power and lies within a potential well. Charged droplets are swept away by the wind doing work on the droplets. The droplets are eventually discharged to the ground. Emission of charged droplets from the emitter develops an electrical current, I, at potential difference, E, above ground with this current returning to the emitter via the load wlth a resistance, $R$.

The charged droplet emitter may utilize any suitable charging method. Some of the constraints utilized in the study have been brought about from practical considerations. It is necessary to keep the water flow as minimum as possible and a limit has been set at $10^{-4} \mathrm{~m} / \mathrm{sec}-\mathrm{m}^{2}$. To produce significant power generation, it is assumed that the voltage will be about $10^{5}$ volts. The power input to actuate the charged aerosol emitter must be a small fraction of the electrical power output from the generator. The single electrode generator, 


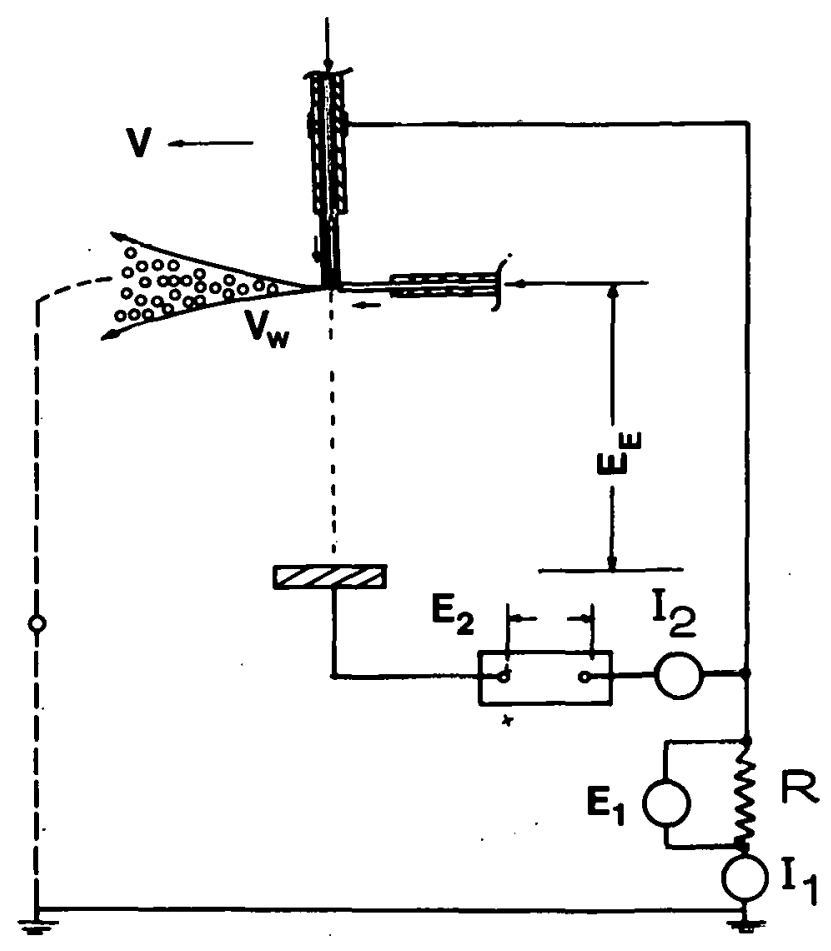

Figure 5-2. Schematic of the Electrojet Charging - Water/Air Method

as illustrated previously, is only one form of generator; multielectrode generators or slotted generators have also bęui considered.

Of the eight methods identified in producing charged aerosol, only three will be discussed at this time.

\subsubsection{Water Jet/Metal Contart Charging Method}

One of the early methods evaluated was the water jet/metal charging method. This method uses water that is forced under moderate pressure ( 50 psig) through a small orifice to produce a streaming electric current. Electric charging is brought about by an electrochemical effect. An electron is absorbed or donated by the metal and produces an excess of ions of one sign in the water, which is discharged from the orifice and breaks into charged droplets. No external source of air or electric power is required. A substantial amount of literature is available on streaming potentials and currents. However, most of the work relates to flow of liquids through capillaries between two continuous water reservoirs. No work is reported relating to capillaries having short lengths with low-pressure drops. The problems of this method relate to jet size, water issuing from the orifice, and formation of charged particles. Preliminary theoretical investigations indicated the validity of this method; however, due to the practical difficulties the method was not pursued.

\subsubsection{Electrojet Charging - Water/Air Method}

In this method, a water jet from a small orifice is directed towards the

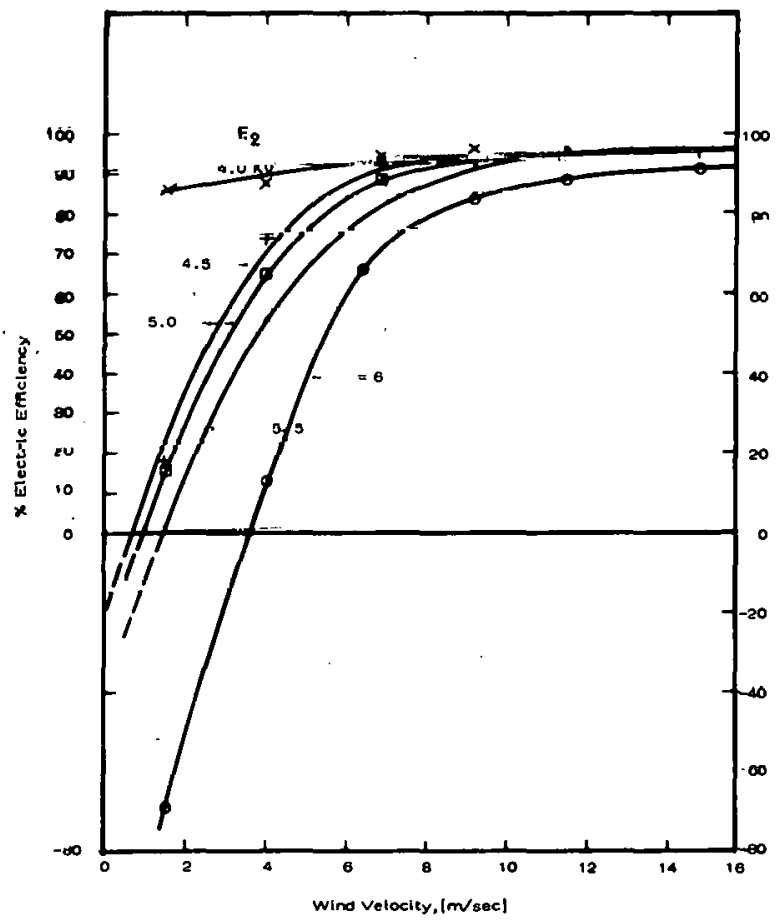

Figure 5-3. Wind Velocity Versus Electric Efficiency 


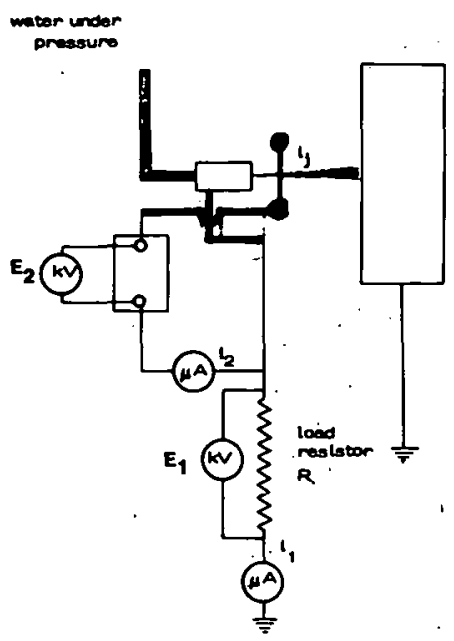

\section{Figure 5-4. Schematic of Water Microjet Charging Method Using Single Electrode}

exciter electrode, which is spaced some distance from a capillary tube (Fig. 5-2). For the particular experiment, the exciter electrode was spaced $10 \mathrm{~mm}$ from the capillary tube. An air jet exhausting from a small tube in the horizontal direction was spaced $2 \mathrm{~mm}$ from the water jet. A voltage, $E_{E}$, is applied between the air jet and the impact point of the water jet. A spray of electrically charged droplets was developed from the impact point. The charge on the droplets is a function. of the applied voltage $\mathrm{E}_{\mathrm{E}}$ and the water pressure. Values of $E_{E}$ of approximately $6 \mathrm{kV}$ were used. The charge per droplet was controlled by adjusting $E_{2}$. This produced a charged aerosol current of approximately $0.05 \mu \mathrm{A}$ using an orifice of $76 \mu$.

Wind tunnel tests were carried out using this method at velocities between 2.5 and $16 \mathrm{~m} / \mathrm{s}$ for a range of relative humidity and air temperature. The electric efficiency was strongly affected by wind velocities less than $8 \mathrm{~m} / \mathrm{s}$ and for exciter emitter voltages between 4 and $6 \mathrm{kV}$
(Fig. 5-3); at $4 \mathrm{kV}$ the electric efficlency was greater than $85 \%$ for velocities as low as $2 \mathrm{~m} / \mathrm{s}$. The electric efficiency in this case is determined only by the electric power out compared to the electrical power in. Measurements were made of the electrical efficlency for $E_{2}=4 \mathrm{kV}$ over a range of temperatures $\left(20^{\circ} \mathrm{C}\right.$ to $40^{\circ} \mathrm{C}$ ) and relative humidities ( $30 \%$ to $80 \%)$.. It was found that at constant temperature an increase in the humidity increased the efficiency, and at constant humidity an increase in the temperature resulted in a slight improvement in the efficiency. The measurements carried out over a range of velocity indicated that the power required for the airjet greatly exceeded the output electrical power. This method in its present form, therefore, is not suitable for production of charged aerosol particles.

\subsubsection{Induction Charging/Water Jet Method}

A charging method was developed utilizing water pressure and electric induction charging only. Water issues from a microjet and is charged by an external electrode. The charged droplets are produced by the instability of the water jet issuing from the orifice. $\Lambda$ schematic of this method is shown in Fig. 5-4. The test system in this case consisted of a 2-mm long stainless steel capillary tube with an I.D. of $7.6 \mu$. Measurements were nade at an air speed of $9.1 \mathrm{~m} / \mathrm{s}$ and the voltage, $E_{2}$, between the exciter electrode and water jet was held constant at $3.1 \mathrm{kV}$. The exciter ring was $1 \mathrm{~cm}$ in I.D. spaced $0.1 \mathrm{~cm}$ from the orifice. Some typical results using this test apparatus are presented.

The electrical input and output powers and hydraulic and water jet powers have been measured as functions 


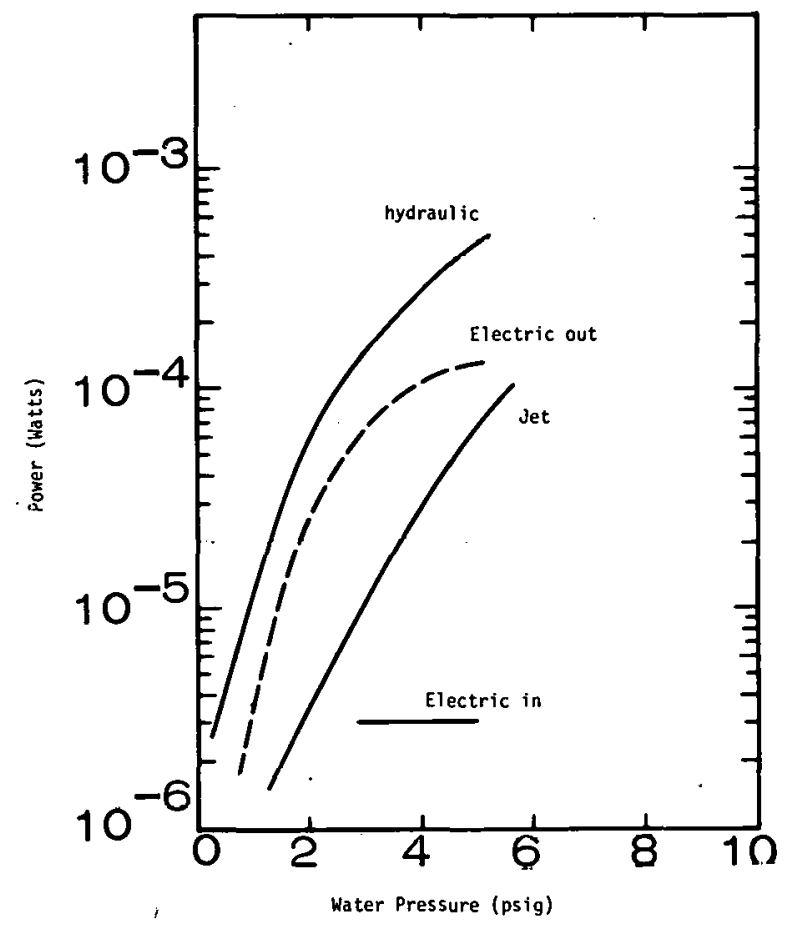

Figure 5-5. Water Pressure Versus Power

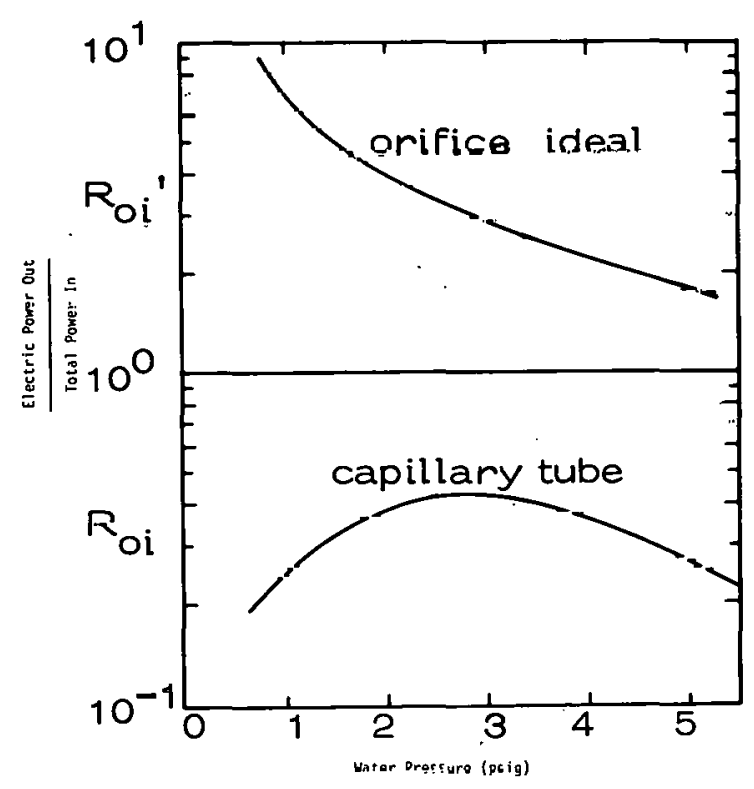

Figure 5-6. Water Pressure Versus Electric Power Out Over Total Power In of the water pressure (Fig. 5-5). The output power is less than the hydraulic power but greater than the input electric power. It is clear from the measurements that the hydraulic power input, has to be decreased, which may be accomplished by reducing the pressure drop in the capillary. Recommendations to reduce the water power loss and to produce smaller charged droplets would be to use a smaller diameter orifice with a shurter length, or a slit orifice in a thin sheet. A configuration of this type is currently being designed.

The ratio of the electrical power out to the total power input as a function of water pressure is shown in Fly. 5-6. As one observes, the electrical efficiency of the system is beluw unlty for a capillary tube. If one assumes an ideal orifice, the electrical efficiency improves considerably. The major difference is caused by the difference in the pressure drops between the two methods. It is observed that for low values of pressure the electriçal power nit.put may be greater than flve times the input lotal power utilized in the system. It should be emphasized that this is a theoretical calculation us ing an ideal orifice.

\subsection{SUMMARY REMARKS}

Preliminary etudico have iudlcaled that the induction charging/water jet method is the best candidate to meet the goals of the projert. current studies are further evaluating - the potential of this method. Tests are to be carried nut using a series of orifices with varying diameter and length for a range of velocitico, temperatures, and humidities to deterinine an optimum configuration for producing charged particles. It is anticipated that the results of the study will be available within the next year. 


\section{SECTION 6.0}

\section{ELECTROFLUID DYNAMIC WIND-DRIVEN GENERATOR}

A project has been conducted for the past four years at the University of Dayton Research Institute on the electrofluid dynamic wind-driven generator concept. Typically, the generator uses high voltages and low currents and consists of the following components (Fig. 6-1): (1) a nechanism for producing charged particles; (2) an inlet or attractor electrode; (3) a collector electrode; (4) a high-voltage power supply; and (5) a control system. The high voltage power supply places the attractor electrode at a high voltage relative to the colloid producing mechanism. Charged particles of one sign produced by the charging. system are swept past the attractor electrode by the moving air towards the collector electrode. The collector voltage depends upon the load and the current. The feedback control system senses the voltage on the collector and adjusts the attractor voltage, thereby controlling the output current in order to hold the output voltage constant. A significant theoretical and experimental effort has been spent in predicting the performance of the EFD generator. The results of those studies are given in Reference 5. A brief review of some of these studies is presented in the text.

\subsection{THEORETICAL STUDIES}

Most of the experimental investigations of charged droplet production methods have been conducted with the generator collector at ground potential. To obtain optimum information from such tests it is desirable to establish theoretical relationships for maximum current as a function of the mobility of the charged droplets for similar conditions. The mobility, $k$, is defined as the average drift velocity of a charged droplet for unit electric field, E. To determine what current level may exist as a function of mobility, a maximum current (zero load) analysis was made for the one-dimensional EFD geometry. It was assumed that an infinite supply of charged particles of uniform mobility was available at the conversion section entrance. For charged droplets of high mobility, the entrance. field strength is less than or equal to the electrical breakdown field strength and the field is limited only by the wind velocity through the conversion section. For one-dimensional flow, equations can be developed for the current density and electric field over the complete range of charged droplet mobility. In practice, the one-dimensional- flow condition does not really hold; however, it does

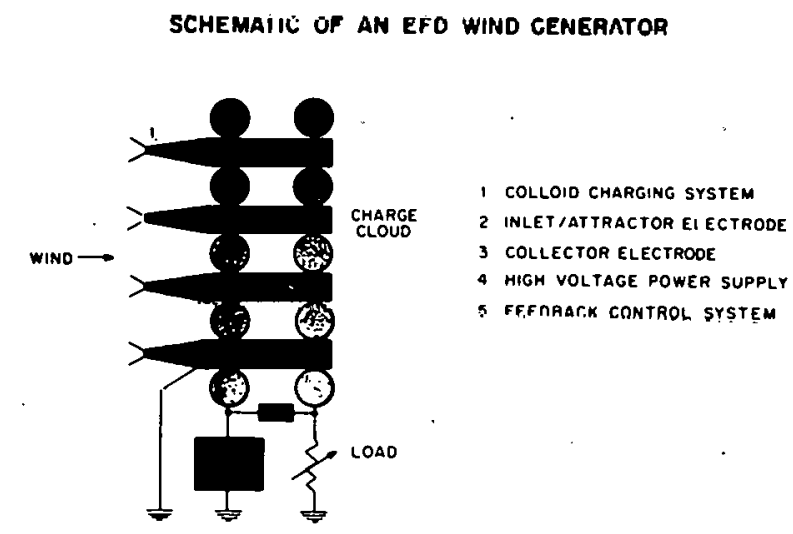

Figure 6-1. Schematic of an EFD WindDriven Generator 


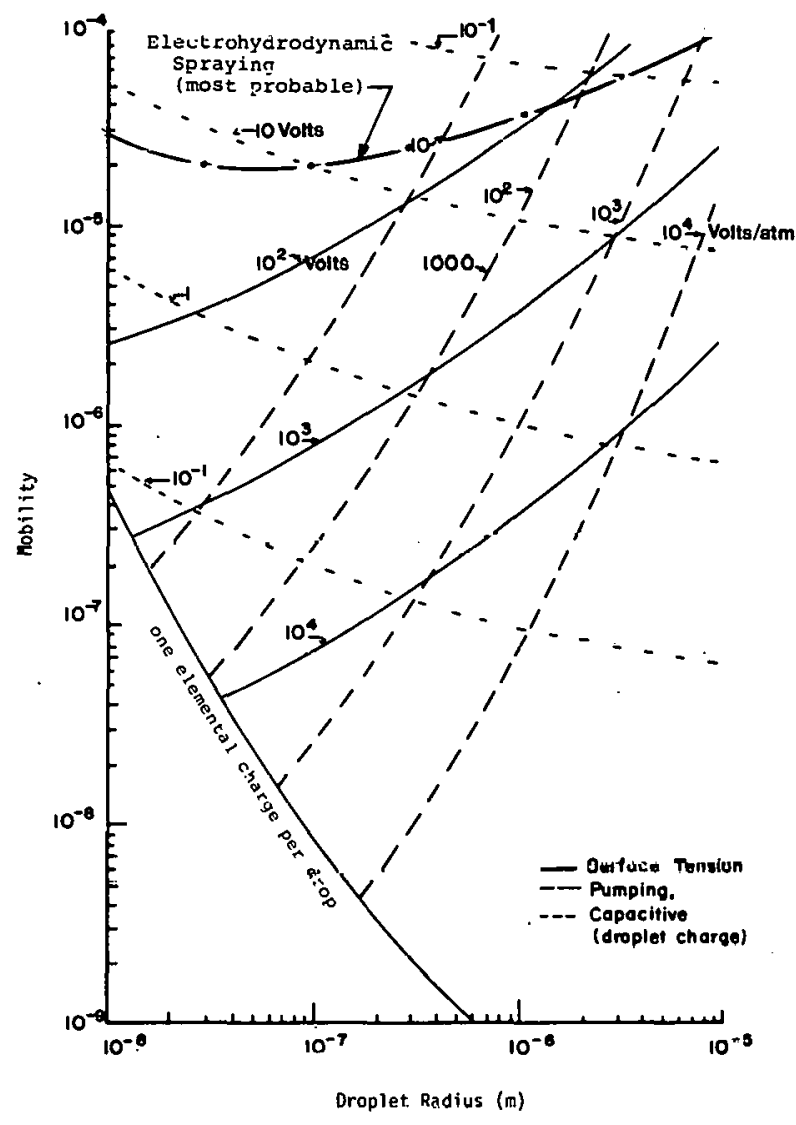

Figure 6-2. Specific Charged Droplet Energy Cost Plotted in the Mobility-Droplet Radius Plane

give a starting point for the evaluation of the system.

From the practical point of view, it is essuntial that the power output from the EFD generator greatly excepd that necessary to generate the particles. Not only must the particles be produced in sufficient quantily, but they urust also have the appropriate diameter and mobility for satisfactory operation of the generator. The mobility of a particle is a neasure of its responsiveness to an electric field. A droplet of high mobility will tend to move along field lines: A droplet of low mobility will tend to move with the vis-. cous flow. The power input to generate charged droplets can be divided into three categories: (1) power to form the droplets, (2) power to charge the particle, and (3) power to pump water, if required.

The energy required to form each droplet depends upon the surface tension, anount of droplet charge, pumping pressure of the water, and droplet radius. A relationship can be derived between the mobility and the droplet size (as related to surface rension) for a range of energy costs per unit droplet charge (coulomb $x$ volts per coulomb). The energy required to pump water from its source to the generator can be calculated and can also be related to the mobility. The results of these calculations over the range of conditions is shown in Fig. 6-2. Energy costs of humidifying the air to saturation conditions were also analyzed. The main results of this portion of the study are to point out that sufficient energy is available to produce charged droplets so that droplets do nut evaporate in the conversion sec-

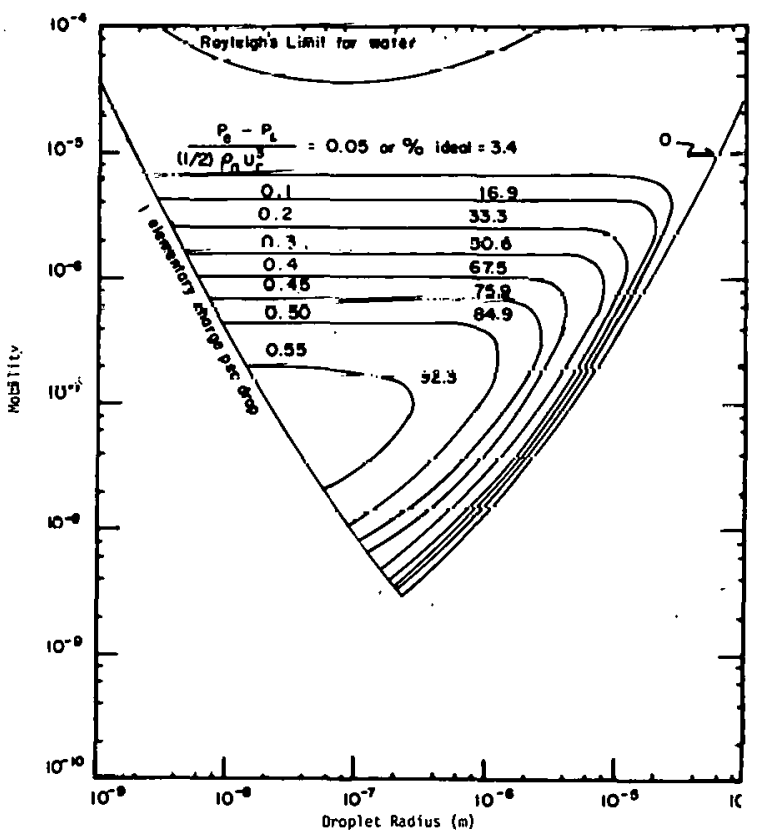

Figure 6-3. Performance Map of an EFD Wind-Driven Generator 


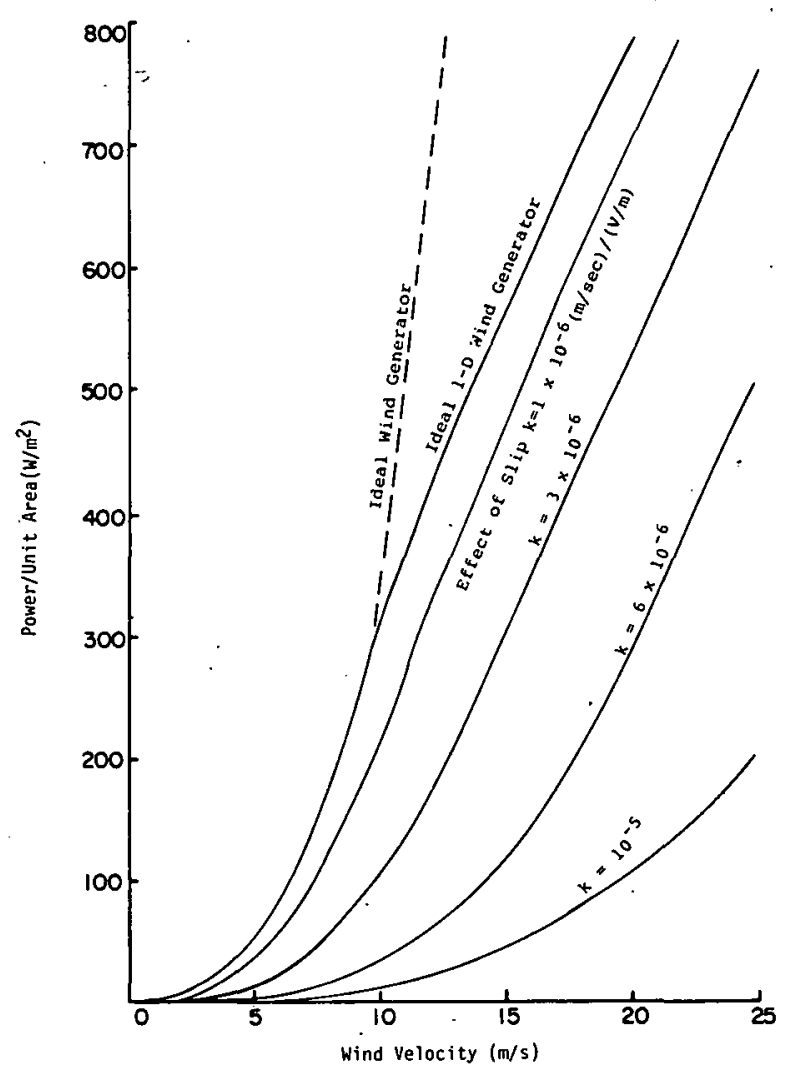

Figure 6-4. Power Versus Wind Velocity for the EFD Wind-Driven Generator

tion and, therefore, produce useful power at reasonably high values of power coefficient for the generator.

A generator performance map was developed that included the effect of surface tension and water punping energy costs for a fixed value of capacity energy cost. The conditions used in developing this map were collection voltage, $300 \mathrm{kV}$; charging work, 100 electron volts per electron; gauge pressure, $68,900 \mathrm{~N} / \mathrm{m}^{2}$ ( $10 \mathrm{psi}$ ); and surface tension of $0.735 \mathrm{~N} / \mathrm{m}$. The plot in the mobility/droplet radius plane provides an identification of the range of interest of the droplet radius for a high performance generatur. To obtain an output power greater than $85 \%$ it is necessary to utilize a parcicle less than $1 \mu$ in radius (Fig. 6-3).
Several methods to produce small particles in sufficient quantity were studied. It does not appear that droplets formed by condensing steam can be used, as the energy required to vaporize water was very great. An additional well-known method, straight hydrodynamic spraying, always produces charged droplets with mobility higher than required.

It is possible to evaluate the ideal performance of a one-dimensional EFD generator. This can be carried out and is shown in Fig. 6-4. The ideal wind generator is shown as well as the power outputs depending upon the nobility. The break in the ideal wind generator and ideal onedinensional EFD/generator occurs at $8.57 \mathrm{~m} / \mathrm{s}$.

The yearly energy production of a generator in a wind regime with an average speed of $10 \mathrm{~m} / \mathrm{s}$ has been calculated (Fig. 6-5). Various values of the rated velocity were used versus the cut-out velocity at which the generator will shut down. In the

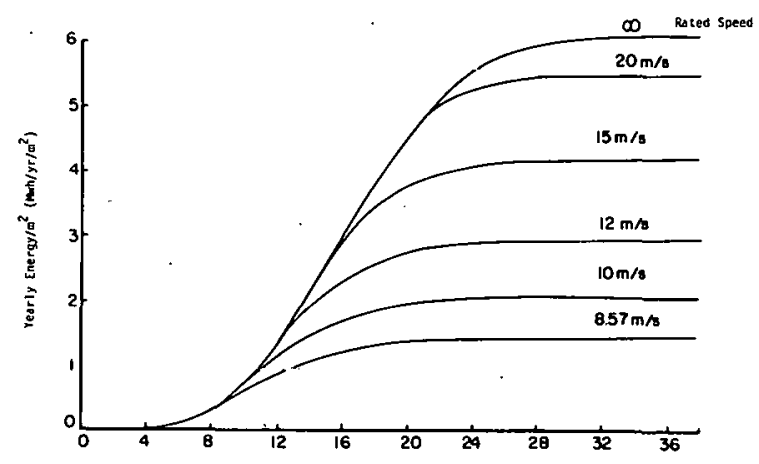

Figure 6-5. Annual Energy Production at an Average Wind Velocity of $10 \mathrm{~m} / \mathrm{s}$. 
case of the EFD wind turbine generator, this cut-out velocity is essentially unlimited. However, as seen in the figure, little is gained after about $25 \mathrm{~m} / \mathrm{s}$ corresponding to about 2.5 times the average velocity. An additional advantage of the EFD generator is that it may be used quite effectively at lower wind speeds to extract the energy from the air.

\subsection{EXPERIMENTAL INVESTIGATIONS}

The performance of the EFD power generation experiments require lowmobility charged droplets at designed charged densities. The initial electrode assemblies were designed so that their electrical and fluid dynanic perfornance could be predicted by a suitable theory. The major efforts in the study were directed at obtaining low-mobility charged droplets in order to perform power generation investigations. Methods of obtaining these particles were certainly not efficient; however, ongoing investigations are being conducted to develop efficient methods of producing the particles.

Analytical studies of energy costs have provided guidance and indicated new cost effective methods of producing charged particles. The experimental investigations have been ronducted to determine improvements in the components in the test facility and to develop performance characteristics for the system. Four different charged-droplet investigations were carried out utilizing a sinall. wind tunnel with a test section of 0.25 by $0.51 \mathrm{~m}$ at $10 \mathrm{~m} / \mathrm{s}$.

\subsubsection{Direct Current Electrohydrodynamic Spray}

The first method evaluated was the direct current electrohydrodynamic spray that utilized an emitter electrode with a hollow, water-tight, sharp, trailing edge airfoil 0.41-m long. Along the trailing edge of the airfoil, seven hypodermic needles (0.71-mm I.D.) are spaced $5.1 \mathrm{~cm}$ apart. Water fed to the airfoil issues from the needles. The attractor and collector electrodes are longer than the emitter airfoil and are supported in slots on the ends of the walls, which are made of plexiglass. Both the attractor and collector have rounded electrodes to reduce field concentration. The collectur utilizes the Faraday cage concept, which is also applied in the generator rig. The experiment was not designed as a new concept, but rather to provide base current values with the operation of the facility. A maximum collector current of $3 \mu \mathrm{A}$ was measured indicating that highmobility charged droplets were being produced. Five water flow rates and three relative positions of the attractor and collector electrodes were studied.

\subsubsection{Direct Current Electrohydrodynamic Spray with Cross Field}

In this experiment two power supplies were used . with different polarity voltages applied to each of the attractor plates. This arrangement provides a large cross-field between the attractor plates that could disrupt positive ions from heavily positively charged droplets while allowing a variable axial field at the emitter: No current was observed below $4 \mathrm{kV}$ or when the two voltages were equal. In this experiment the peak current obtained was $1.2 \mu \mathrm{A}$ for a positive voltage of $4 \mathrm{kV}$ and $a$ negative voltage of $9 \mathrm{kV}$. This low current level indicates that there is no significant change in the chargeto-mass ratio of the highly positive charged droplets while passing through the high cross-field of the attractor. 


\subsubsection{Bipolar Direct Current Electrohydrodynamic Spray}

The purpose of this investigation was to demonstrate the principal of bipolar charging. Two emitter airfoils were used and water was supplied to the trailing edge of the emitter by surface condensaliun. Cooled Frenn was circulated inside the emitter airfoils to provide surface temperatures below the dewpoint of the air. Steam was sprayed into the inlet section of the wind tunnel to humidify the air. Freun was used because of its low conductivity, low viscosity, and high boiling temperature. The two main alrfuils were positioned such that their trailing edges were closest. Two DC power supplies used in the experiment provided positive polaricy Lu one emitter and negative polarity lu the other. In this method, the principle is to produce nearly equal but relatively high currents of positive and negative charged droplets in a field structure that results in the combining of the opposite polarity droplets. The attractor was placed at ground potential and was used as a biasing electrode. In these tests, the positive emitter voltage was fixed and the negative voltage was increased incrementally until sparkover occurred. 'The validity of the concept was demonstrated; however, the collector current levels were very low. Improvements of this method are being considered and plans are being made for further experiments.

\subsubsection{Bipolar Alternating Current Electrohydrodynamic Spray}

Preliminary studies have been carried out on the AC bipolar charging investigation. Only one emitter is used, which is centered ahead and along the flow axis of the pair of attractor electrodes. Variable AC

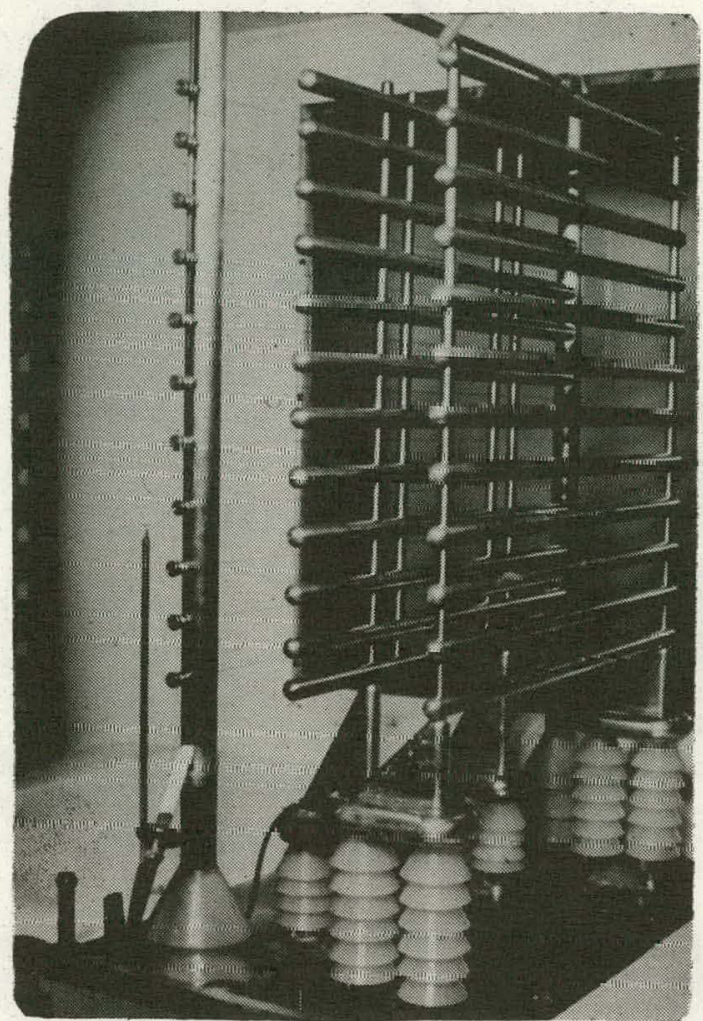

\section{Figure 6-6. Test Rig With Original Cylindrical Collector Electrodes}

voltage is applied to the attractor by $5 \mathrm{kV}$ to $20 \mathrm{kV}$ power supply. Charged droplets of alternate sign are produced that overrun one another in the reversing field such that unipolar charged droplets with low mobility should result. No conclusive results have been obtained by this technique at the present time. The study is still underway.

\subsubsection{Generator Performance}

Generator performance investigations have been conducted in a low-speed closed circuit wind tunnel with a square cross section of $0.91 \mathrm{~m}$, which is approximately four times larger than the generator test array. The original generator geometry utilized cylinders (Fig. 6-6). Ions, normally of negative polarity, were seeded in the flow by corona occurring on wires located about $2.54 \mathrm{~cm}$ ahead of the 


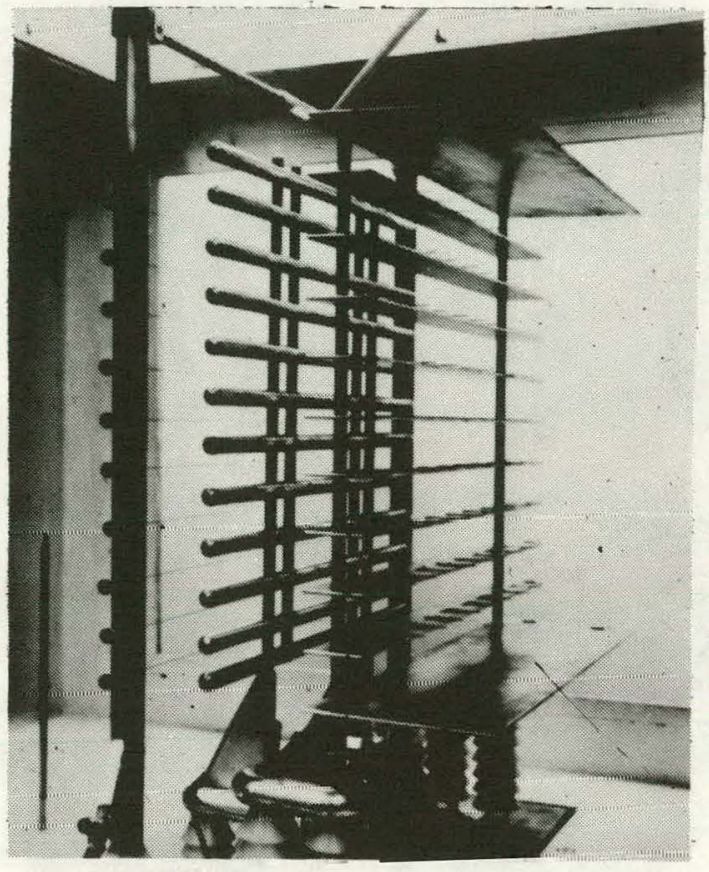

Figure 6-7. Revised Test Rig with Side Walls Removed

attractor. The attractor in this configuration is made up of 12 rods $1.6 \mathrm{~cm}$ in diameter. The spacing between the two arrays of the rods is the conversion region where work is done by the flow in transporting unipuldi-charged droplets from near ground potential to a vcry lifgh potential of the same sign as that of the charge on the droplets.

The downstream array of electrodes is the electric current collector. The electrode arrays operate at high potential and are we11-insulated frum ground by plexiglass supports. Cylindrically shaped electrodes were selected for the first geometry as they provide a uniform curvature surface which is favorable for the electrical field and berause a large body of experimental data is avai1able to determine their drag loss. This design was followed by a revised generator design shown in Fig. 6-7. The corona wire and attractor assembly are unchanged but the col- lector has been changed to a shielded needle configuration utilizing the Faraday cage concept.

In the generator performance tests, maximum current tests were performed initially. Such tests entail high voltage on the corona wire array, with the attractor and collector at ground potential. These tests, conducted at no load, provide a great deal of information. Predictions made for these conditions at a velocity of $11 \mathrm{~m} / \mathrm{s}$ gave values of collector current of $500 \mu \mathrm{A}$ which was achieved indicating a satisfactory condition for droplet mobility and density. Also achieved from these tests was a near optimal operating condition of $68 \mathrm{kV}$ at $24 \Omega \mu \mathrm{A}$, corresponding to a power density of $78 \mathrm{~W} / \mathrm{m}^{2}$ (Fig. 6-8). The agreement between the theory and experimental data is quite good.

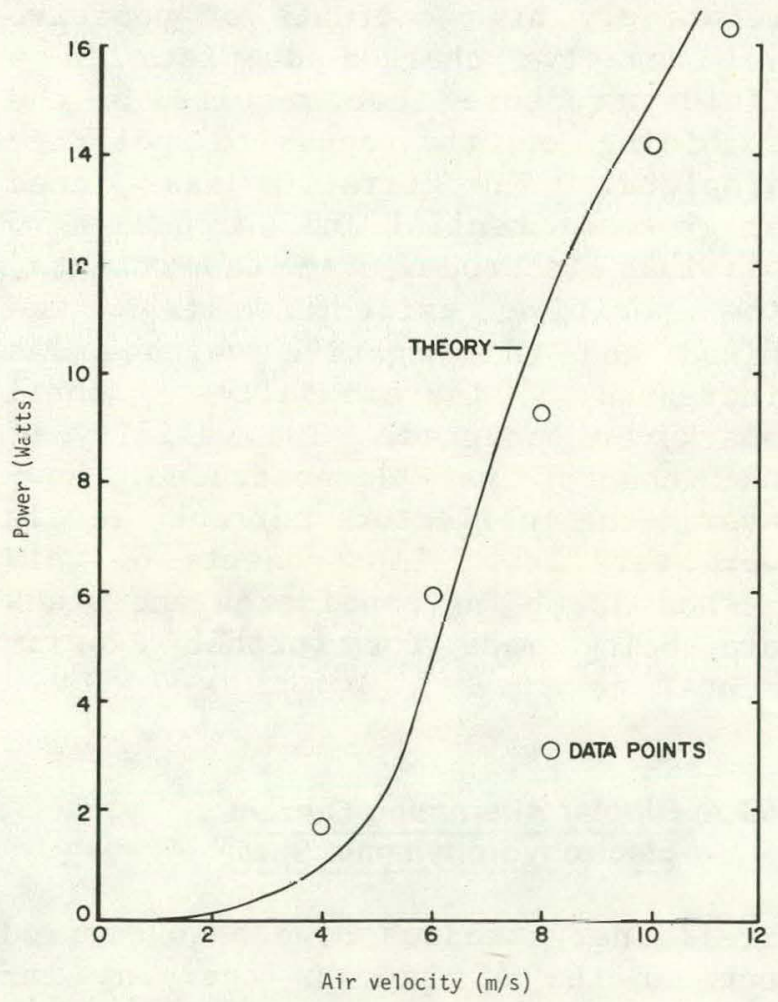

Figure 6-8. Test Generator Data Compared to Theory 
For an attractor made up of twelve $1.6-\mathrm{cm}$ rods with a $10-\mathrm{cm}$ spacing and a velocity of $8.9 \mathrm{~m} / \mathrm{s}$, a power of $14 \mathrm{~W}$ was predicted. The effect of spacing is shown in Fig. 6-9. Mucil higher levels of power are predicted for swaller spacing with significantly reduced electrode drag losses for cylindrical rod arrays. The significant parameters that impact drag loss are longitude spacing to cylinder diameter and Reynolds number based on the electrode diameter. For the same number of attractor rods as in the present geonetry, about $29 \mathrm{~W}$ of power would be predicted for a 2.5-cin longitudinal spacing. The power density level corresponding to the predicted $29 \mathrm{~W}$ would be about $140 \mathrm{~W} / \mathrm{n}^{2}$.

It should be noted that the application of large diameter electrodes can provide further lowering of the drag losses without the necessity of such close spacing. This is shown in Fig. 6-10 where the conversion length is $15 \mathrm{~cm}$, the electrode diameter is $30.4 \mathrm{~cm}$, lateral spacing $40.8 \mathrm{~cm}$, and air velocity $10 \mathrm{~m} / \mathrm{s}$. For $a=2.34$, where $a$ is the ratio of the distance between the centerlines of the tubes and the tube diameter, the theory predicts about $220 \mathrm{~W} / \mathrm{m}^{2}$ whereas an ideal conventional system can produce about $360 \mathrm{~W} / \mathrm{m}^{2}$ (Betz value). Thus the EFU wind-driven generator in a full-size version could produce approximately $62 \%$ of the ideal wind turbine energy, or approxinately $37 \%$ of the total available kinetic energy.

\subsection{SUMMARY REMARKS}

Recent studies carried out at the University of Dayton have indicated methods of obtaining energy utilizing the EFD concept confirming the theory with measurements. Energy levels as high as $78 \mathrm{~W} / \mathrm{m}^{2}$ have been measured at $10 \mathrm{~m} / \mathrm{s}$. The theoretical potential is considerably ligher than this value. Current studies are directed

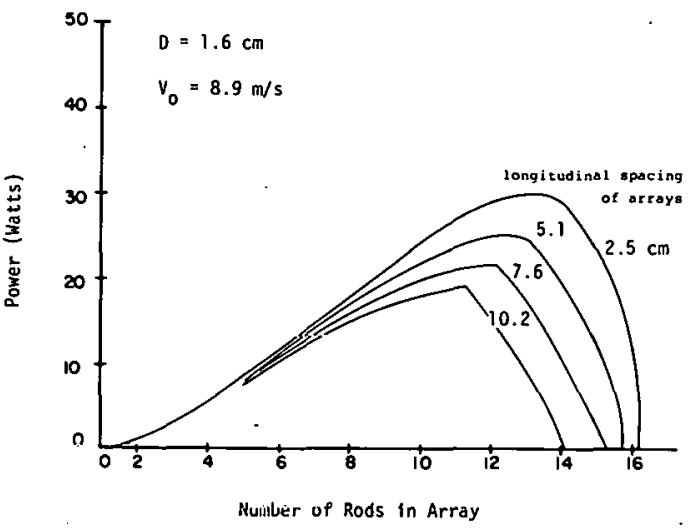

Figure 6-9. Theoretical Power Versus Number of Rods

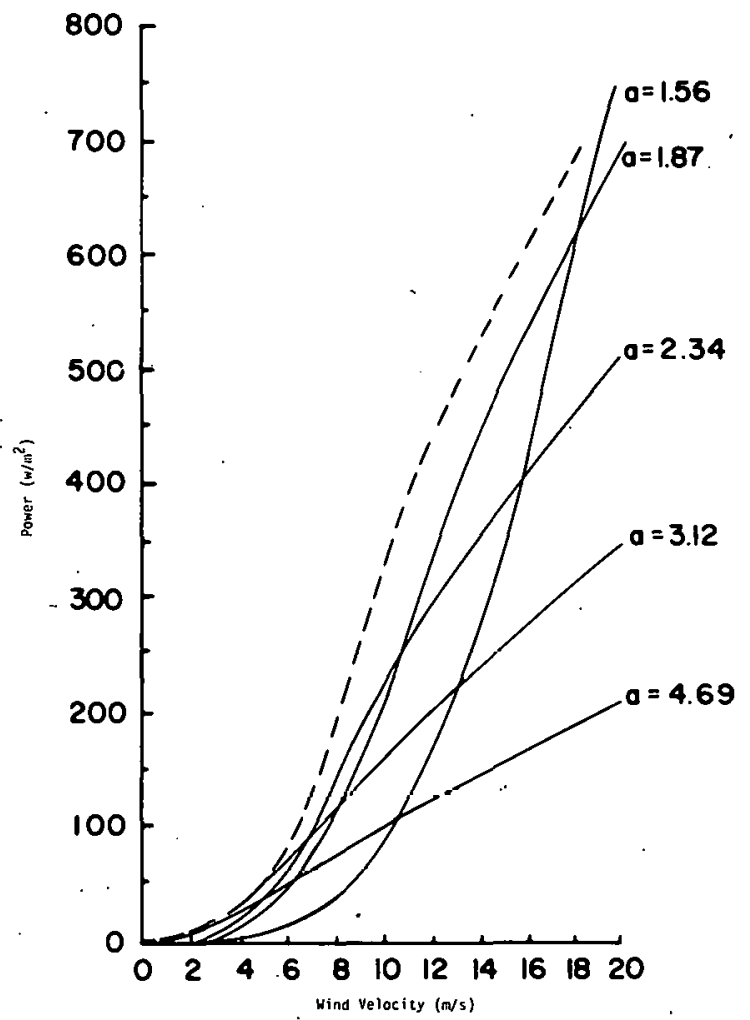

Figure 6-10. Theoretical Power for a Full-Sized Generator Using 30.4-cm Diameter Rods

towards finding an energy effective method of producing the particles. The development of such a method is one of the goals of the current study in order to realize a cost effective system. 


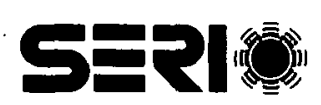




\section{SECTION 7.0}

\section{ENERGY FROM HUMID AIR}

During the past three years, a numerical study has been carried out at the South Dakota School of Mines and Technology to determine whether a cost effective process exists to convert the energy in humid air into mechanical work. The principle considered utilizes the concept of condensing the water vapor in tile air thereby releasing latent heat. Details of some of the preliminary work have been published in reports cited in Reference 6 . Methods that have been utilized in this study are presented below.

\subsection{NATURAL DRAFT TOWER}

The simplest method of extracting energy from humid air is by a vertical natural draft condensation tower (Fig. 7-1). The efficiency of such a tower depends upon the degree of saturation, the tower height, and the prevailing atmospheric conditions. As the air rises in the tower, its temperature and pressure follow the inoist adiabat. The air inside the towar is warmer than the ambient air and rises due to buoyancy. Computer uodels have been developed for this system assuming saturated air and it has been found that the power output varies with the tower height to the 1.4 power.

Calculations were made for a natural draft tower at flve optimally chosen locations, and even at the most favorable location in Hawaii it was determined that the output energy from the system was not cost effective. This method was analyzed as a first step because it was a convenicnt way of looking at the overall concept.

\subsection{EXPANSION-COMPRESSION CYCLE ANALYSES}

To develop a system that might possibly be cost effective it is necessary to lower the operating temperature in order to obtain more condensation than is obtained from the natural draft tower. Such a mechanical process may be developed by an expansion-compression cycle. In this cycle, moist ambient air is expanded adiabatically to a low pressure and work is extracted from this process.

During the expansion process, moisture condenses and falls out at its dewpoint and is removed from the system. The remaining air and water vapor is compressed adiabatically back to atmospheric pressure for which work must be supplied. If this compression work is accomplished with cooling through a polytropic process, the work done in this cycle will be less than in the expansion cycle. With sufficient cooling, positive work output is possible from the expansion-compression cycle. The performance of the cycle, therefore, depends upon the degree of expansion, the amount of cooling, the degree of

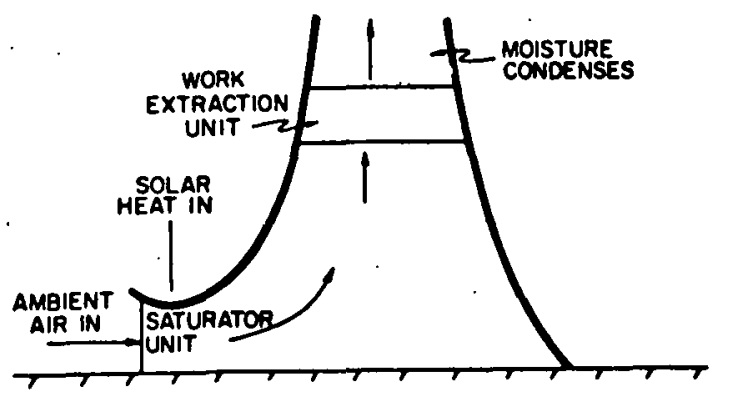

Figure 7-1, Schematic of a Natural Draft Tower 
$\int^{\prime}=$

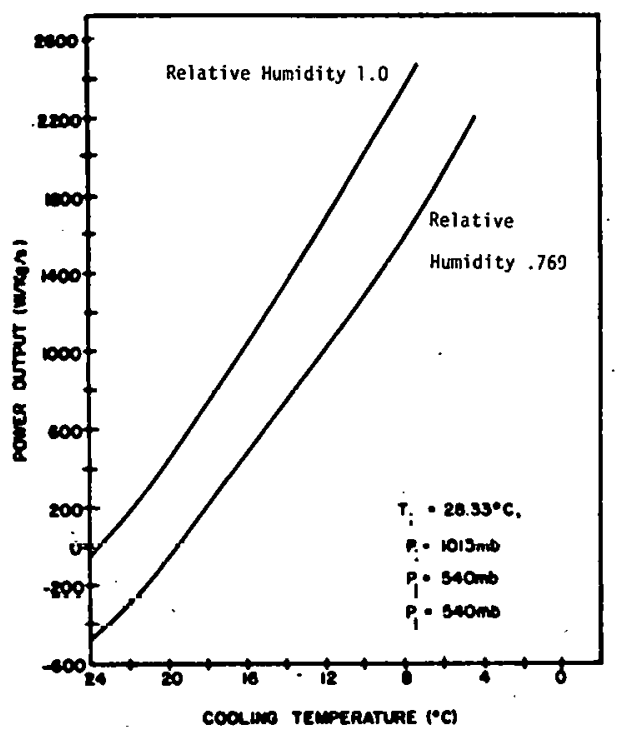

Figure 7-2. Power Output Versus Cooling Temperalure

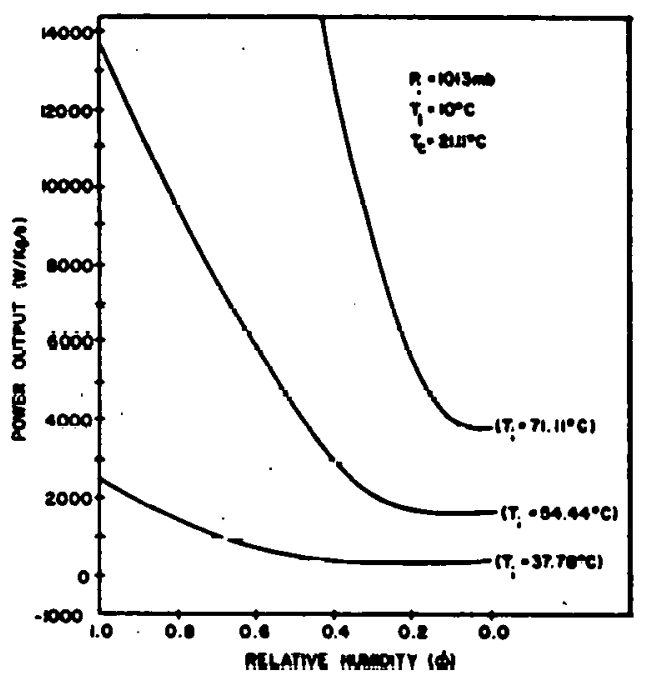

\section{Figure 7-3. Power Output Versus Degree of Saturation}

saturation, the height of the tower, and the efficiency of each of the subsystems.

An analysis was carried out for this system with the following assumptions: (1) expansion process is isentropic; (2) compression process is raade up of isentropic compression from the low pressure back to a fixed temperature and an isothermal process at the water temperature; (3) the isothermal work expended is obtained by assuming the air mixture is ideal and follows a polytropic process curve; (4) a constant velocity tower is used in the study of tower height effects; and (5) machine losses are ignored in the calculations.

Parametric studies have been made of the cycle where the power output has been obtained as a function of cooling temperature, degree of expansion, degree of saturation, and tower height. Results of these calculations for power output as a function of temperature and degree of saturation are shown in Figs. 7-2 and 7-3. As is obvinus, power output increases as cooling temperature decreases and is strongly dependent upon the relative humidity. The power output also increases as the expansion pressure decreases and decreases as tower height increases.

One of the most significant assumptions made in the systen study conceris machitie efficiency. Large amounts of energy are extracted durling the cxpundion procese and a large but slightly less amount of energy is put back into the system during compression. The difference between these two large amounts of energy is the available energy. Unless this is greater than the machine's losses, no useful energy can be extracted from the entire system. Utilization of a single machine In the expantion=cunpressiun cyclu would tend to reduce the losses in the entire system. An illustration of this system with a single machine utilizing vortex-type flows in both the expansion and the compression cycles is shown in Fig. 7-4. Humid air enters through vanes on the upwind side of the expansion chamber spirals towards the center (with constant vorticity) passing through the 
minimum, low-pressure section into the diverging section where it is compressed. Cooling is introduced in the compression cycle. One of the major assumptions is that the vortex will sustain itself, an assumption that must be verified.

A preliminary andysis was carried out to predict the hourly-monthly power generation for 1975 on the island of Puerto Rico near Punta Tuna. The plant was located on land with the capacity to process $10,000 \mathrm{~kg} / \mathrm{s}$ of air. Cooling water at $6^{\circ} \mathrm{C}$ was obtained via a concrele pipe $2.9 \mathrm{~m}$ in diameter placed on the ocean bottom $2.77 \mathrm{~km}$ from the plant and 2.3 km offshorc. An analysis was carried out under the following assumptions: a turhine was used to extract net output power with an efficiency of $90 \%$; flow losses in the vortex were neglected; friction losses in the pipe were calculated using a sinooth insulated pipe, with a water velocity of $1.5 \mathrm{~m} / \mathrm{s}$. For these conditions, the net output power for an average day in January and August were calculated (Fig. 7-5). It was observed that the output power could vary between approximately 4 and 10 MW depending upon the month but was fairly uniform during the day. The variation in power for each 12 months of the year was also calculated and is shown to vary from a maximum of about 10 MW to a low of 1 MW in January (Fig. 7-6).

Cost estimates were made for this plant based on the assumptions that the plant would process $10,000 \mathrm{~kg} / \mathrm{s}$ of air with a rating of $10.5 \mathrm{MW}$. The site and electric power transmission lines were not included in the cost.

Expansion and compression processes were considered frictionless, and cooling was conducted by a direct contact heat exchanger with an efficiency of $90 \%$. The entering air is accelerated from $5 \mathrm{~m} / \mathrm{s}$ to $105 \mathrm{~m} / \mathrm{s}$ in the vortex chamber. The construction of the unit is similar to airplane hangar construction. With these assumptions the capital cost was found to be approximately $\$ 16$ million or about $\$ 1,500$ per rated $\mathrm{kW}$. The two

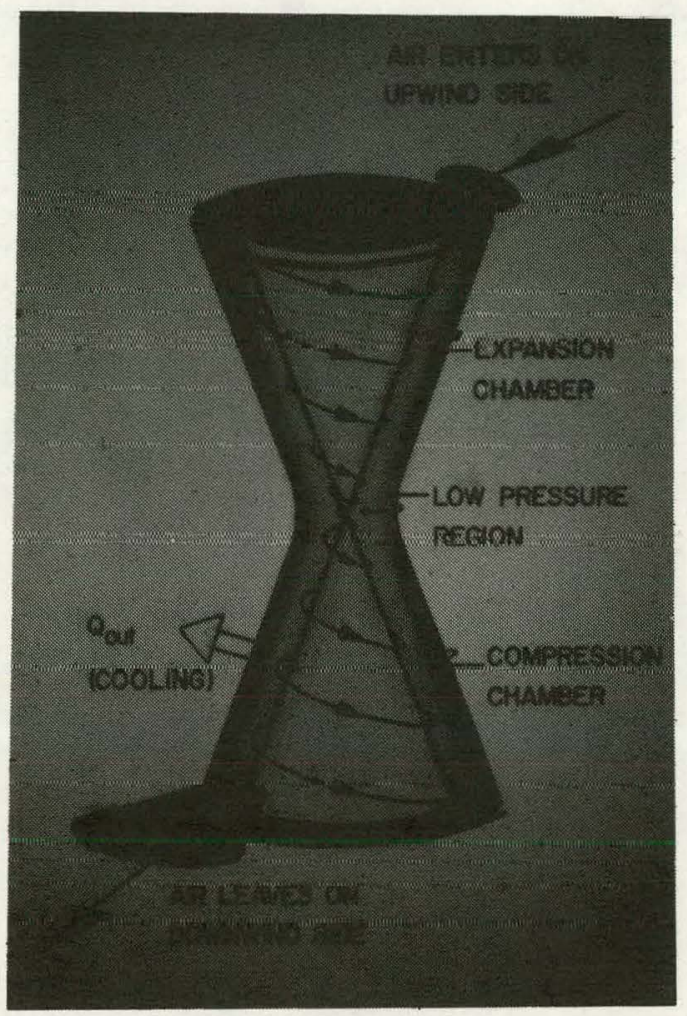

Figure 7-4. Vortex Mechanization of an Expansion-Compression Cycle

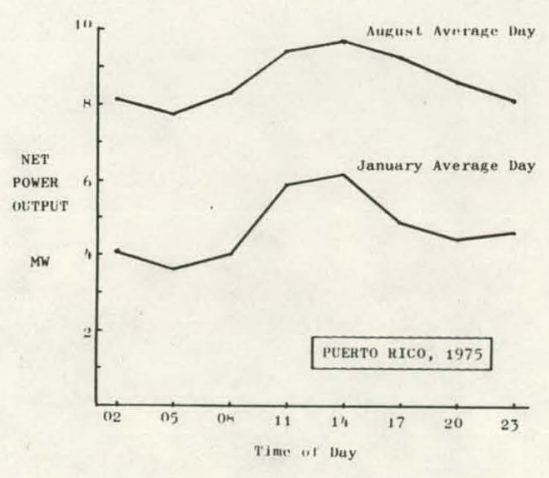

Figure 7-5. Net Power Output Versus Time of Day 


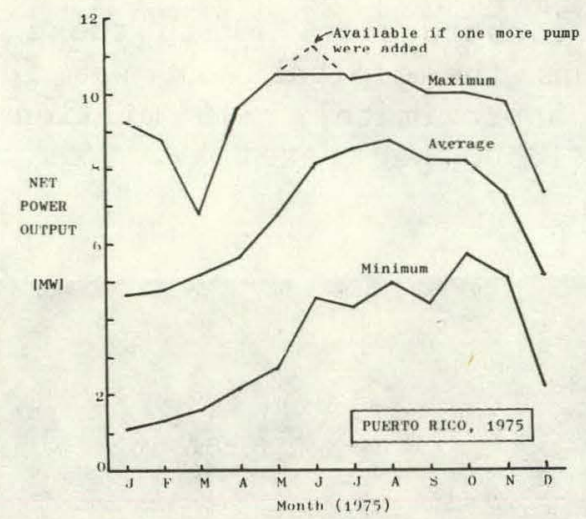

Figure 7-6. Net Power Output Versus Month of Year major cost items were structural costs, approximately 43\%, and the cold water pipe, approximately $35 \%$.

\subsection{SUMMARY REMARKS}

The current effort at the South Dakota School of Mines is to assess the expansion-compression system using vortex flows including frictional, turbulence, cooling, and turbine losses. In addition, vcrification of structural characteristics and design are to be performed in order to substantiate costs for the major components. It is anticipated that the rusulls of these stuales will be available by the end of FY80. 


\section{SECTION 8.0}

\section{THE MADARAS ROTOR POWER PLANT}

A study has been carried out at the University of Dayton Research Institute on the Madaras Rotor power plant concept. The primary objective of the study was to evaluate the Madaras concept including wind tunnel tests of a rotating cylinder, an electromechanical design study, and a cost analysis for the system.

During the period 1929-34, analytical wind tunnel and full-scale aerodynamic studies were carried out on a wind-powered Madaras rotor power plant, a system invented by Julius D. Madaras (Fig. 8-1).

The Madaras concept uses rotating cylinders, vertically-mounted on flat cars to react with the wind like a sail, that propel an endless train of cable-connected cars around a closed track at constant speed. Electricity is generated by alternators on each car that are geared to the wheels.
Electrical power is transmitted from each car to the central control house by a trolley system. The Madaras system originally considered a circular closed track $457 \mathrm{~m}$ in diameter. The cylinders, called rotors, are $6.8 \mathrm{~m}$ in diameter and $27 \mathrm{~m}$ high. Madaras planned to use 18 cylinders to generate $18 \mathrm{MW}$ of power at a rated wind speed of $13 \mathrm{~m} / \mathrm{s}$ and a track speed of $8.9 \mathrm{~m} / \mathrm{s}$. At two points in each orbit ( $\pm 90^{\circ}$ from the wind) the rotor spin direction is changed. This schedule is required so that the driving force generated by the rotors continuously drives the train of cars around the track in the same orbital direction. A rotating cylinder instead of an airfoil was used because a rotating cylinder generates a lift force ten times larger than that of an airfoil (Fig. 8-2) and thus optimum power can be extracted at lower track speeds than that of an airfoilpowered car. Details of this study

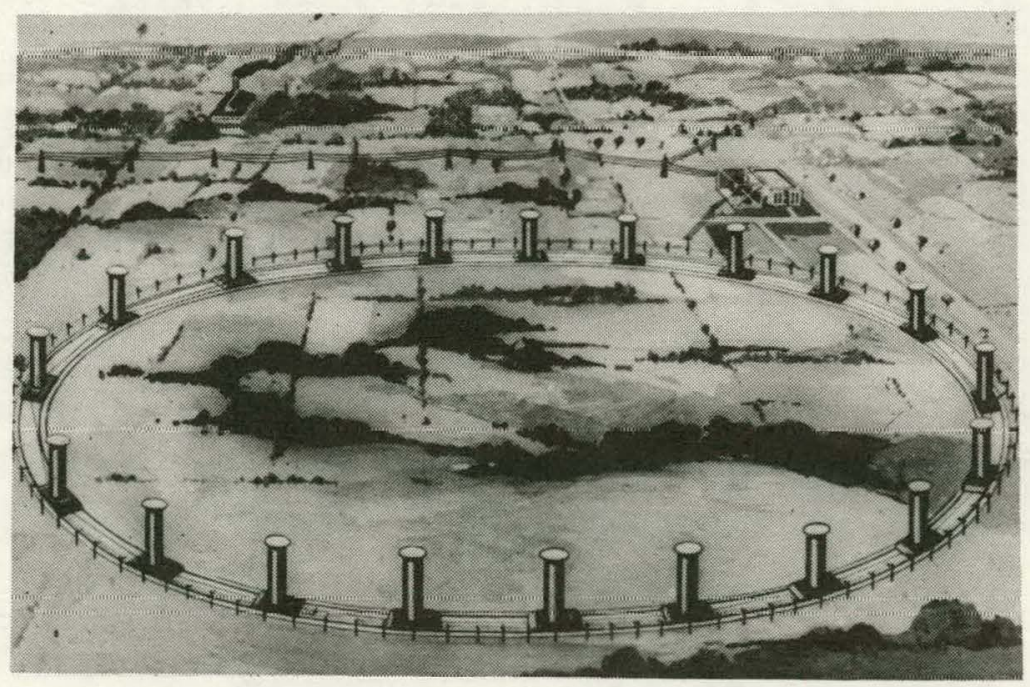

Figure 8-1. The Madaras Rotor Power Plant 


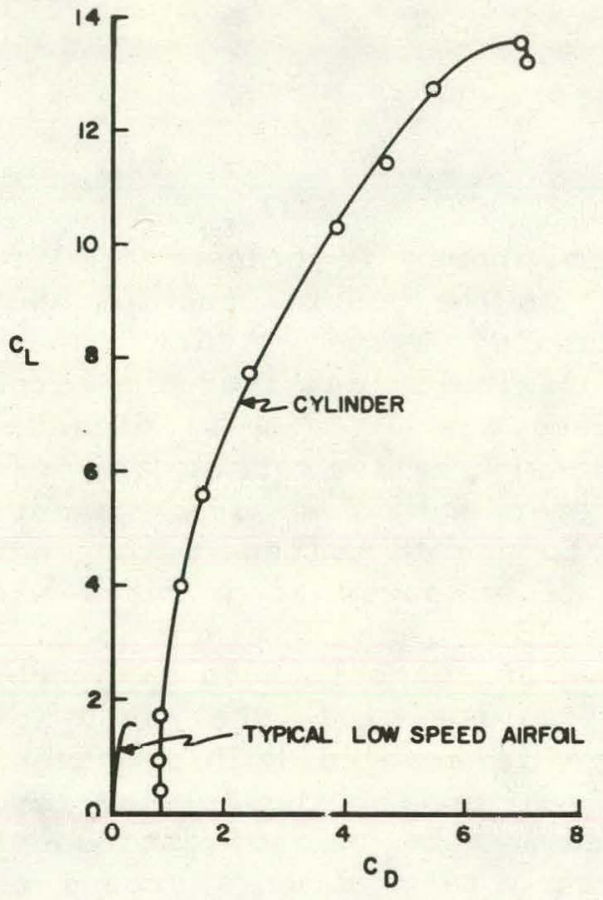

Figure 8-2. Lift-Drag Polars of a Rotating Cylinder and Airfoil

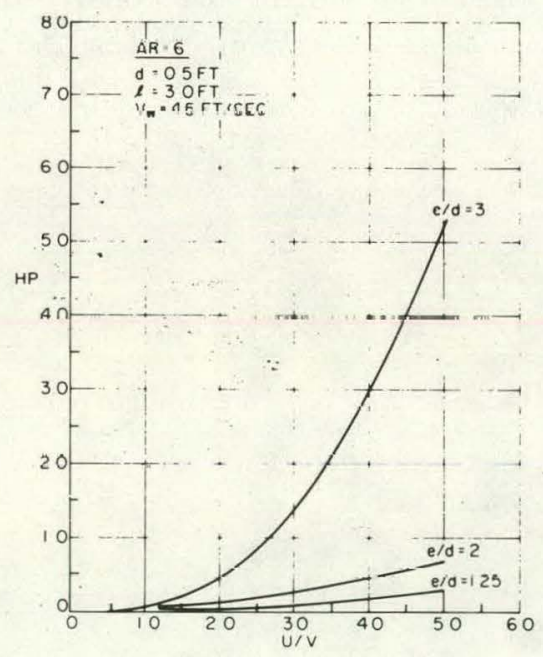

Figure 8-3. Power Required to Rotate Cylinder for Various End Cap Diameter Ratios and Two Aspect Ratios may be obtained from papers listed in Reference 7.

\subsection{EXPERIMENTAL STUDIES}

The performance of the Madaras rotor is complicated by the interaction of the atmospheric boundary layer with the flow generated by the spinning rotor. Wind tunnel tests were carried out to evaluate this complex phenumenun. These tests were performed under the direction of Professor Willmarth in the University of Michigan's Aerospace Engineering Department wind tunnel that has a cross section of $2.1 \mathrm{~m} \mathrm{x} 1.5 \mathrm{~m}$. The purpose of the tests was to validate existing wind tunnel data of rotating cyllnders, develup aervdymamic chasacteristics of rotating cylinders with end plates, obtain power requirements for rotating the cylinder and evaluate cylinder performance in an atmospheric boundary layer. Models of $15 \mathrm{~mm}$ and $152 \mathrm{~mm}$ in diameter were tested. All cylinders were equipped with internally housed motors capable of rotating the $\mathrm{cy}-$ linder at speeds up to $20,000 \mathrm{rpm}$. The wind tunnel test cylinders were rotated at this high $\mathrm{rpm}$ to provide the same rirrumferential speed-towind speed (U/V) ratios of a fullscalc cylinder ( $4.9 \mathrm{~m}$ diameter) that would rotate at $186 \mathrm{rpm}$. Tests were made for various aspect ratios, end plates, and spin speed. The power required to rotate the cylinder is shown in Fig. 8-3. It is observed that there is a significant increase in power absorbed by the rotor for e/d greater than 2. Tests performed at different aspect ratios indicated that there was little difference in power absorbed as a function of aspect ratio.

The lift and drag coefficients have also been measured for different aspect ratios for $U / V$ up to 6 (Fig. 8-4). The $\mathrm{C}_{\mathrm{L}}$ increases 
dramatically with increased end plate size especially for e/d between 1.25 and 2.0. For large values of aspect ratio the benefit of increasing e/d beyond 2.0 is not apparent. From these results, it appeared that a good design could be achieved with the rotor having an $A R=6$ and $\mathrm{e} / \mathrm{d}=2$. This combination would provide higher lift, lower drag, and reasonable input power levels for spinning the rotor.

Measurements were also taken utilizing a boundary layer that was developed on the tunnel wall. Most of the data observations from tests conducted with this contrived boundary layer were similar to those obtained with the free-stream data. It was also concluded that the use of top and bottom end plates instead of only top plates, would be beneficial to the performance.

\subsection{DESIGN STUDIES}

A Madaras performance simulation program was developed that predicted the ces of the various components as a function of the angular position on the track. Design loads on the rotor, rotor support tower, rotor car, and track were obtained from the program. Three wind conditions were evaluated: operational, operational plus gust, and static operations at hurricane conditions. The operational plus gust load was found to be the most severe condition. Additional load conditions analyzed were those caused by aerodynamic loading on the end plate, centrifugal acceleration caused by rotor car motion, centrifugal body forces, angular acceleration during rotor spin-up from 0 to $186 \mathrm{rpm}$, car weight, and wheel and lateral restraint loads. With the assumptions and conditions imposed, a rotor car design evolved.

$\begin{array}{ll}\text { aspect ratio } & =8 \\ \text { e/d } & =2 \\ \text { cylinder diameter } & =4.9 \mathrm{~m} \\ \text { track gauge } & =11 \mathrm{~m} \\ \text { car height } & =3.8 \mathrm{~m} \\ \text { cylinder length } & =38.1 \mathrm{~m} \\ \text { end-plate diameter } & =9.8 \mathrm{~m} \\ \text { car length } & =19.2 \mathrm{~m} \\ \text { car width } & =17.4 \mathrm{~m} \\ \text { gross car weight } & =328,000 \mathrm{~kg}\end{array}$

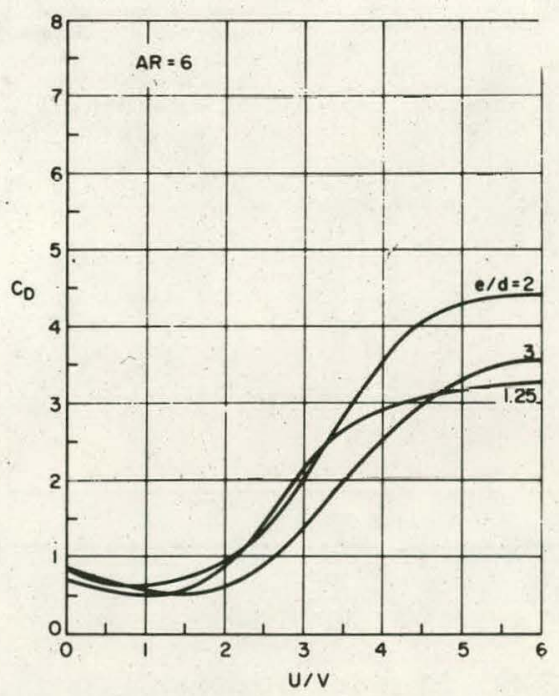




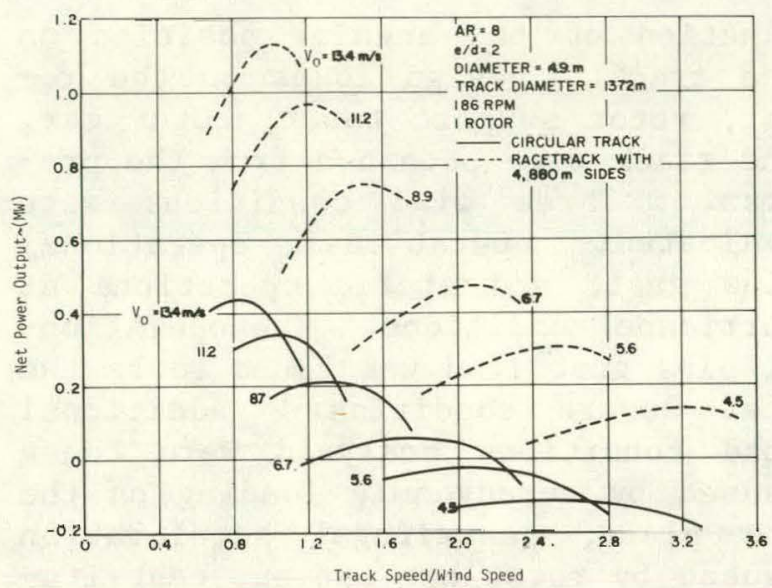

Figure 8-5. Net Power Output for One Rotor Versus Track Speed/Wind Speed

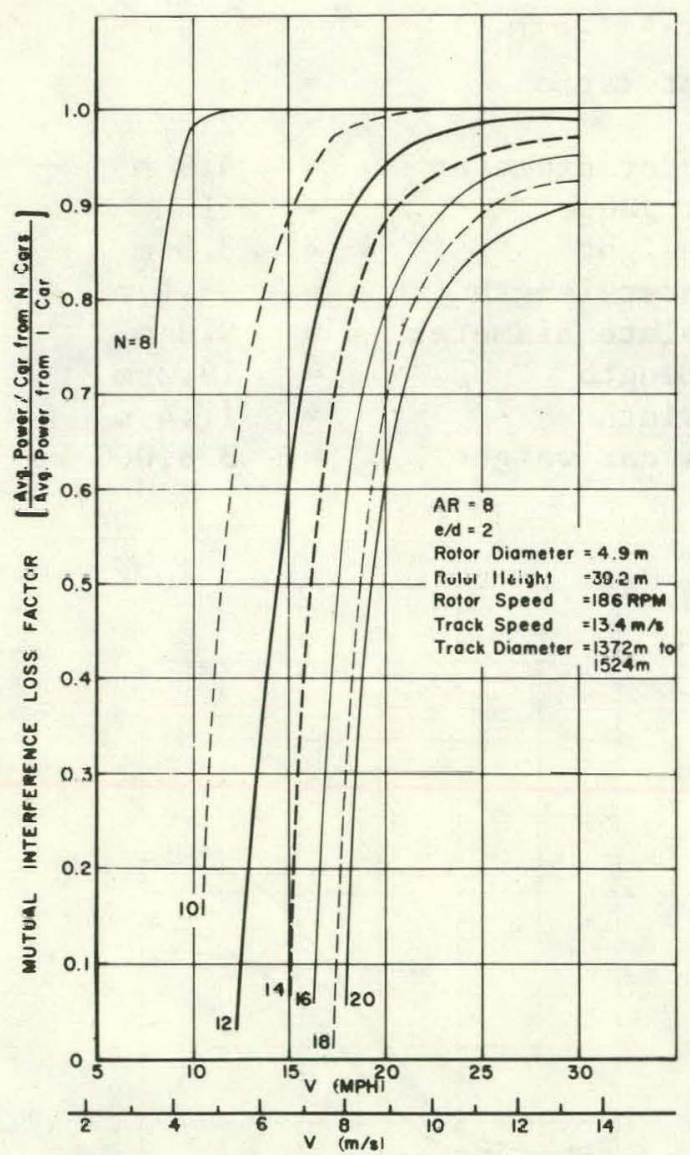

Figure 8-6. Mutual Interference Los

Factor Versus Wind Speed for Various Number of Rotors
In addition, the structural configuration and materials for the rotor, track, support tower, and rotor car suspension system were all developed. Each rotor car developed approximately 1 MW at a wind and track speed of $13 \mathrm{~m} / \mathrm{s}$.

The electrical design considered four components, the rotor spin system, the generator system, the controls and instrumentation system, and the electrical interface system. The rotor spin system consists of a 450 $\mathrm{kW}$ DC motor that is used to provide acceleration and dynamic braking to the rotor. Direction reversal is achieved by viscous breaking followed by reversing polarity of the power leads to the armature. Speed control is achieved by balancing the input power level to the armature against the demand of the control function signal. One of the results of the spin motor study was to discover that there are three very significant sources of spin motor losses: power required to overcome the viscous friction of the rotor caused by spinning; power required to overcome rotor inertia while accelerating from 0 to $186 \mathrm{rpm}$ and loss of encrgy during the rutor deceleration; and thr power lost in heating the motor windings during the low-speed acceleration stage at which time the motor is operating at a very low efficiency. Four 250-kW, threephase, $60 \mathrm{H}$ AC induction generators were used for each car. 'l'he control system included a mini-computer to command rotor car operations to the control house and a wiud sensor network to provide data for the spin schedule imposed on the rotor. The electrical interface system included the necessary feeder lines, synchronous reactors for power feeder correction, and utility feeder circuits and substations for the operation of the facility.

A performance analysis of the system was carried out to determine optinum 
characteristics for the rotor size, track diameter, and other variables. Circular and racetrack configurations were studied. For the racetrack configuration, the track speed was $13.4 \mathrm{~m} / \mathrm{s}$ and the track size had an end diameter of $1372 \mathrm{~m}$ with a straight section that varied from $3050 \mathrm{~m}$ to $19210 \mathrm{~m}$. The calculated net power output for circular and racetrack configurations is shown in Fig. 8-5. It is observed that the racetrack configuration develops over twice as much net power as the circular track configuration. In general, track speeds less than twice wind speeds appear appropriate, particularly at high wind speeds.

In order to determine an optimum spacing for the rotor cars, a mutual interference study was conducted using the vortex analysis developed for the giromill. The analysis determines the effect of all vorticies shed froin each rotor in the plant, on the vorticies shed from all other rotors in the plant, and then determines the effect of this vortex field on the wind velocity vector at all point around the track. As rotor spacing decreases, mutual interference losses increase. As is shown in Fig. 8-6 at constant wind speed, increasing the number or rotors decreases the performance of each rotor.

Based upon the rotor and track characteristics, cost estimates were developed for a system utilizing generalized equations that described plant geometry in terms of modular cost variables. The cost estimation was carried out by M. L. McClellen and Company, a professional engineering company specializing in cost estimation of large plants. The analysis indicated that the most efficient circular plants were not sufficiently economical for further consideration. Large racetrack plants appear to be more cost effective but require sites that have predominant wind directions. The results of some of these studies are shown in Figs. 8-7 and 8-8. The plots indicate the relationship of various parameters on the unit cost and energy related to rated power. The effects of interrotor spacing, number of rotors, and length of straight track were evaluated for a wind duration curve having a mean wind speed of $8.1 \mathrm{~m} / \mathrm{s}$. The curves do not reflect the effect of learning curves or land costs, and are based on an annual cost equal to $16.5 \%$ of total plant costs and 30year lifetime. Typically, for a 100-MW system with 75 rotor cars the system cost could vary between $\$ 2,000$ and $\$ 3,000$ per installed $\mathrm{kW}$ depending upon the track size. This results in an energy cost of between 7.5 to $9.0 \AA / \mathrm{kWh}$ for the first item.

Additional calculations were made utilizing $85 \%$ and $90 \%$ learning curves on the major elements used in this system for various-sized plants 1ocated at Medicine Bow, Wyoming, and at a sea level location having a mean wind speed of $8.1 \mathrm{~m} / \mathrm{s}$. Land costs varying from 0 to $\$ 3,000 /$ acre were considered. Comparisons were made between Madaras plants and comparable arrays of horizontal axis wind turbines. Based upon the assumptiuns employed, plant and energy costs of a racetrack-configured Madaras system were found to be similar to those costs of an equally sized farm of conventional first generation wind turbines.

\subsection{SUMMARY REMARKS}

The results of the University of Dayton study indicate that a Madaras system utilizing a racetrack configuration would be preferred to one with a circular track. Sufficient information is available on the aero- 


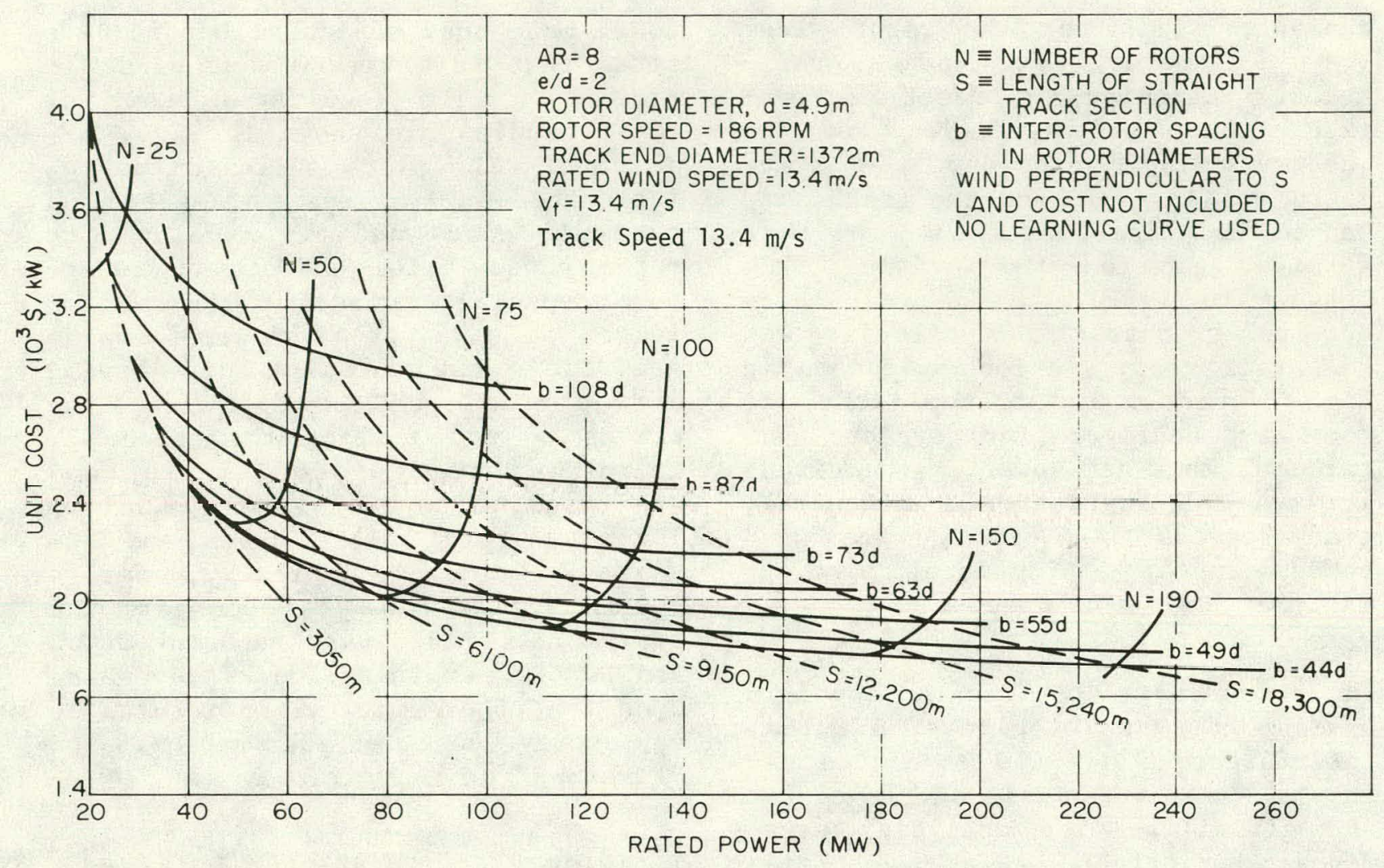

Figure 8-7. Unit Plant Cost Versus Rated Power for Racetrack Configuration

dynamics of a rotating cylinder to provide performance characteristics of the rotor. Optimization of the sysleIII lias provided an indication of the rotor diameter, height, and endplate geometry. It is clear that the Madaras system composed of translating rotor cars is more complex than a stationary array of conventional wind systems. Thus, it is anticipated that the operation and maintenance cost for the Madaras system would probably be higher than that of conventional wind systems. Calculations based upon costs developed for the system indicated that the energy cost is similar to a conventional first generation system located at Medicine Bow.

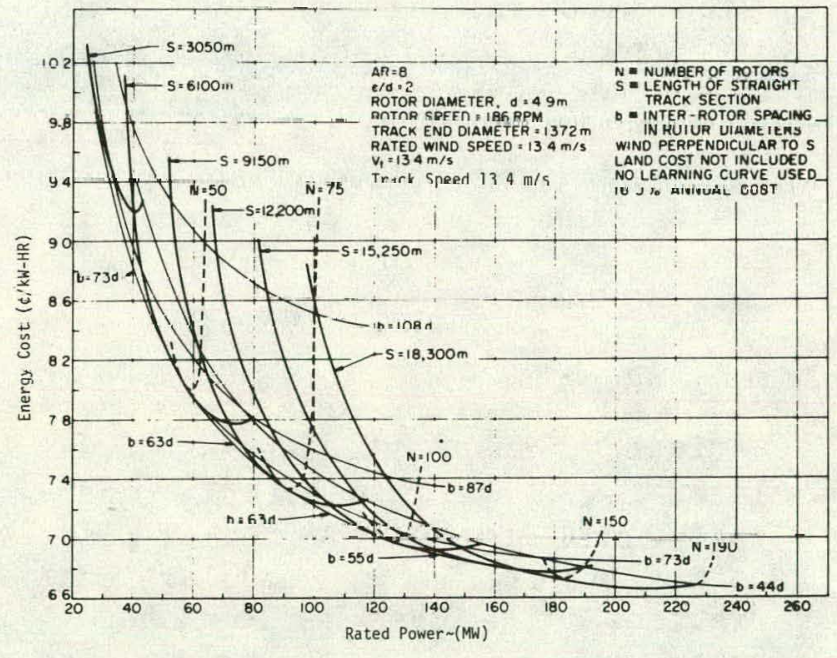

Figure 8-8. Energy Cost Versus Rated Power for Racetrack Configuration 
11

\section{SECTION 9.0}

\section{VORTEX AUGMENTOR CONCEPT}

The Vortex Augmentor Concept (VAC) has been studied at the Polytechnic Institute of New York Eor the past four years. The concept involves the generation and control of discrete high-power density vorticies by appropriate interaction of aerodynamic surfaces with natural winds of lowpower density. The thrust of the work is to utilize this phenomenon to develop an improved wind energy conversion system. To do this, it was necessary to provide a method to generate and control these vorticies by appropriate interaction of an aerodynamic surface, and to design and extract the energy from the vortex produced. As the vortex attempts to focus the energy, it is possible to itilize smaller rotors to extract the energy. The study was to develop the concept and perform a field test pro- zram on an instrumented system. Details of this study may be obtained from papers listed in Reference 8.

\subsection{EXPERIMENTAL STUDIES}

In order to determine the performance characteristics of the system, it was necessary to provide accurate spatial measurements of wind velocity and direction in a region several times larger than the test model. The field test site had an array of four towers instrumented at three different heights, laid out in a circle centered $11 \mathrm{~m}$. from the test site. The towers, located at the cardinal points of the compass, monitored wind speed and direction at 3,5 , and $7 \mathrm{~m}$ above the ground. With this network it is possible, with the appropriate

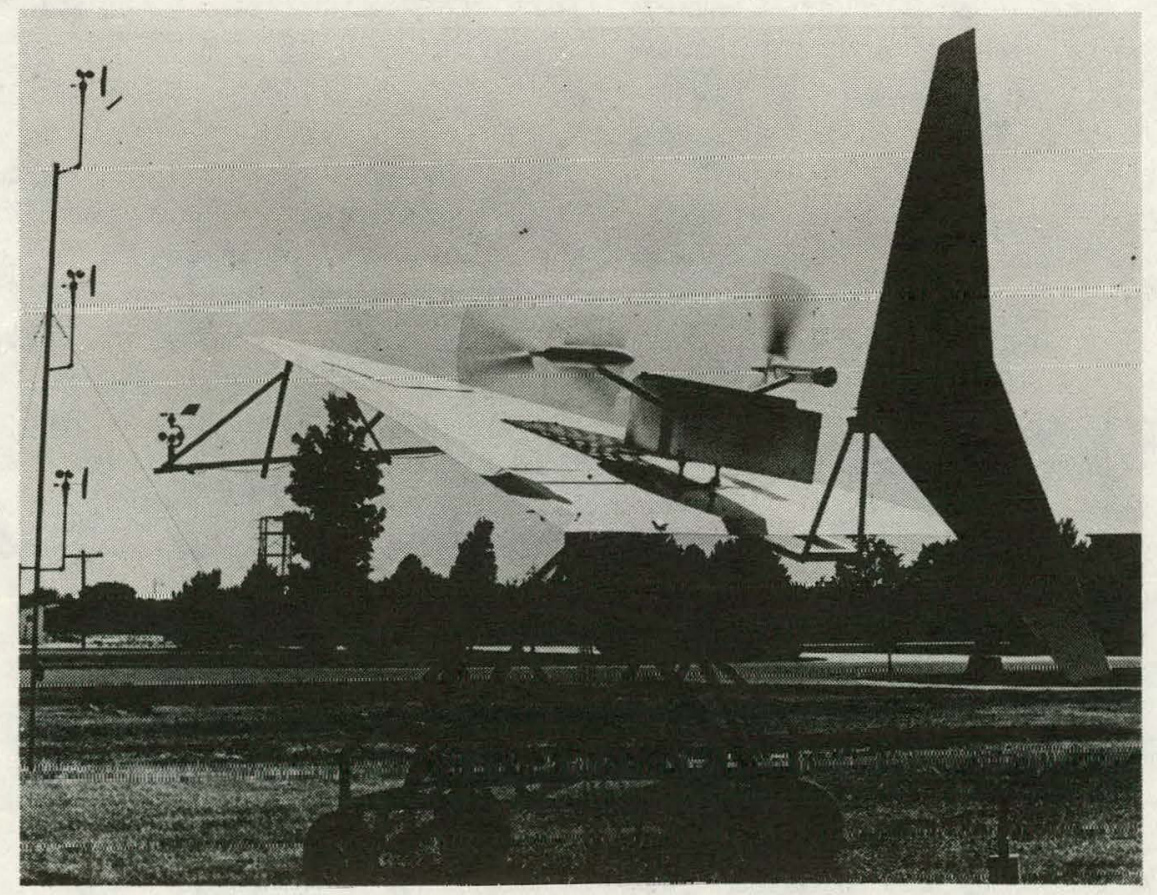

Figure 9-1. Prototype Model of the VAC 


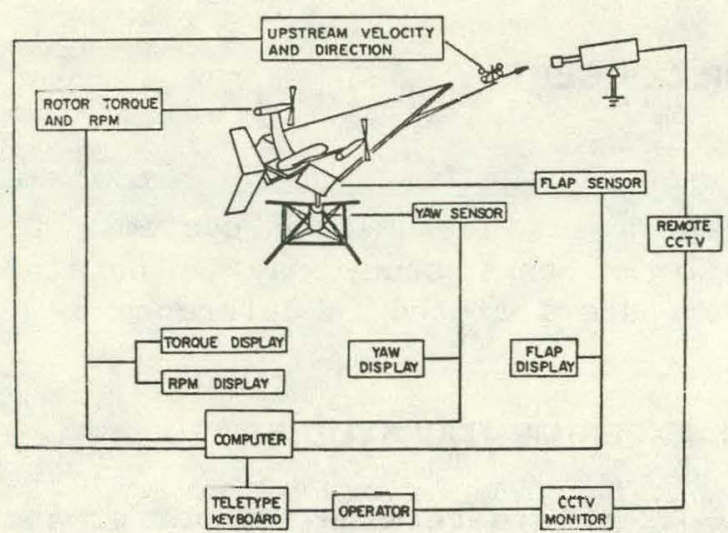

\section{Figure 9-2. Schematic Diagram of the Sensor System}

data processing, to study vertical gradients and correlations, horizontal gradients and correlations, wind energy fluxes at the test site, etc. The wind speed and direction outputs are processed by signal conditioning units that were calibrated in a wind tunnel facility. The prototype model developed for this study was a simple flat-plate delta configuration wlll a $75^{\circ}$ swccpback, $5.6 \mathrm{~m}$ long (Fig. 9-1). The performance of the turbines mounted on the model is monitored by a dynamometer contained within the nacelle. The dynamometer consists of a torque meter and a tachometer, coupled to an electrically activated friction brake. Directional control is by a vertical tin positioned along the center line of the vortex augmentor. The tower Lliat supports the vorlex dugmentor aystem is of the open truss type construction and is fashioned from welded iron. It is approximately $3 \mathrm{~m} \mathrm{high,}$ and rests on a four-wheeled carriage with steerable wheels and a towbar. The sensor system for the field prototype test is shown schematically in Fig. 9-2. All sensors are tied into a central computer for recording and processing.

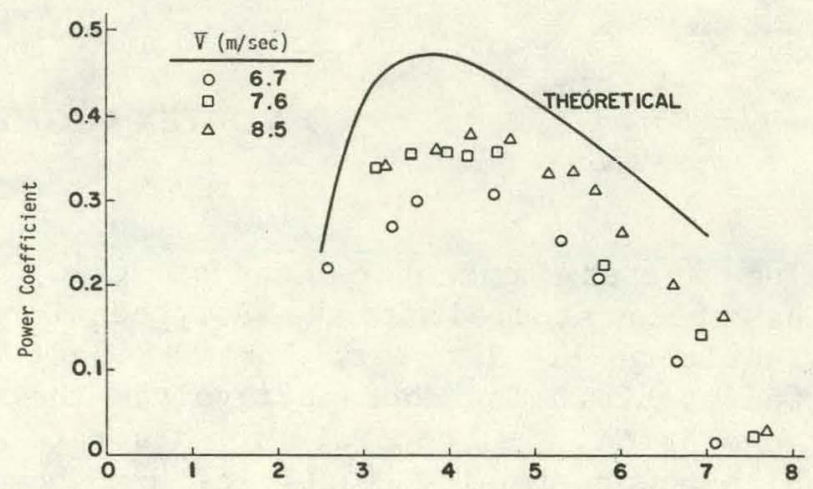

Tip Speed Ratio

Figure 9-3. Power Coefficient Versus Tip Speed Ratio for the Prototype Rotor in Uniform Flow

The rotor tor the protolype sysleil was designed using simple blade element theory that depends upon a knowledge of the vortex velocity characteristics. The adequacy of this method is unclear, particularly for an advanced type system. Calibration of the rotor was carried out in the Rotor Test Facility in order to determine rotor power generation charactetistics. The 1.5-m diameter air jet produced by the Rotor Test Facility was itself calibrated for uniforn cxit flow velocity. The prototype rotor with a diameter of $0.92 \mathrm{~m}$ was calibrated in a uniform flow over a range of velocities and tip speed ratios (Fig. 9-3). The measured power coefficient is lower than predicted; however, the measured and predicted peak value of the coeffirient occurred at about the same tip speed ratio.

During the past year the VAC prototype with its instrumentation has been field tested, wind conditions permitting. Field tests could only be conducted under the following conditions: wind speed in excess of $6 \mathrm{~m} / \mathrm{s}$, ambient temperature in excess of $0^{\circ} \mathrm{C}$, no precipitation, proper 
functioning of instruments and computer, and regular working hours. The basic problem in using this "uncontrolled atmospheric facility" was the variability of the wind speed.

The observations made during the field tests indicated that the time response of the rotor was significantly greater than the characteristic period of wind variation and that the operation of the rotor was nearly always transient rather than steady state. More detailed studies of wind-rotor interaction of this type would be very useful. The measurements included instantaneous values of rotor torque, rotor rotational speed, reference speed, and direction. The reference speed and direction could be that from a sensor at rotor height located 0,1 , and 2 unit lengths upstream of the rotor plane. A typical trace for instantaneous wind power and rotor power is shown in Fig. 9-4.

The associated record of the angular deviation of the flow corresponding to the power recordings is shown in Fig. 9-5. It is evident that the flow is highly turbulent in nature, which will tend to degrade the rotor performance from predicted values.

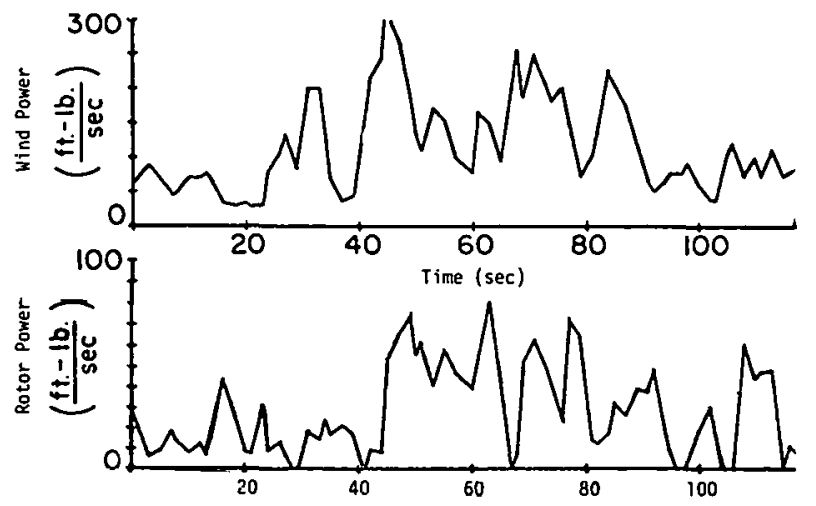

Figure 9-4. Time Variation of Wind and Rotor Power
In addition, calculation of the instantaneous power coefficients would give wide variations in the coefficient. In order to develop a first approximation of the performance of the prototype, a time averaged power coefficient was defined.

$$
C_{P}=\frac{T^{-1} \int_{0}^{T} P d t}{(1 / 2) \rho \pi R^{2}\left[T^{-1} \int_{0}^{T} v d t\right]^{3}}
$$

The value of the time, $T$, was chosen between 30 and 100 seconds to provide a good statistical average of the data. In general, the results for the power coefficient of $\alpha=0$ were not much different from those at high angles of attack. A typical case is shown in Fig. 9-6, where the power coefficient for $\alpha=20^{\circ}$ was approximately $50 \%$ higher than $\alpha=0^{\circ}$. It is significant that the results of tip speed ratio in the range of three to four are superior to those between four and five. The theoretical study indicates that a higher power coefficient should result at the higher value of the tip speed ratio.

\subsection{SUMMARY REMARKS}

The effort of the Polytechnic Institute of New York has included a well-

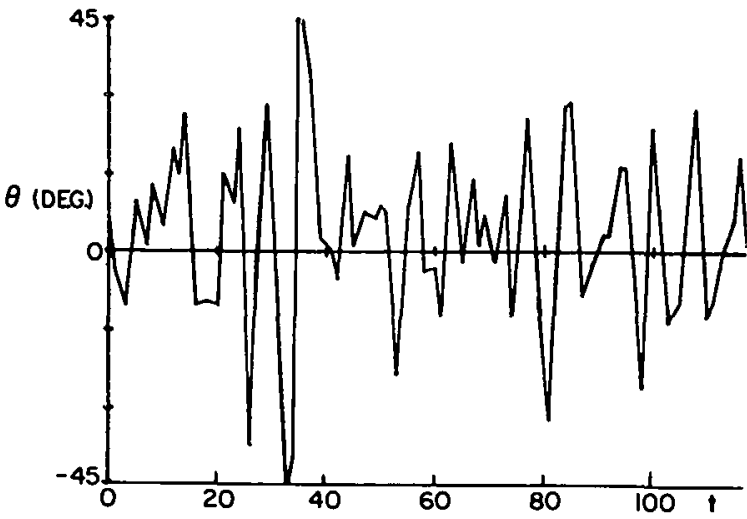

Figure 9-5. Trace of Angular Flow Devlation from Delta Centerline Versus Time 


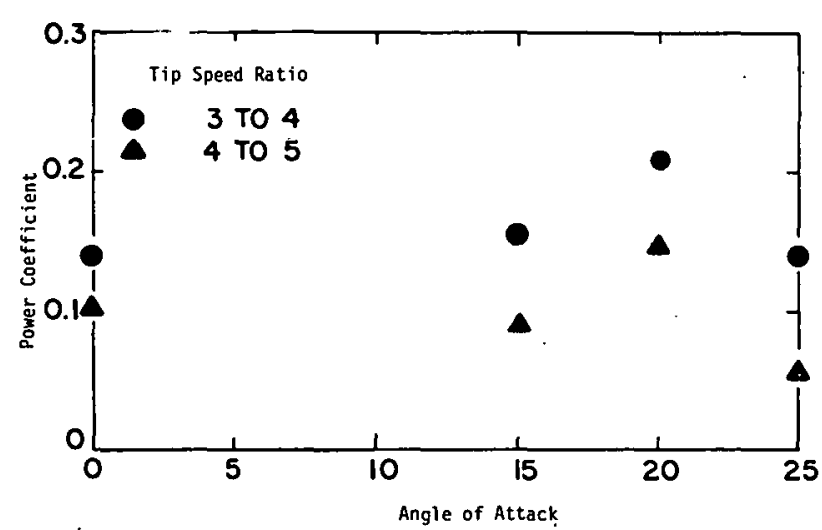

Figure 9-6. Mean Power Coefficient Versus Angle of Attack

equipped field test facility for wind energy systems including extensive data management and processing capa- bility. The study has also indicated the significant problems inherent in testing in an uncontrolled wind energy environment. Such testing can be most fruitful at sites of good wind speed and direction characteristics. The prototype showed a. $50 \%$ improvement over the unaugmented mode of operation. Most of the design features of the VAC prototype were frozen in the earlier portion of the program and, therefore, to not really constitule an optimum configuration. The majority of the time was spent in the calibration, construction, and operation of the model and its associated instrumentation and data processing capability. Additional results are to be available at the end of the contract period during the current fiscal year. 


\section{SECTION 10.0}

\section{CONCLUDING REMARKS}

The past fiscal year was the first complete year that the Wind Energy Innovative Systems program was managed by SERI for DOE. During this period the elght $R \& D$ projects initially funded by DOE were monitored, renewals were provided to three of them through SERI, and one of them was closed out. Three new R\&D subcontracts were recently awarded and six assessment studies were carried out of innovative generic concepts. Lastly, a Conference/Workshop was held to disseminate the latest information on the innovative concepts and to provide recommendations and suggestions for future efforts in the program.

The present paper presented the major themes of the supported research studies. No details were presented of the generic studies, as they generally utilized the data available in the R\&D studies. No information was presented on the three new studies as these have recently been initiated.

The results of these studies have been well documented. All the studles alm to be cost effective energy producers. It is important that accurate performance characteristics be confirmed in order to establish a base cost of energy for the system. Accurate costs may only be developed as a result of an optimization design study, engineering design, and proofof-concept. The Wind Energy Innovative Systems program supports research of these concepts in order to determine their cost effectiveness. 
SEPI糙 


\section{REFERENCES}

\section{Reference 1}

Walters, R. E. "Innovative Vertical Axis Wind Machines." Second Workshop on Wind Energy Conversion Systems, sponsored by ERDA Solar Energy Division and NSF, Washington, DC; June 9-11, 1975.

Walters, R. E; Fanucci, J. B.; Loth, J. L.; Ness, N.; Palner, G. M.; Squire, W. Innovative Wind Machines: Six Month Report, March 1 - August 31, 1975. ERDA/NSF/0036775/Tl. Department of Aerospace Engineering, West Virginia University; September 1975.

Loth, J. L. "Wind Energy Concentrators," Second Annual UMR-MEC Conference on Energy. Rolla, MO; October 7-8, 1975.

Fanucci, J. B.; Walters, R. E. "Theoretical Performance of a Vertical Axis Wind Turbine." Vertical Axis Wind Turbine Technology Workshop. Sponsored by ERDA, Albuquerque, NM: Sandia Laboratories; May 17-20, 1976.

Walters, R. E.; Fanucci, J. B.; Loth, J. L.; Migliore, P. G.; Ness, N.; Palmer, G. M.; Squire, W.; Yusuff, S. Innovative Wind Machines: $\mathrm{Ex}^{-}$ ecutive Summary and Final Report. ERDA/NSF/00367-76/2. Department of Aerospace Engineering, West Virginia University; June 1976.

Loth, J. L. "WVU Wind Energy Concentrators." International Symposium on Wind Energy Systems; Churchill College; Cambridge, England; September 7-9, 1976.
Migliore, P. G.; Fanucci, J. B.; Squire, W. "Numerical Solution for the Unsteady Lifting Characteristics of Variable Pitch Cross-Flow Wind Turbines." Eleventh Intersociety Energy Conversion Engineering Conference. State Line, NV; September 12-17, 1976.

Huq, R.; Loth, J. L. "Vortex Kinetic Energy Concentrator." Eleventh Intersociety Energy Conversion Engineering Conference. State Line, NV; September 12-17, 1976.

Walters, R. E..; Fanucci, J. B.; Loth, J. L.; Squire, W.; Migliore, P. G.; Huq, R. "Innovative Wind : Turbines." Third Annual UMR-MEC Conference on Energy. Rolla, MO; October 12-14, 1976.

Yen, R. H. "Time Decay of a Turbulent Line Vortex." Masters Thesis, West Virginia University; Deceuber 1976.

Loth, J. L. "Betz Type Limitation of Vortex Wind Machines." Wind Engineering. Vol. 1 (No. 3): pp. 169$185 ; 1977$.

Loth, J. L.; Ness, N.; Huq, R. Innovative Wind Turbines; The Wind Vortex Generator. Progress Report for March 1-December 31, 1976. ORO/5135-77/2, TR-53, Department of Aerospace Engineering, West Virginia University; January 1977.

Walters, R. E.; Fanucci, J. B.; Jones, E. R.; Hill, P. W.; Migliore, P. G.; Squire, W.; Waltz, T. L. Innovative Wind Turbines; The Circulation Controlled Vertical Axis Wind Turbine. Progress Report for March 1 - December 31, 1976. 
OR0-5135-77/1, TR-52, Department of Aerospace Engineering, West Virginia University; January 1977.

Loth, J. L. Betz Type Limitations of Vortex Wind Machines. ORO/513577/3, TR-54, Department of Aerospace Engineering, West Virginia University; April 1977.

Elko, D. G. "Design Instrumentation and Calibration of a Vertical Axis Wind Turbine." Masters Thesis, West Virginia University; May 1977.

Loth, J. L.; Ness, N.; Yen, R. H. Vortex-Type Wind Machines; Final Report. ORO/5135-77.6, TR-59. Department of Aerospace Engineering, West Virginia University; July 1977.

Ness, N.; Yen, R. H. Wing Trailing Vortices. ORO/5135-77/4, TR-55. Department of Aerospace Engineering, West Virginia University; July 1977.

Walters, R. E.; Fanucci, J. B.; Hill, P. W.; Migliore, P. G. Vertical Axis Wind Turbine Development. ORO/5135-77/5, TR-58. Department of Aerospace Engineering, West Virginia Univeraity; July 1977.

Loth, J. L. "Betz Type Limits for Vortex W1nd Machines." Third Biennial Conference and Workshop on Wind Energy Conversion Systems. Sponsored by ERDA, Washington, DC; September 19-21, 1977.

Walters, R. E.; Migliore, P. G. "The Circulation Controlled Vertical Axis Wind Turbine." Third Biennial Conference and Workshop on Wind Energy Conversion Systems. Sponsored by ERDA, Washington, DC; September 19-21, 1977.

Hoy, D. L. "Theoretical Study of Vertical Axis Wind Turbines Using Aft Tail for Blade Tracking." Mas- ters Thesis, West Virginia University; December 1977.

Migliore, P. G; Wolfe, W. P. Some Effects of Flow Curvature on the Aerodynamics of Darrieus Wind Turbines. 0R0/5135-77/7, TR-60. Department of Aerospace Engineering, West 'Virginia University; December 1977.

Kuhlke, K. D. "Experimental Investigation of the WVU Straight Bladed Darrieus Wind Turbine." Masters Thesis, West Virginia University; May 1978.

Walters, R. E.; Fanucci, J. B.; Hill, P. W.; Hoy, D. L.; Kuhlke, K. D.; Migliore, P. G.; Wolfe, W. P. Vertical Axis Wind Turbine Experiments and Analysis. 0R0/5135-78/1, TR-61. Department of Aerospace Engineering, West Virginia University; May 1978.

Wolfe, W. P. "Analysis of Test Results for the WVU Straight-Bladed Darrieus Wind Turbine." Masters Thesis, West Virginia University; May 1978.

Migliore, P. G. "A Free-Vortex Model will Nuluerlcal Solurion for the Unsteady Lifting Characteristics of Straight Bladed Darrieus Wind Turbines." Ph.D. Dissertation, West Virginia University; May 1979.

Walters, R. E'.; Migliore, P. G.; Wolfe, W. P. "Innovative StraightBladed Vertical Axig Wind Turbine." DOE Wind Energy Innovative Systems Conference, Colorado Springs, $\mathrm{CO}$; May 23-25, 1979.

\section{Reference 2}

Oman, R. A.; Foreman, K. M. "Advantages of the Diffuser Augmented Wind Turbine." Proceedings of the 
NSF-NASA Workshop on Wind Driven Generator Systems. NSF/RA/W-73006. Decenber 1973; pp. 103-106.

Oman, R. A.; Foreman, K. M. "Cost Effective Diffuser Augmentation of Wind Turbine Power Generators." Proceedings of the NSF-ERDA Second Workshop on Wind Energy Conversion Systems. NSF-RA-N75-050, MTR-6970. The MITRE Corporation; June 1975; pp. 426-432.

Oman, R. A.; Foreman, K. M.; and Gilbert, B. L. Investigation of Diffuser-Augmented Wind Turbines. Part II - Technical Report. ERDA Report C00-2612-2. January 1977; Grumman Aerospace Corporation, Research Department; Report RE-534; January 1977.

Oman, R. A.; Foreman, K. M.; Gilbert, B. L. "A Progress Report on the Diffuser Augmented Wind Turbine." Proceedings of the Third Biennial Workshop on Wind Energy Conversion Systems. Report Conf770921. U.S. Dept. of Energy; Vo1. II : pp. 819-828; September 1977.

Foreman, K. M.; Gilbert, B. L. "Diffuser Designs for Improved Wind Energy Conversion." Fluids Engineering in Advanced Energy Syetems. American Society of Mechanical Engineers, Publication H0012. New York, NY; 1978; pp. 73-91.

Foreman, K. M. ; Gilbert, B.; Oman, R. A. "Diffuser Augmentation of Wind Turbines." Solar Energy. Vol. 20 (No. 4): pp. 305-311; April 1978.

Gilbert, B. L.; Onan, R. A.; Foreman, K. M. "Fluid Dynamics of Diffuser Augmented Wind Turbines." Proceedings 12th Intersociety Energy Conversion Engineering Conference. Vol. 2: pp. 1651-1659; 1977; Also in AIAA Journal of Ener- gy. Vol. 2 (No. 6): pp. 368-374; November/December 1978.

Foreman, K. M.; Gilbert, B. L. Further Investigations of DiffuserAugmented Wind Turbines. DOE $\mathrm{Re}^{-}$ port C00-2612-2. Grumman Aerospace Corporations Research Dept., Report RE-585; July 1979.

Gilbert, B. L.; Foreman, K. M. "Experimental Demonstration of the Diffuser Augmented Wind Turbine Concept." Proceedings 13th Intersociety Energy Conversion Engineering Conference. SAE Publication P-75. Vol. 3: pp. 2082-2089; 1978. Also published in AIAA Journal of Energy. Vol. 3 (No. 4); July/August 1979.

\section{Reference 3}

Yen, J. T. "Tornado-Type Wind Energy System." Proceedings, Intersociety Energy Conversion Engineering Conference. September 1975; pp. 987994.

Ýen, J. T. Tornado-Type Wind Energy System, Basic Considerations. ASME Paper 76-WA-Ener-2; 1976.

Yèn, J. T. "Summary of Recent Progress on Tornado-Type Wind Energy Systems." Third Wind Energy Workshop. Washington, DC: JBF Scientific Corp.; September 1977; pp. 808-818.

Yen, J. T. "Tornado-Type Wind Energy System Semi-Annual Status Report." Grumman Aerospace Corporation Research Department Meinorandum RM-643; September 1977.

Hsu, C. T.; Mellor, G.; Yen, J. T. "Some Flow Analysis of a TornadoType Wind Turbine." Proceedings of the ASME Wincer Annual Meeting. 78-59888; December 1978 . 
Reference 4

Marks, A. M. "Optimum Charged Aerosols for Power Conversion." Journal of Applied Physics. Vol. 43; 1972.

Marks, A. M. Wind Power Charged Aerosol Generator. October 1975 June 1976; National Science Foundation.

Marks, A. M.; Fitsgibbon, M. Charged Aerosol Wind/Electric Power Generator. FC78118. Marks Polarized Corporation; January 16, 1978.

\section{Reference 5}

Minardi, J. E.; Lawson, M. 0. "Electrofluid Dynamic (EFD) Wind Generator." 2nd U.S. National Conference on Wind Energy Research. Fort Collins, CO; June 1975.

Minardi, J. E.; Lawson, M. 0.; Williams, G. Electrofluid Dynamic (EFD) Wind Driven Generator. C00/4130-77-1. Occober 1976.

Minardi, J. E.; Lawson, M. 0. Annual Progress Report on the Electrofluid Dynamic Wind Generator. VDRI-TR77-38. University of Dayton Research Institute; Ju1y 22, 1977.

Minardi, J. E.; Lawson, M. 0. "Progress in Electrofluid Dynamic (EFD) Wind Driven Generator Research." "hird Biennial Conference and Workshop in Wind Energy Conversion Systems. Washington, DC; September $19-21,1977$.

Minardi, J. E.; Lawson, M. O. Electrofluid Dynamic (EFD) Wind Driven Generator Research. Society of Engineering Science, Inc., 14th Annual Meeting, Bethlehem, PA; November $14-16,1977$.
Minardi, J. E.; Lawson, M. 0. "Research in the Electrofluid Dynamic (EFD) Wind Driven Generator." IEEE 1978 National Aerospace and Electronic Conference. Dayton, $\mathrm{OH}$; $\mathrm{pp}$. 869-873; May 16-18, 1978.

Minardi, J. E.; Lawson, M. O. "Electrofluid Dynamic (EFD) Wind Driven Generator." Wind Energy Innovative Systems Conference. Colorado Springs, CO; May 1979.

Minardi, J. E.; Lawson, M.' $0_{.}$; Wattendorf, F. L. Third Annual Progress Report on the Electrofluid Dynamic Wind Generator. $\mathrm{COO}$ 4130-2. Univarsity of Dayton Research Institute; May 1979.

\section{Reference 6}

Oliver, T. K.; Groves, W. N•; Gruber, C. L.; Cheung, A. . "Energy from Humid Air." Third Wind Energy Workshop Proceedings. Conf. 770921, Vol. 2: pp. 865-872; September 1977.

Oliver, T. K.; Gluves, W. N.; Gruber, C. L.; Chcung, $\Lambda$. "Alternative Energy from Humid Air." Alternative Energy Sources. McGraw Hil1 International Book Co., Vol. 4: p. 1887; December 1977.

Oliver, T. K.; Groves, W. N.; Gruber, C. L.; Cheung, A. "Energy from Humid Air." Journal of Energy. Vol. 2 (No. 1); January/February 1978.

Oliver, T. K.; Groves, W. N.; Gruber, C. L.; Cheung, A. Energy from Hunid Air. DSE/2553-79/1. South Dakota School of Mines \& Technology; February 1979.

Oliver, T. K.; Groves, W. N.; Gruber, C. L.; Cheung, A. "Energy from Humid Air." Wind Energy Innovative 
Systems Conference Proceedings. SERI/TP-49-184; PP. 267-282; December 1979.

\section{Reference 7}

Whitford, D. H.; Minardi, J. E.; West, B. S.; Dominic, R. J. An Analysis of the Madaras Rotor Power Plant: An Alternative Method of Extracting Large Amounts of Power from the Wind. HQS-2554-78/2. University of Dayton Research Institute; June 1979.

\section{Reference 8}

Sforza, P. M. "Vortex Augmentor Concepts for Wind Energy Conversion." Proceedings of the Second Workshop on Wind Energy Conversion Systems. Washington, DC: The MITKE Corporation; June 9-11, 1975; pp. 433-442.

Sforza, P. M. Vortex Augmentor Concept for Wind Energy Conversion: Progress Report May-November 1975. POLY-AE/AM Report No. 76-1. Polytechnic Institute of New York; January 1976.

Sforza, P. M. Vortex Augmentors for Wind Energy Conversion. POLY-AE/AM-76-1. Polytechnic Institute of New York; September 1976.

Sforza, P. M. "Vortex Augmentors for Wind Energy Conversion." Proceedings of the International Symposium on Wind Energy Systems. Cambridge, England; September 7-9, 1976.

Sforza, P. M. Vortex Augmentors for Wind Energy Conversion. Polytechnic Institute of New York; December 1976; also issued as U.S. ERDA Dept. of Energy Report No. TID27885.
Sforza, P. M•; Stasi, W.; Pazienza, J.; Smorto, M. "Flow Measurements in Leading-Edge Vortices." Presented at the AIAA 15th Aerospace Sciences Meeting, Los Angeles, CA; January 1977; also appeared in the AIAA Journal, Vol. 16 (No. 3): pp. 218-224; March 1978.

Sforza, P. M. "Vortex Augmentation of Wind Energy." Wind Engineering. Vol. 1 (No. 3): pp. 186-197; 1977.

Sforza, P. M. "Vortex Augmentors." Presented and appeared in Proceedings of the Third Biennial Conference and Workshop on Wind Energy Conversion Systems. Washington, DC; September 1977; pp. 803-807.

Sforza, P. M. "Vortex Augnented Wind Energy Conversion." Presented and appeared in Proceedings of the $14 \mathrm{th}$ Annual Meeting of the Society of Engineering Sciences, Inc. entitled Recent Advances in Engineering Science. Lehigh University Publication; November 1977; pp. 12331236.

Sforza, P. M.; Stasi, W.; Gotkin, L. "An Experimental Facility for Wind Engineering Research." Presented and appeared in A Collection of Technical Papers, AIAA 10th Aerodynamic Testing Conference. San Diego, CA; April 1978.

Sforza, P. M.; Stasi, W. J. "Field Testing the Vortex Augmentor Concept." Submitted for presentation at the 2nd International Symposium on Wind Energy Systems. Amsterdan, The Netherlands, October 1978.

Sforza, P. M.; Stasi, W. "Wind Power Distribution, Control, and Conversion in Vortex Augmentors." C. H. Marston, ed. Fluids Engineering in Advanced Energy Systelas. ASME; New York; 1978; pp. 45-57. 
$\sqrt[1]{1}^{=}=$

Sforza, P. M. "Vortex Augmented Wind Energy Conversion." Proceedings of the International Symposium on Wind Energy Conversion, Amsterdam, The Netherlands; October 1978.

Sforza, P. M.; Stasi, W. "Field Testing the Vortex Augmentor Concept." Presented at Symposium on Wind Energy Innovative Systems. Golden, CO: Solar Energy Research Institute; May 1979. 


\begin{tabular}{|c|c|c|c|}
\hline $\begin{array}{c}\text { Document Control } \\
\text { Page }\end{array}$ & $\begin{array}{l}\text { 1. SERI Report No. } \\
\text { TP-361-469 }\end{array}$ & 2. NTIS Accession No. & 3. Recipient's Accession No. \\
\hline \multirow{2}{*}{\multicolumn{3}{|c|}{$\begin{array}{l}\text { 4. Title and Subtitle } \\
\text { A Review of the Current Status of the Wind } \\
\text { Energy Innovative System Projects }\end{array}$}} & $\begin{array}{l}\text { 5. Publication Date } \\
\text { March } 1980\end{array}$ \\
\hline & & & 6. \\
\hline \multicolumn{3}{|l|}{$\begin{array}{l}\text { 7. Author(s) } \\
\text { Irwin E. Vas }\end{array}$} & 8. Periorming Organization Rept. No. \\
\hline \multicolumn{3}{|c|}{$\begin{array}{l}\text { 9. Pertorming Organization Name and Address } \\
\text { Solar Energy Research Institute } \\
1617 \text { Cole Boulevard } \\
\text { Golden, Colorado }\end{array}$} & $\begin{array}{l}\text { 10. Project/Task/Work Unit No. } \\
\text { Task \#3533. } 35 \\
\text { 11. Contract (C) or Grant (G) No. } \\
\text { (C) } \\
\text { (G) }\end{array}$ \\
\hline \multirow{2}{*}{\multicolumn{3}{|c|}{ 12. Sponsoring Organization Name and Address }} & $\begin{array}{l}\text { 13. Type of Report \& Period Covered } \\
\text { Technical Paper }\end{array}$ \\
\hline & & & 14. \\
\hline
\end{tabular}

15. Supplementary Notes

16. Abstract (Limit: 200 words)

The responsibility to provide program management of the Wind Energy Innovative Systems program was transferred to the Solar. Energy Research Institute from the Department of Energy during the latter part of FY78. The major activities carried out in this program are subcontracted research and development (R\&D) studies and assessments of innovative concepts. The present paper reviews the efforts of eight of the R\&D subcontractors.

17. Document Analysis

a. Descriptors Wind Energy ; Wind Energy Conversion Systems ; Small Wind Energy Conversion Systems ; Research Programs ; Performance Testing; Design ; Vertical Axis. Turbines ; Diffuser Augmented Turbines ; Tornado Turbines ; Vor tex Augmented b.ldentifiers/Open-Ended Terms Turbines; Wind Turbines: Madaras Rotor; Wind Power Plants EFD Wind Generators

c. UC Categories

$$
\mathrm{UC}=60
$$

18. Availability Statement

National Technical Information Service

U.S. Department of Commerce

5285 Port Royal Road

Springfield, Virginia 22161

\begin{tabular}{|l|l|}
\hline $\begin{array}{l}\text { 19. No. of Pages } \\
77\end{array}$ \\
\hline 20. Price \\
\end{tabular}

